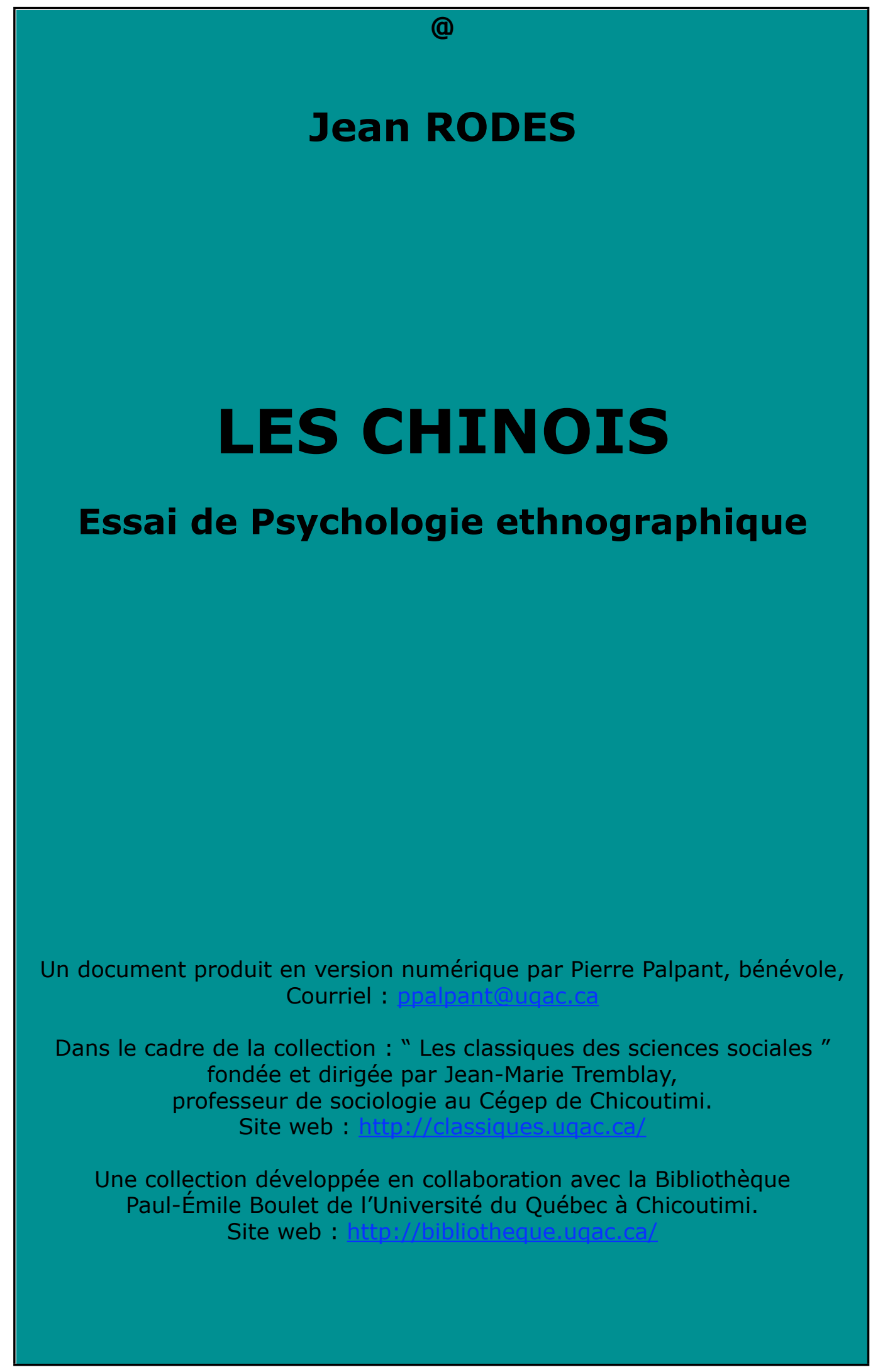




\section{Les Chinois}

Essai de Psychologie ethnographique.

Un document produit en version numérique par Pierre Palpant, collaborateur bénévole,

Courriel : ppalpant@uqac.ca

à partir de :

\section{LES CHINOIS, \\ Essai de Psychologie ethnographique par Jean RODES}

Librairie Félix Alcan, Bibliothèque d'Histoire contemporaine, Paris, 1923, 234 pages.

Police de caractères utilisée : Verdana, 12 et 10 points.

Mise en page sur papier format Lettre (US letter), 8.5"x $11^{\prime \prime}$.

[note : un clic sur @ en tête de volume et des chapitres et en fin d'ouvrage, permet de rejoindre la table des matières]

Édition complétée le 15 décembre 2006 à Chicoutimi, Québec. 


\title{
Les Chinois
}

Essai de Psychologie ethnographique.

\section{TABLE DES MATIÈRES}

Préface

\author{
INTRODUCTION
}

I. L'antiquité des Chinois.

II. L'origine des Chinois.

III. Les relations avec le Monde ancien.

\section{PSYCHOLOGIE DES CHINOIS \\ TÉMOIGNAGES ET OPINIONS}

I. Premières relations de voyages à la Chine.

II. Les Jésuites et le XVIII siècle.

III. Relations de voyageurs contemporains.

\section{LE CHINOIS TEL QU'IL EST}

I. La sensibilité chinoise, ses manifestations contradictoires. L'instinct grégaire. La conception païenne de la vie. Le sentiment artistique. La nervosité.

II. Le stoïcisme et l'insouciance. La pusillanimité. Les armes du faible. Le « squeeze ». La « face ». L'instinct anarchique.

III. Les bizarreries du cerveau chinois. Superstitions et scepticisme religieux. Philosophie de pédagogues. Pas d'esprit scientifique. Inaptitude à la précision. Dédain de l'exactitude. Esprit d'accommodement. Chinoiserie réformiste.

CONCLUSION 


\section{Les Chinois}

Essai de Psychologie ethnographique.

\section{PRÉFACE}

Le but de cet ouvrage est de donner une explication de l'âme chinoise. Ceci paraîtra sans doute prétentieux à ceux qui ont adopté cette opinion bien établie et commode que le Chinois est impénétrable et que nous ne pourrons jamais arriver à le comprendre. Certes, on l'a généralement fort mal compris, en effet, car on a répandu à son sujet de nombreuses erreurs, telles que son insensibilité, son absence de nerfs, etc., que nous rectifierons au cours de cette étude, mais nous voulons, avant toute chose, nous inscrire contre ce que nous considérons comme un lieu commun aussi intolérable qu'injustifié.

Ainsi, on considère qu'il est légitime et très possible de s'attacher à la psychologie des animaux ou aux études les plus inaccessibles, les plus hypothétiques, de la philosophie métaphysique et on trouve téméraire d'oser entreprendre une analyse de la mentalité des Célestes. Nous avons eu cette témérité, nous avons pensé que le Chinois étant un homme, non seulement, suivant le mot du poète latin, rien de ce qui le concerne ne doit nous être étranger, mais encore que nous pourrions arriver à saisir les mobiles de ses actions, les mouvements de son âme, le rythme de sa vie. Il n'est pas plus mystérieux que cet autre prétendu sphinx : la femme, dont les romanciers de l'école psychologique ont si souvent déjà éclairci la soi-disant énigme. 


\section{Les Chinois}

Essai de Psychologie ethnographique.

Nous avons entrepris ce travail avec une véritable allégresse, le peuple chinois étant à coup sûr le sujet le plus excitant qu'il puisse y avoir au monde, par les prodigieuses évocations qu'il suggère. Si on est ému par le squelette d'une Pompéi ou d'un Timgad, combien est-il plus passionnant de voir vivre sous ses yeux, dans son cadre original, une humanité beaucoup plus ancienne encore ! Il se dégage du reste de ce peuple, à certains égards si vieillot et décrépit, un charme de jeunesse incomparable, parce que, à bien des points de vue, il a conservé la fraîcheur, l'ingénuité et la grâce des anciennes civilisations païennes.

Avant de donner nos observations personnelles, nous avons cité un certain nombre d'opinions sur les Chinois, en nous arrêtant plus particulièrement à celles du $\mathrm{XVIII}^{\mathrm{e}}$ siècle, époque où la Chine passionna les milieux lettrés au point de susciter, parmi eux, d'ardentes polémiques. Il ne pouvait être question de rapporter tous les témoignages ; ceux-ci constituant une bibliothèque considérable, nous avons dû nous borner à relever les jugements les plus importants et les plus caractéristiques.

Nous avons pensé aussi qu'il n'était pas inutile de faire précéder cet essai de psychologie d'une introduction où serait exposé ce que I'on sait positivement, en même temps que toutes les hypothèses que I'on a pu construire, sur l'antiquité et I'origine des Chinois. Question attachante entre toutes, en ce qu'elle reporte l'esprit aux débuts mêmes de I'histoire humaine. Rien n'est indifférent, nous semble-t-il, de ce qui peut aider à mieux connaître ce dernier vestige des plus vieilles civilisations. 


\section{Les Chinois}

Essai de Psychologie ethnographique.

(a) 


\section{Les Chinois}

Essai de Psychologie ethnographique.

\section{INTRODUCTION}

\section{L'antiquité des Chinois}

De fervents sinologues ont prétendu que la civilisation chinoise est la plus ancienne de toutes celles que mentionne I'histoire. C'était, au XVII ${ }^{\mathrm{e}}$ siècle, I'opinion du célèbre professeur de Leyde, Isaac Vossius ${ }^{1}$. Au XVIII ${ }^{\text {, }}$ le spécialiste, sinon le plus compétent, du moins le plus en vue, éditeur de l'Histoire de la Chine, du père de Mailla, et auteur lui-même d'un important ouvrage de compilation sur ce pays, I'abbé Grosier, ne souffrait pas qu'on le mît en doute. Il admettait comme établi tout ce que racontent les classiques chinois et les Annales impériales, non seulement à partir de Yao, mais aussi sur les princes légendaires antérieurs, en remontant jusqu'à Fou-hi. Ceux qui pensaient différemment étaient à ses yeux des « détracteurs de la Chine 2 ».

Parmi les « détracteurs » que combattait I'abbé Grosier, les sinologues de Guignes, père et fils, s'étaient surtout fait

${ }^{1}$ Cette opinion fut vivement combattue par l'abbé Renaudot qui reprochait à Vossius de s'être laissé circonvenir par les pères Martin et Couplet. (Voir à ce sujet, dans les Lettres édifiantes, une lettre écrite à $M$. de Mairan par le père Parennin, qui, à son tour, prenait à partie l'abbé Renaudot.)

${ }^{2}$ Description de la Chine. Discours préliminaire. 


\section{Les Chinois}

Essai de Psychologie ethnographique.

remarquer en déniant cette ancienneté à la race chinoise ${ }^{1}$. Ils basaient leur jugement, entre autres raisons, sur le fait que I'empereur Tsin-Chi-Hoan-ti ayant ordonné, en I'an 213 avant notre ère, qu'on brûlât tous les livres, I'histoire de la Chine ne pouvait avoir aucune base sérieuse. A cela l'abbé répondait que ce prince avait préservé du feu tous les ouvrages relatifs à la médecine et au labourage, ainsi que I'histoire particulière de sa dynastie, qui remontait jusqu'à 900 ans avant Jésus Christ. Il faisait en outre observer que bien des œuvres condamnées, par exemple celles de Confucius et Mencius, et beaucoup d'autres sans doute, n'avaient néanmoins pas disparu. Ainsi, estimait-il, les fastes de l'histoire chinoise s'étaient conservés avec une garantie d'authenticité suffisante.

Dans I'Encyclopédie, qui donnait sur toutes choses, avec un effort d'objectivité, I'opinion des milieux savants, Diderot, au cours d'un article sur la « Philosophie chinoise », écrivait : «Quoi qu'on ne puisse accorder aux Chinois toute l'antiquité dont il se vantent et qui ne leur est guère disputée par leurs panégyristes, on ne peut nier toutefois que la date de leur Empire ne soit très voisine du déluge ».

Le témoignage sur lequel s'appuyaient les panégyristes ${ }^{2}$ dont parle Diderot était celui des Jésuites : le père de Mailla, auteur

\footnotetext{
${ }^{1}$ Selon la chronologie généralement adoptée, le règne de Yao date de 2357 ans avant J.-C. D'après des textes chinois traduits par le père Wieger, Hoan-ti, souverain semi-historique, serait de 2967 à 2598 et Fou-hi, personnage légendaire, de 4477.(Textes historiques, t. I, p. 23 et 28.)

${ }^{2}$ Il est assez curieux de noter que l'un de ces panégyristes fut Voltaire qui semble avoir à cet égard subi entièrement l'influence des Jésuites qu'il attaquait si vivement par ailleurs. « Il est certain, dit-il dans les Essais sur les Mœurs, que l'empire de la Chine était formé il y a plus de quatre mille ans. »
} 


\section{Les Chinois}

Essai de Psychologie ethnographique.

de l'Histoire générale de la Chine, et ses confrères, rédacteurs de copieux travaux que l'on venait de publier sous le titre de : Mémoires concernant l'histoire, les sciences, les arts, les mœurs, les usages, etc., des Chinois, par les missionnaires de Pékin. Il est à constater que ces « Mémoires » n'ont pas, sur cette question de l'antiquité des Chinois, une opinion unique. Alors que le père Cibot, non seulement admet l'authenticité du règne de Yao, premier souverain dont Confucius parle dans le Chouking, mais proclame sa croyance en tout ce que les annales racontent à partir de Hoang-ti ${ }^{1}$, un autre Jésuite, le père Ko, auteur d'un long article sur le même sujet, montre moins de confiance. Parlant des annales chinoises relatives aux époques les plus reculées, il dit :

« Les plus éclairés entre nos lettrés ne peuvent remonter dans I'histoire des premières dynasties que par des livres remplis de traditions ridicules, de fables burlesques, de contes faits à plaisir, de systèmes pitoyables, d'opinions opposées les unes aux autres, etc. L'école de Confucius les méprise, mais elle ne peut s'en passer, faute d'autres ${ }^{2}$.

Il semble que cela devrait diminuer, dans l'esprit de ce dernier rédacteur, I'autorité du Chou-king qui, pour relater, au VI ${ }^{\mathrm{e}}$ siècle avant J.-C., des événements plus anciens d'une vingtaine de siècles, ne pouvait avoir d'autre base que ces récits sans valeur. Il n'en est rien cependant, car ce missionnaire déclare plus loin :

\footnotetext{
${ }^{1}$ Mémoires, t. II, p. 112 et 146.

2 Mémoires, t. I, p. 19.
} 


\section{Les Chinois}

Essai de Psychologie ethnographique.

«Outre que le Chou-king est le plus ancien monument que nous ayons, les faits qu'il rapporte s'éclairent et s'appuient réciproquement, sont prouvés par nos mœurs et par nos lois, ont pour eux toutes les traditions et ne sont contredits par aucune histoire ${ }^{1 .}$

Déjà, au siècle précédent, un autre jésuite, le père Le Comte, écrivait dans ses Nouveaux Mémoires sur l'état présent de la Chine :

« Il est bien vray que I'histoire populaire de celle grande monarchie est non seulement douteuse, mais encore manifestement fausse, car elle compte plus de quarante mille ans depuis la fondation de l'Empire.

Et il ajoutait aussitôt :

«Mais celle dont tous les sçavants conviennent est si suivie, si bien circonstanciée, établie par une tradition si constante, qu'on ne peut en douter parmi eux sans passer pour ridicules et, comme ils s'expliquent euxmêmes, pour hérétiques ${ }^{2}$.

Voilà le mot jeté : il eût été sacrilège et plus sûrement encore dangereux de soutenir, sur ce point, une thèse autre que celle qui était officielle, lorsqu'on vivait à la cour de Pékin. C'était le cas du père Le Comte, comme ce fut plus tard celui de ses confrères, sous le régime de Kien-long ; il avait l'emploi de mathématicien auprès de l'empereur Khang-hi, dont il fait un si

\footnotetext{
${ }^{1}$ Mémoires. t. I, p. 153.

${ }^{2}$ Nouveaux Mémoires, t. I. p. 205.
} 


\section{Les Chinois}

Essai de Psychologie ethnographique.

dithyrambique éloge dans la préface de son ouvrage et qui se montrait, par ses édits tour à tour favorables et hostiles aux chrétiens, un maître si capricieux et si redoutable ${ }^{1}$. Au demeurant, le père de Magaillans, également missionnaire jésuite, à la même époque, le déclare de la façon la plus claire, dans sa Nouvelle Relation de la Chine. Après avoir donné les trois versions chinoises des origines de l'Empire, il écrit au sujet de la troisième, celle de Yao, qui est la moins chimérique et qui remontait à quatre mille vingt-cinq ans avant la date à laquelle il composait son livre :

«Si quelque Chinois refusait de croire cette dernière opinion qui est entr'eux comme de foy, il seroit considéré comme un hérétique et en cette qualité rigoureusement châtié ; et si les Prédicateurs de I'Évangile témoignoient de bouche ou par écrit qu'ils en doutent, cela suffiroit pour fermer la porte à notre sainte Religion et pour les faire tous condamner à mort, un simple soupçon, quoique sans fondement, sur cette matière, ayant été suffisant pour les faire bannir ${ }^{2}$.

A dire vrai, en dehors des fables, dont il est question plus haut, on manque absolument de documents sérieux sur les anciennes dynasties des Hia, des Chang et même des Tchéou, à plus forte raison sur les souverains précédents : Hoang-ti et Yao.

\footnotetext{
${ }^{1}$ Ces caprices du souverain chinois s'expliquent d'ailleurs amplement par le différend que les divers ordres catholiques de Chine avaient alors entre eux et par l'attitude singulière qu'eurent à son égard les légats envoyés à Pékin, par le pape, pour juger ce conflit. Voltaire a manifesté sa surprise de la patience de Khang-hi en cette circonstance.
}

${ }^{2}$ Nouvelle Relation de la Chine, p. 74. 


\section{Les Chinois}

Essai de Psychologie ethnographique.

L'inscription que $\mathrm{Yu}$, fondateur de la dynastie des Hia, aurait fait graver sur la montagne qu'il coupa, pour permettre le passage du Hoang-ho (fleuve Jaune), et qui est le seul texte vraiment ancien dont on ait fait mention, semble apocryphe. Son authenticité a été mise en doute par les Jésuites eux-mêmes, dans les Mémoires ${ }^{1}$ et, selon le père Amiot, elle n'a d'autre garant que la parole d'un lettré chinois du XIII ${ }^{e}$ siècle après J.C. 2. Pour avoir des travaux historiques dont on puisse faire état, il faut arriver aux Annales de la première dynastie des Han, de I'annaliste impérial Pan-kou (92 ans avant J.-C.) et aux Mémoires de Sseu-ma-ts'ien (85 ans avant J.-C.). Encore faut-il, quant à la véracité de ces écrits et de tous ceux qui ont suivi, tenir compte que, pour les temps les plus anciens, leurs auteurs n'avaient d'autre base que des traditions et que, d'ailleurs, pour les historiens chinois, le souci de l'exactitude passe après bien d'autres considérations. «Chaque fois qu'un fait vrai est odieux, dit le père Wieger, on le gaze sous un faux titre ${ }^{3}$. »

Les Chinois établissent la chronologie de leur haute antiquité sur des observations astronomiques. Cette science leur ayant été contestée par les « détracteurs», de Guignes et de Paw, auteur des Recherches sur les Egyptiens et les Chinois, les rédacteurs des Mémoires et l'abbé Grosier leur ripostèrent à ce sujet d'autant plus vivement qu'ils pouvaient leur dénier toute

\footnotetext{
${ }^{1}$ T. I, p. 24.
}

2 Abrégé chronologique, p. 20, manuscrit du p. Amiot à la Bibliothèque nationale. L'original de cette inscription, envoyé de Pékin à la Bibliothèque impériale, à Paris, fut traduit, au début du XIXe siècle, par l'orientaliste Hager, auteur du Panthéon chinois.

${ }^{3}$ Textes historiques, t. I, p. 26. 


\section{Les Chinois}

Essai de Psychologie ethnographique.

compétence. Mais ils passèrent sous silence qu'un célèbre astronome du siècle précédent, Cassini, avait démontré que les calculs faits sur les éclipses, par les Chinois, avaient 600 ans de moins qu'ils ne comptaient ${ }^{1}$.

Malgré ces obscurités et ces incertitudes qui devraient inspirer au moins le doute philosophique, l'authenticité de I'histoire chinoise commençant à Yao et même à Hoang-ti est moins discutée encore par les sinologues contemporains que par ceux des $\mathrm{XVII}^{\mathrm{e}}$ et $\mathrm{XVIII}{ }^{\mathrm{e}}$ siècles, du moins en France. C'est assez curieux à une époque où la critique historique est devenue si exigeante.

«L'histoire de la Chine, dit Abel Rémusat, remonte avec certitude jusqu'au vingt-deuxième siècle avant notre ère, et des traditions qui n'ont rien de méprisable permettent d'en reporter le point de départ quatre siècles plus haut, à I'an 2637 avant J.-C., 61 ${ }^{\mathrm{e}}$ du règne de Hoang-ti 2.

Pauthier est aussi affirmatif. Il fait partir I'histoire chinoise de Hoang-ti et il prévient qu'il s'est servi, pour les dates, de la chronologie que l'empereur Kien-long fit faire par l'Académie des Han-lin jusqu'à la $61^{\mathrm{e}}$ année de Hoang-ti et qui, écrit-il, «porte le plus haut caractère de certitude 3 ». Dans un Mémoire sur I'Antiquité de I'Histoire et de la Civilisation chinoises ${ }^{4}$, il s'étonne

\footnotetext{
${ }^{1}$ Mémoires de I'Académie des Sciences de Paris, t. VIII.

${ }^{2}$ Nouveaux Mélanges asiatiques, p. 65.

${ }^{3}$ La Chine, p. 27.

${ }^{4}$ Journal asiatique. septembre-octobre 1867.
} 


\section{Les Chinois}

Essai de Psychologie ethnographique.

de ce que certains sinologues « résidant en Chine, et qui ont à leur disposition tous les monuments de la littérature chinoise conservés jusqu'à nos jours, nient ou mettent en doute I'antiquité de I'histoire, de la chronologie et de la civilisation chinoises »1. Pour lui, d'ailleurs, l'autorité des Jésuites de Pékin, du XVIII ${ }^{e}$ siècle, est souveraine.

« Les nombreux travaux des anciens missionnaires Parennin, Gaubil, de Mailla et Amiot, déclare-t-il au cours de cette étude, doivent porter la conviction dans l'esprit des érudits qui traitent des anciens peuples.

Cette affirmation est d'autant plus surprenante que I'un des missionnaires mentionnés ci-dessus, le père Gaubil, avait fait toutes réserves sur les Annales chinoises, en regrettant de ne pas y voir plus de critique européenne. L'ouvrage sur la Chronologie chinoise, dans lequel il s'exprimait ainsi, ne se trouve pas dans les Mémoires sur les Chinois, et il est facile de

\footnotetext{
1 Pauthier fait ici allusion à M. James Legge, des Missions de Londres, qui joignait, reconnaît-il, « à une grande connaissance de la langue chinoise une érudition non moins grande ». Ce missionnaire anglais, qui publiait, à HongKong, une « fort belle » édition des Livres classiques de la Chine, avait contesté, dans ses Prolégomènes et dans ses Notes exégétiques, la plupart des opinions avancées par les missionnaires catholiques précités, sur I'antiquité historique des Chinois, en disant que «I'année 775 avant J.-C. est la plus ancienne date que l'on puisse dire être déterminée avec certitude ».

D'autres ethnographes ont donné un avis semblable à celui de Legge ; I'Allemand Lassen dit qu'il ne faut pas demander d'histoire positive aux Chinois avant I'année 782 qui précéda notre ère (Indische Alterthumskunde, t. I, p. 51).

Le comte de Gobineau écrit, dans son Essai sur l'Inégalité des races humaines : " Je me trouve, d'abord, en dissentiment avec une idée assez généralement répandue. On incline à considérer la civilisation chinoise comme la plus ancienne du inonde, et je n'en aperçois l'avènement qu'à une époque inférieure à l'aurore du brahmanisme, inférieure à la fondation des premiers empires chamites, sémites et égyptiens. » (T. 1, p. 462.)
} 


\section{Les Chinois}

Essai de Psychologie ethnographique.

voir, par la manière dont on parle de lui, à la Table de ce « compendium » de la sinologie, que son orthodoxie chinoise était suspecte au yeux de ses confrères.

L'un des sinologues actuellement les plus réputés, le père Wieger, n'a pas touché, dans ses travaux, à cette question de l'antiquité chinoise, et il semble ainsi admettre à ce sujet la thèse courante. Toutefois, plus libre que ses confrères des siècles passés et ne courant pas les risques dont parle le père de Magaillans, il n'a pas craint d'indiquer, comme on l'a déjà vu, le peu de crédit qu'il convient d'accorder aux historiens chinois et il lui arrive même, dans la traduction des textes, d'accompagner un passage du mot «amusant » qui, mis entre parenthèses, montre bien le cas qu'il fait de la véracité du témoignage. Il ne s'est permis cela, il est vrai, que pour des récit relativement modernes dont la fausseté peut aisément s'établir, mais si cette inexactitude en quelque sorte systématique des historiens célestes s'exerce sur des faits contrôlables, on juge de ce qu'il peut en être pour des périodes si lointaines où le respect superstitieux de la tradition et l'orgueil national étaient leurs seuls guides. Ils se trouvaient, en somme, dans le même cas que les exégètes chrétiens en face des saintes écritures.

L'opinion la plus nette et la plus raisonnable a été donnée par M. Henri Cordier, successeur de Pauthier dans la chaire d'Histoire de l'Extrême-Orient, à I'École des Langues orientales, chaire qu'il occupe encore :

«Sans nier, dit-il, la haute antiquité de la nation chinoise, nous devons avouer que les documents sur 


\section{Les Chinois}

Essai de Psychologie ethnographique.

lesquels on se base généralement pour l'affirmer ne sont rien moins que probants. L'étude de la Chine n'est pas encore entrée dans cette période de critique scientifique à laquelle on est arrivé pour d'autres pays de I'antiquité ; on n'approche même pas de ce moment de recueillement où les matériaux déjà acquis sont analysés, discutés, acceptés, classés, pour servir de point de départ à de nouvelles découvertes. Nous trouvons bien chez les Chinois les éléments de nos recherches, mais c'est tout ; ils ne possèdent pas cet esprit de critique et cette sagacité persévérante qui sont la caractéristique des études contemporaines en Europe. Un dictionnaire historique de la langue chinoise sera fait non par un Chinois, mais par un Européen, non pas de nos jours, mais dans cinquante ans. »

« Il est bien certain, ajoute-t-il plus loin, que nous ne nous trouvons pas en présence d'une histoire tracée d'une main indélébile dans la pierre comme en Égypte et en Assyrie ou fournissant des documents authentiques remontant à une époque aussi ancienne que les livres religieux de I'Inde ${ }^{1}$.

Quoi qu'il en soit de l'authenticité de la chronologie chinoise et fût-elle prouvée d'une manière irréfutable jusqu'à Hoang-ti, cette civilisation ne serait pourtant pas, malgré son extraordinaire vieillesse, la première qui se soit produite dans I'histoire du monde.

${ }^{1}$ Mélanges d'Histoire et de Géographie orientales, t. I, p. 96 et 99. 


\section{Les Chinois}

Essai de Psychologie ethnographique.

On a beaucoup discuté sur la question de savoir quelle a été la plus ancienne. Dans son Essai sur les Mœurs, Voltaire se prononce pour la civilisation indienne, sans en donner de raisons probantes. Bien des indianistes et spécialistes du sanscrit partagent du reste cette opinion. Certes, ce pays possède des documents écrits beaucoup plus anciens que ceux de la Chine, ce sont les Védas. Le plus ancien, le Rig-Véda, aurait été composé 4800 ans avant notre ère, selon le savant allemand Jacobi, et 2600 ans, selon son compatriote Oldenberg ${ }^{1}$. Le compilateur Vyasa, qui les recueillit, est placé, par les uns, au $X V$ e siècle, par les autres, au XVI ${ }^{e}$ siècle avant J.-C. Il n'y a en somme là-dessus aucune certitude.

Le Zend-Avesta, de Zoroastre, le philosophe de l'Iran, qui est un reflet des Védas, daterait, d'après les orientalistes les plus qualifiés, de 2500 ans environ avant J.-C.

Pour la Chaldée, on possède des inscriptions provenant de Ninive et Babylone et qui sont vieilles de 2000 à 3000 avant l'ère chrétienne.

Mais il est un pays qui a précédé ceux-là, que I'on ignorait historiquement au XVIII ${ }^{\mathrm{e}}$ siècle, puisqu'on ne déchiffrait pas encore les hiéroglyphes, et sur lequel on a des renseignements beaucoup plus précis, c'est l'Égypte. Selon Voltaire, dans I'ouvrage précédemment, cité, la situation géographique de cette région, resserrée entre deux déserts, en proie à l'infection des eaux croupissantes du Nil débordé, fit qu'elle dut être une des dernières terres habitées. Les travaux des Champollion, de

${ }^{1}$ De Milloué, Le Brahmanisme, p. 5. 


\section{Les Chinois}

Essai de Psychologie ethnographique.

Mariette et autres égyptologues ont rétabli la vérité sur ce point. Renan, qui, en 1864, accomplit, en compagnie de Mariette, un voyage en Haute-Égypte, écrivit, dans un article de La revue des Deux Mondes : «La solidité parfaite de I'Histoire d'Égypte est pour moi une chose démontrée ». Il avait d'abord «quelques hésitations », mais tout ce qu'il vit avec son savant guide l'amena à déclarer que cette civilisation était « vieille d'au moins six mille cinq cents ans ${ }^{1} \gg$.

Un autre spécialiste des études religieuses, l'égyptologue Amélineau, après avoir, lui aussi, parlé d'une date supérieure à 6000 ans, a dit : «C'est en Égypte que nous possédons sans contredit la littérature écrite la plus ancienne que possède I'homme ${ }^{2}$. » Il semble donc bien que ce pays doive tenir la tête dans une classification des peuples dont I'histoire est connue ${ }^{3}$. Les constatations faites sur l'identité des légendes et des symboles religieux chez tous ces ancêtres de l'humanité tendent de plus à faire croire que la religion primitive, conçue dans la vallée du Nil, a rayonné ensuite de là sur le reste du monde, jusqu'à la Chine lointaine. Mais on sait qu'une autre hypothèse a attribué à un peuple antérieur, préhistorique, habitant un continent disparu dans les catastrophes cosmiques du commencement des âges : I'Atlantide, le mérite de cette civilisation première.

\footnotetext{
${ }_{1}^{1}$ Mélanges d'histoire et de voyages. L'ancienne Égypte, p. 27 et 68.

2 Prolégomènes à l'étude de la religion égyptienne, p. 63 et 187.

3 Parlant de l'Égypte ancienne, l'ethnographe Letourneau dit : « Nous nous trouvons en face du plus ancien foyer de culture actuellement connu, dont, historiquement, les origines sont encore mystérieuses. 》 (La Psychologie ethnique p. 278.)
} 


\section{Les Chinois}

Essai de Psychologie ethnographique.

Platon est le premier qui ait parlé de l'île Atlantide, dans deux de ses dialogues : le Timée et le Critias. Il tenait ce qu'il en dit de son aïeul, Critias, âgé de quatre-vingt-dix ans et qui avait été instruit par Solon, ami de son père Dropidas. C'est donc là une source vénérable et une tradition digne de confiance. Solon avait raconté à Critias ce que lui avait appris à ce sujet, au cours de son séjour en Égypte, un prêtre de Saïs. Il en résultait que cette île, d'une superficie considérable, se trouvait, dans I'océan Atlantique, en face des Colonnes d'Hercule. Ses habitants, qui avaient atteint une civilisation très avancée, s'étaient emparés de la Lybie, jusqu'à l'Égypte, ainsi que d'une partie de l'Europe et de I'Asie. A la suite de tremblements du globe et d'inondations formidables, I'Atlantide avait ensuite été submergée dans la mer.

Tel serait le peuple disparu avant que commençât I'histoire et qui, ayant créé tous les concepts religieux et philosophiques, les aurait légués aux nations de l'antiquité la plus reculée, l'Égypte se trouvant la première, dans l'ordre chronologique, à cause de son voisinage et sans doute aussi de sa colonisation par les Atlantes. C'est ce que pressent Renan lorsqu'il écrit dans l'étude signalée plus haut :

«Quand on songe que cette civilisation, vieille au moins de six mille cinq cents ans, n'a pas d'enfance connue ; que cet art, dont il reste d'innombrables monuments, n'a pas d'époque archaïque, que l'Égypte de Chéops et de Chéphren est supérieure en un sens à tout ce qui a suivi, on est pris de vertige. On se demande si la race 


\section{Les Chinois}

Essai de Psychologie ethnographique.

qui a peuplé l'Égypte n'était pas déjà complètement civilisée quand elle entra dans la vallée du Nil${ }^{1}$.

De nombreux savants ont admis l'existence de ce premier peuple civilisateur tout en différant sur sa position géographique. Buffon écrit, dans ses Époques de la Nature :

« Les Atlantes, chez lesquels régnait Atlas, paraissent être les plus anciens peuples de l'Afrique, et beaucoup plus anciens que les Égyptiens. La théogonie des Atlantes, rapportée par Diodore de Sicile, s'est probablement introduite en Égypte, en Éthiopie et en Phénicie dans le temps de cette grande irruption dont il est parlé dans le Tymée de Platon, d'un peuple innombrable qui sortit de l'île Atlantique, et se jeta sur une grande partie de I'Europe, de l'Asie et de I'Afrique.

D'une manière qui semble contradictoire, dans un autre endroit de ce même ouvrage, Buffon assigne le plateau central asiatique, comme lieu d'origine, à la première civilisation. Au XVII ${ }^{e}$ siècle, le célèbre anatomiste et naturaliste suédois, Rudbeck, prétendit que cette Atlantide était située non loin du cercle polaire et que sa capitale s'élevait dans un lieu voisin d'Upsal 2. En France, au XVIII ${ }^{e}$ siècle, le savant Bailly émit, dans une série de lettres adressées à Voltaire, qui persistait à croire à la primauté civilisatrice de I'Inde, cette opinion non moins singulière que le royaume des Atlantes se trouvait dans les îles

\footnotetext{
${ }_{1}^{1}$ Mélanges d'histoire. L'ancienne Égypte, p. 68.

2 Atlantica, sine Manheim, vera Japheti posterorum sedes, ouvrage sur les antiquités de la Suède.
} 


\section{Les Chinois}

Essai de Psychologie ethnographique.

du Nord de I'Asie ${ }^{1}$. La civilisation, selon lui, ne pouvait avoir qu'une origine hyperboréenne. Au début du XIXe siècle, un autre savant, le naturaliste Bory de Saint-Vincent, explorateur de I'archipel des Canaries, énumère, dans un très curieux ouvrage 2 , un certain nombre d'usages et de concepts qu'il a constatés chez les Guanches, lointains descendants des Atlantes, et qui ont existé, identiques, chez tous les peuples de l'Orient, y compris les Chinois. Bory de Saint-Vincent se rapproche de la théorie de Buffon et, en quelque sorte, explique sa contradiction en soutenant que I'Atlantide fut à l'origine colonisée par des peuplades parties du haut plateau de Tartarie ${ }^{3}$. C'est également cette commune origine qui explique les similitudes troublantes avec la vieille Égypte qu'ont révélées les fouilles faites dans les antiques tombeaux du Mexique.

Ainsi donc, non seulement la civilisation chinoise n'est pas la civilisation-mère que pensait Vossius, mais elle n'est pas davantage la plus ancienne parmi celles qui furent le reflet de la civilisation initiale. Par contre, elle est la seule - avec ses rameaux du Japon, de la Corée et de l'Annam - qui ait subsisté, conservant les idées religieuses, la morale patriarcale, la tournure d'esprit et jusqu'à l'écriture hiéroglyphique qui, selon le père Cibot dans son Essai sur les caractères chinois ${ }^{4}$ a dû être, à l'aurore des âges, l'écriture de tous les peuples héritiers de cette

\footnotetext{
${ }^{1}$ Lettres sur I'Atlantide, p. 446.

${ }^{2}$ Essais sur les îles Fortunées, chap. VII et VIII.

${ }^{3}$ Ibid., p. 474.

${ }^{4}$ Mémoires sur les Chinois, t. IX.
} 


\section{Les Chinois}

Essai de Psychologie ethnographique.

civilisation primordiale. Elle est donc la seule survivante du passé le plus lointain et elle constitue à ce titre un très émouvant sujet d'observation et de méditation. 


\section{Les Chinois}

Essai de Psychologie ethnographique.

\section{L'origine des Chinois}

D'après la tradition chinoise, l'origine la plus lointaine des Célestes serait une petite horde de primitifs, les « Cent familles », errant dans les régions qui séparent le Thibet de la Chine. Cette horde, descendue dans les plaines abondamment arrosées qui formèrent par la suite l'Empire du Milieu, fut l'embryon du peuple le plus nombreux de la Terre. Les Chinois seraient de la sorte d'une souche purement jaune, sans autre apport que celui d'autres groupements de même race descendus des hauts plateaux de Mongolie. Ils auraient donc créé euxmêmes leur civilisation, la plus ancienne du monde, qui, selon les sinologues fervents de l'école Grosier, ne doit rien à aucun autre peuple. Cette conviction est telle chez certains que lorsque, tel Hager ${ }^{1}$, ils découvrent quelques-unes des nombreuses analogies existant, dans les coutumes et les idées, entre la Chine et les civilisations anciennes de I'Orient, voire avec la Grèce et Rome, c'est aux Célestes qu'ils attribuent le mérite de l'antériorité, les donnant ainsi comme les éducateurs de I'humanité tout entière.

De nombreux auteurs, cependant, n'ont pas admis cette originalité de la civilisation chinoise et cette pureté d'origine.

\footnotetext{
${ }^{1}$ Le Panthéon Chinois, ou parallèle entre le culte religieux des Grecs et celui des Chinois, p. 156.

Schlegel donne une opinion du même genre quand, dans son Uranographie chinoise, il prétend que l'astronomie primitive a été empruntée par les anciens peuples orientaux à la sphère chinoise.
} 


\section{Les Chinois}

Essai de Psychologie ethnographique.

Diverses hypothèses ont été émises ; celle qui a provoqué le plus de discussions donne aux Chinois une ascendance égyptienne. Le XVIII ${ }^{e}$ siècle s'est passionné pour cette question. L'académicien Huet, évêque d'Avranches, attacha le grelot en disant, dans son Histoire du Commerce chez les Anciens, que les Indiens et les Chinois descendaient des Égyptiens. Il écrivait :

« La correspondance des Indiens et des Chinois est si clairement établie par les anciennes histoires, qu'on ne peut s'empêcher de croire, en les lisant, que si toute la nation des Indiens et des Chinois n'est pas descendue des Égyptiens, elle l'est du moins en la plus grande partie.

Et plus loin :

« Entre tous ces essaims d'Égyptiens qui inondèrent les Indes, les Chinois méritent bien d'être considérés en leur particulier. On trouve chez eux des marques bien sensibles de leur origine, une grande conformité de coutumes avec celles des Égyptiens, leurs doubles lettres, hiéroglyphiques et profanes, quelque affinité même de leurs langues, la doctrine de la métempsycose, le culte de la vache et, ce qui me paraît fort remarquable, cette aversion constante que font paraître les Chinois à recevoir les négociants étrangers dans leur pays, et qui les a possédés dans tous les temps, pareille à celle que Strabon attribue aux anciens Égyptiens. Je ne puis donc assez m'étonner que, contre des preuves si claires, un écrivain de ces derniers 


\section{Les Chinois}

Essai de Psychologie ethnographique.

temps, plein d'esprit, d'ailleurs, et de suffisance, mais sujet à beaucoup de préventions, ait pu soutenir, au contraire, que les Égyptiens et les Phéniciens ont reçu leurs sciences des Indiens ${ }^{1 .}$

Plus loin, il dit encore :

« Il me seroit aisé de faire voir qu'il faut chercher dans l'Égypte la source de l'érudition indienne et chinoise 2.

Le témoignage historique qu'invoque Huet est évidemment celui de Diodore de Sicile, tant dans ce que celui-ci rapporte de la tradition d'Osiris, conquérant des Indes et de l'Asie entière, que de ce qu'il dit des expéditions de Sésostris qui, ayant passé le Gange, «traversa toutes les Indes et parvint jusqu'à I'océan oriental » (océan Pacifique), pénétrant dans des pays « où Alexandre lui-même ne put jamais entrer 3 ».

M. de Mairan, directeur de I'Académie des Sciences, très impressionné par ce jugement de Huet, écrivit à un jésuite de Pékin, le père Parennin, en lui demandant son avis. Le missionnaire répondit par une longue lettre explicative. Après avoir reconnu que toutes les similitudes découvertes entre les Égyptiens et les Chinois étaient de nature à émouvoir et que I'on pouvait même pousser le parallèle plus loin encore qu'on ne

\footnotetext{
${ }^{1}$ Histoire du Commerce et de la Navigation chez les Anciens, p. 39 et 43. L'écrivain visé par Huet est Voltaire.

${ }^{2}$ Ibid., p. 378.

${ }^{3}$ Histoire universelle, traduction de l'abbé Terrasson, livre 1, sections I et II. Il convient de noter que Diodore de Sicile, considéré comme un des historiens les plus véridiques du monde ancien, avait étudié l'Égypte en Égypte même et qu'il avait pu ainsi user de toutes les ressources de la fameuse bibliothèque d'Alexandrie, détruite plus tard par les Arabes.
} 


\section{Les Chinois}

Essai de Psychologie ethnographique.

l'avait fait, il disait que, cependant, en l'examinant de près et en détail, on verrait «qu'il ne prouvait pas assez ». Une autre fois, sur la même question, il écrit à son correspondant :

«Je vous avouerai franchement, Monsieur, que toutes vos ressemblances me portent seulement à juger que ces deux anciens peuples ont puisé dans la même source leurs coutumes, leurs sciences et leurs arts, sans que l'un soit un détachement ou une colonie de I'autre ${ }^{1 .}$

Cette dénégation n'était pas très catégorique et la démonstration qui suivait ne l'était pas davantage, surtout lorsqu'un savant comme le père Kircher - le premier qui ait étudié les hiéroglyphes égyptiens - et un autre missionnaire jésuite, le père Prémare, sinologue réputé, avaient, avant Huet et de manière beaucoup plus affirmative, émis cette même opinion sur I'origine des Chinois. Comme le père Gaubil, et sans doute pour la même raison d'hétérodoxie en matière chinoise, le père Prémare est très critiqué par ses confrères, rédacteurs des Mémoires. (Voir le t. II, p. 140.)

En 1758, M. de Guignes père lut, dans une assemblée publique de I'Académie royale des Inscriptions et Belles-Lettres, un Mémoire, dans lequel il prétendait prouver que les Chinois étaient une colonie égyptienne. Après avoir dit qu'il avait eu d'abord, sur le problème posé par Huet, le même sentiment que le père Parennin, il expliqua que la lecture d'un Mémoire de l'abbé Barthélemy sur les lettres phéniciennes l'avait amené à

${ }^{1}$ Lettres édifiantes, lettres des 28 sept. 1735 et 20 sept. 1740. 


\section{Les Chinois}

Essai de Psychologie ethnographique.

une étude comparative avec les caractères chinois et qu'il avait été étonné par la foule de preuves qui s'étaient présentées à lui :

« Je fus alors convaincu, continuait-il, que les caractères, les lois et la forme du Gouvernement, le Souverain, les Ministres mêmes qui gouvernaient sous lui et I'Empire entier étoit Égyptien ; et que toute I'ancienne histoire de la Chine n'étoit autre chose que I'histoire d'Égypte ${ }^{1}$ qu'on a mise à la tête de celle de la Chine, comme si des François établis en Amérique y fondoient actuellement un royaume dont le premier souverain seroit regardé comme le successeur du monarque qui règne en France : par là toute I'histoire de France antérieure deviendroit I'histoire ancienne de cette colonie 2 .

L'orientaliste Deshauteraies, interprète à la bibliothèque du roi, éleva quelques doutes, en 1759, contre ce mémoire. M. de Guignes lui répondit et ce fut le commencement d'une querelle qui devait devenir plus tard, très vive, entre son fils et l'abbé Grosier.

\footnotetext{
1 La tradition de l'écriture primitive, identique chez les deux peuples et débutant, chez l'un et I'autre, - selon les pères Gaubil et de Mailla, pour les Chinois, et Warburthon, pour les. Egyptiens, - par les cordelettes nouées, donne une particulière force à cette opinion de De Guignes. D'après de Mailla, cet usage remonterait à un règne antérieur à Fou-hi, c'est-à-dire par conséquent à la plus lointaine ascendance égyptienne de la Chine, sinon à un ancêtre conmmun des deux peuples, Noé, par exemple, qui, selon Bory de StVinrent, devait être un Atlante.

D'après ce système barbare, le nombre des nœuds de chaque corde formait un caractère et l'assemblage des cordes tenait lieu d'une espèce de livre qui servait à rappeler ou à fixer, dans l'esprit des hommes, des choses qui, sans cela, se seraient effacées. Ce n'était qu'un moyen mnémotechnique.
}

2 Mémoire lu à l'Académie des Inscriptions le 14 novembre 1758, p. 36. 


\section{Les Chinois}

Essai de Psychologie ethnographique.

Pendant que cette guerre littéraire se poursuivait à Paris, un fait nouveau se produisait qui avivait encore l'intérêt de cette question de l'origine des Chinois. Les Mémoires sur les Chinois le rapportent de la manière la plus détaillée et donnent à ce sujet une longue consultation du père Cibot ${ }^{1}$ : M. Needham, de la Société royale de Londres, avait cru trouver, sur un buste d'Isis, conservé à Turin, des caractères égyptiens qu'il disait être fort ressemblants à ceux des Chinois. Il en avait pris les empreintes et il s'était rendu à Rome pour les vérifier. Un Chinois, garde de la bibliothèque du Vatican, auquel il les soumit, ne leur trouva aucune ressemblance avec l'écriture de son pays. Pourtant, quelques jours après, il présenta à $M$. Needham une douzaine de caractères de l'Isis qu'il avait traduits en latin à l'aide d'un dictionnaire chinois imprimé à Pékin sous le règne de Kang-hi. $M$. Needham, désireux d'élucider ce point si curieux, le soumit à un certain nombre de savants qui se trouvaient à Rome et il écrivit, sur ce même sujet, une dissertation dont le Journal des Savants donna un long extrait. Le rédacteur de ce Journal dit que M. de Guignes, ayant examiné les caractères, ne leur avait trouvé aucune analogie avec ceux de la Chine, malgré que le contraire eût renforcé la thèse qu'il avait à cœur.

Pour en finir, M. Needham envoya son travail aux Missionnaires de Pékin, et la Société royale de Londres intervint auprès d'eux pour qu'ils voulussent bien l'examiner. Le père Cibot fut chargé d'étudier la question ; la réponse qu'il fit est très importante en ce qu'elle donne I'opinion de l'un des

\footnotetext{
${ }^{1}$ T. I, préface, p. VII et suivantes, et Lettre sur les caractères chinois, p. 275.
} 


\section{Les Chinois}

Essai de Psychologie ethnographique.

principaux rédacteurs des fameux Mémoires, sur la question de I'origine des Chinois. Cette opinion est loin d'être aussi intransigeante que celle qu'émirent par la suite des sinologues comme l'abbé Grosier ; elle est bien plutôt conciliante qu'hostile à la thèse de l'origine égyptienne des Chinois.

« Je suppose, disait-il, comme un fait qu'il serait difficile de nier, que les Chinois subsistoient en corps de nation dès les temps des grandes émigrations qui suivirent la confusion des langues. L'antiquité des Égyptiens date de la même époque ; par là il est naturel de croire que ces deux grands peuples ont quitté à peu près en même temps les plaines de Sennaar, l'un pour venir au fond de I'Asie orientale, l'autre pour aller habiter ces vastes campagnes de I'Afrique qu'arrose le Nil. Si les savants vouloient décider quand a commencé l'écriture, soit avant, soit après la dispersion des enfants de Noé, ils trancheroient bien des difficultés; en effet, si elle est postérieure à cette séparation des grandes familles qui ont repeuplé l'univers, si chaque nation a inventé la sienne, les Chinois n'auront plus rien de commun avec les Égyptiens, et il seroit inutile de chercher à expliquer les hiéroglyphes des uns par les caractères des autres, vu surtout qu'ils habitoient des climats si éloignés et qu'on n'a pas le moindre indice qu'il y ait eu aucun commerce entre ces deux grands peuples, dans les temps si reculés des obélisques de Thèbes et d'Héliopolis. Dans la supposition, au contraire, que les lettres aient été inventées avant le déluge et 


\section{Les Chinois}

Essai de Psychologie ethnographique.

conservées par les enfants de Noé à leurs descendants, il est croyable que les Chinois et les Égyptiens ayant puisé à la même source, il doit y avoir eu longtemps bien de la ressemblance entre la manière d'écrire des uns et des autres. Cette seconde supposition a bien des avantages sur l'autre du côté de la probabilité et de la vraisemblance et on en conclut fort bien qu'en comparant aujourd'hui les hiéroglyphes d'Égypte avec les caractères chinois, on peut espérer d'expliquer les uns par les autres ${ }^{1}$.

Voilà qui se rapproche singulièrement de I'hypothèse de la communauté d'origine des vieilles civilisations, filles d'une civilisation antérieure, celle des Atlantes ou de tout autre peuple disparu.

Quant à l'objet précis de la consultation, le père Cibot écrivait :

«Pour la ressemblance et conformité des symboles de I'Isis avec les caractères chinois cités par M. Needham, j'avoue qu'elle est sensible, en particulier pour ceux des $n^{\circ} 2,3,8,9$ et 31 . On verra plus bas ce que je pense de cette ressemblance et l'usage qu'on en pourroit faire, mais pour ce moment je me borne à observer qu'il y a plusieurs de ces symboles dont le contour et les traits sont différents de ceux des Chinois. Voici qui est plus décisif : l'ensemble de tous ces caractères n'a

${ }^{1}$ Mémoires, t. I, p. 278. 


\section{Les Chinois}

Essai de Psychologie ethnographique.

rien de chinois. Un coup d'œil sur quelque livre que ce soit suffit pour s'en convaincre ${ }^{1}$.

Cette négation est peu concluante, surtout après l'aveu de la conformité de certains des hiéroglyphes de l'Isis avec des anciens caractères chinois. Bien qu'il s'efforce de l'établir ensuite par une analyse détaillée, il l'affaiblit encore en reconnaissant plus loin que «les conjectures de M. Needham pourraient conduire à bien des découvertes », et en disant à plusieurs reprises que I'on pourrait utiliser la connaissance de l'écriture chinoise pour débrouiller le chaos des hiéroglyphes égyptiens.

« S'il y a, termine-t-il, une vraie ressemblance entre les hiéroglyphes d'Égypte et les caractères chinois et qu'on veuille en profiter pour les expliquer, on n'y réussira jamais que par des recherches immenses, une critique plus timide que celle de ce siècle et une longue application à débrouiller les hiéroglyphes et à les classer jusqu'à un certain point : peut-être même les plus savants auraient-ils besoin encore du secours de la Chine, mais ce secours, de qui l'espérer?

Et il se dérobe, en disant que les Missionnaires ont un objet plus sérieux et plus pressant ${ }^{2}$. Il pourrait ajouter qu'une telle étude serait susceptible de déplaire gravement aux maîtres de la Chine, aussi ombrageux sur la tradition de leur pays qu'on I'a jamais été à Rome sur tout ce qui touche à la doctrine chrétienne. De là, sans doute, l'embarras et la confusion de cette

\footnotetext{
1 Page 290.

2 Page 305.
} 


\section{Les Chinois}

Essai de Psychologie ethnographique.

consultation du missionnaire ${ }^{1}$. Ce qui est, par contre, beaucoup plus clair et de nature à justifier l'émoi de M. Needham, c'est le tableau comparatif qui est placé à la fin du premier volume des Mémoires et dans lequel on voit côte à côte des hiéroglyphes et de vieux caractères chinois absolument identiques. La reproduction de I'Isis de Turin, qui y est jointe, est également fort impressionnante 2 .

Tableau comparatif de quelques caractères chinois et hiéroglyphes égyptiens.

CHINOIS ÉGYPTIENS CHINOIS ÉGYPTIENS

\footnotetext{
${ }^{1}$ Le résultat d'une autre enquête faite déjà par les Jésuites sur cette question de I'origine égyptienne semble devoir s'expliquer de la même façon. Il est dit, en effet, dans la « Préface » des Mémoires. que deux Chinois, envoyés à Paris pour étudier les sciences occidentales sous l'égide des missionnaires, furent consultés sur la question de l'origine égyptienne des Chinois, à propos de laquelle MM. de Guignes et Deshauteraies divergeaient d'opinion. Ils s'entretinrent avec les deux adversaires, mais manquant, en France, d'éléments pour juger ce conflit, ils s'abstinrent. De retour à la Chine et après avoir comparé, avec quelques morceaux d'ancienne écriture chinoise, les extraits d'écriture égyptienne que leur avait remis $M$. de Guignes, ils abondèrent dans son sens. Mais, dit cette «Préface », « revenus sur leurs pas, ils ont de concert avec nos missionnaires rédigé le mémoire en question (sur l'Antiquité de la Chine), qui développa leur sentiment d'une manière sensible et détruit la première opinion ».

2 Une des planches de ce tableau comparatif est reproduite [ci-après. Elle ne constitue] qu'une partie du tableau comparatif publié par les Jésuites du XVIII siècle dans leurs Mémoires sur les Chinois, tableau qui était accompagné d'une reproduction des caractères et de la statue de I'Isis de Turin.
} 


\section{Les Chinois}

Essai de Psychologie ethnographique.

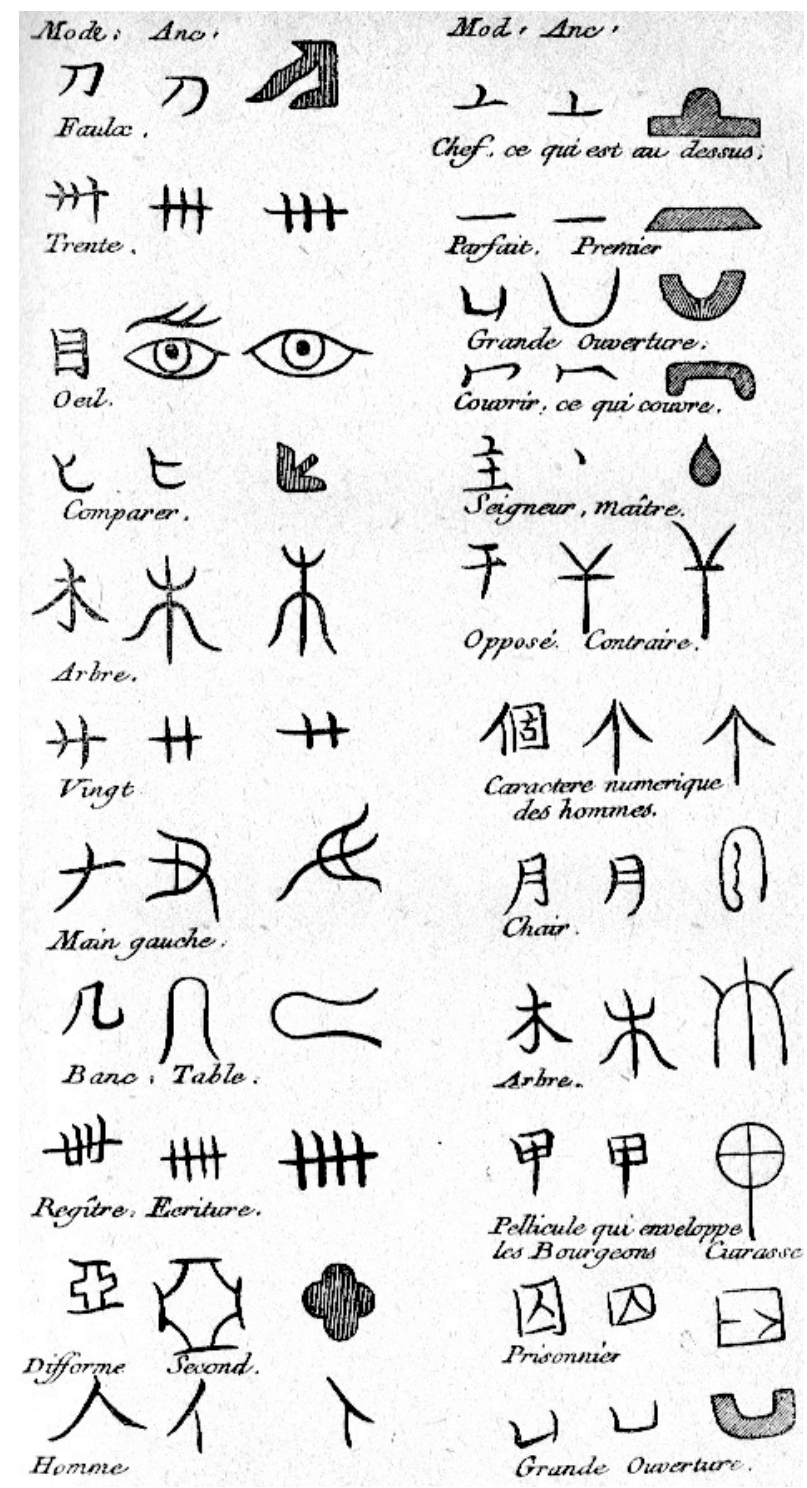

Plus tard, lorsque de Guignes fils, au retour d'un voyage en Chine, renouvellera la thèse de son père sur l'origine égyptienne des Chinois, I'abbé Grosier répondra en disant que

« ces systèmes, ces hypothèses romancières, mal accueillies des savants, sont heureusement tombées dans I'oubli ${ }^{1}$.

${ }^{1}$ Description de la Chine. Discours préliminaire. 


\section{Les Chinois}

Essai de Psychologie ethnographique.

A la vérité, cette opinion sur l'origine des Chinois eut peu de succès dans les milieux lettrés, en France. Elle heurtait tellement les idées reçues sur ce point que les plus sérieuses références ne pouvaient même inspirer là-dessus le moindre doute ; on ne voulait voir, dans ce problème passionnant, qu'un paradoxe insensé.

Le président de Brosses se gausse, dans une de ses lettres les plus spirituelles, d'un vieux missionnaire de Chine, le père Fouquet, qui, rencontré à Rome, lui a raconté que les Chinois étaient venus de Chaldée et leur écriture, des hiéroglyphes égyptiens. « Il dit moins ce qui est que ce qu'il se figure », explique-t-il à son correspondant 1 .

Pour Voltaire, l'hypothèse est absurde.

« Il a toujours soupçonné, dit-il, que les grands peuples ont été autochtones, c'est-à-dire originaire des pays qu'ils habitent, comme leurs quadrupèdes, leurs singes, leurs oiseaux, leurs reptiles, leurs poissons, leurs arbres et toutes leurs plantes. Il nous a paru, par exemple, que les Chinois ne descendent pas plus d'une colonie d'Égypte que d'une colonie de Basse-Bretagne 2.

Et ailleurs :

« Il ne paraît pas que les Chinois soient venus d'Égypte plus tôt que de Romorantin ${ }^{3}$.

\footnotetext{
${ }^{1}$ Lettres familières d'Italie, lettre XLVI.

${ }^{2}$ Euvres complètes. Mélanges historiques, t. I, art. IV.

${ }^{3}$ Lettres chinoises à M. de Paw, par un bénédictin, lettre VII.
} 


\section{Les Chinois}

Essai de Psychologie ethnographique.

Grimm, dans sa célèbre Correspondance avec Diderot, accable de sarcasmes non seulement les tenants de l'origine égyptienne : Huet, de Guignes, I'anglais Needham, mais ceux mêmes qui, tel $M$. de Mairan, ont eu à ce sujet un instant d'hésitation ${ }^{1}$.

Il reproche au père Cibot de n'avoir pas été assez catégorique dans sa consultation sur les hiéroglyphes de l'Isis, du musée de Turin 2 , et il finit par prétendre que ce buste est un faux antique fabriqué au Piémont ${ }^{3}$.

De Paw, I'auteur des Recherches philosophiques sur les Égyptiens et les Chinois, s'élève contre I'hypothèse de cette origine des Célestes et la juge, lui aussi, absurde.

« Quant à la communication, écrit-il, qu'on suppose avoir existé entre la Chine et l'Égypte, on se convaincra par la lecture de cet ouvrage que jamais supposition ne fut moins fondée ${ }^{4}$.

Selon lui, les Chinois sont d'origine tartare, anciennement scythique.

Bailly est également hostile à cette thèse qui se trouve en contradiction avec celle qu'il expose dans ses lettres à Voltaire.

\footnotetext{
${ }^{1}$ Correspondance, t. II, 15 septembre 1759.
}

${ }^{2} I d .$, t. VIII, août 1773.

${ }^{3}$ Id., ibid., septembre 1773. Cette allégation de Grimm ne peut être prise au sérieux, car les Mémoires sur les Chinois, ayant été publiés postérieurement à sa lettre, le premier volume en 1776 et le dernier en 1784, ne font pas la moindre mention de cette soi-disant supercherie. Si elle avait eu lieu, les éditeurs ne l'auraient pas ignorée plus que Grimm et ils n'auraient alors pas laissé, à cette question, la place qu'elle occupe dans l'ouvrage.

${ }^{4}$ Préface, p. XVII. 


\section{Les Chinois}

Essai de Psychologie ethnographique.

Ainsi qu'il a été déjà dit à propos de l'antiquité des Chinois, il est convaincu que la Chine, comme la Perse et la Chaldée, a reçu la civilisation d'un peuple ignoré de I'histoire, qui l'a colonisée, après être descendu des régions hyperboréennes ${ }^{1}$. Selon lui, Chinois, Indiens, Chaldéens et Persans sont ainsi des frères ${ }^{2}$.

Le bon abbé Pluche est à peu près le seul, parmi les érudits de cabinet du XVIII ${ }^{e}$ siècle, qui ait fait quelque crédit à cette origine égyptienne des Chinois ${ }^{3}$.

On ne peut guère citer avec lui que l'auteur de curieuses Recherches historiques sur le Nouveau-Monde, Jean-Benoist Schérer, qui prétendait prouver $: 1^{\circ}$ que I'Amérique a été colonisée par des Chinois ; $2^{\circ}$ que les hiéroglyphes étaient passées des Égyptiens aux Chinois et de ceux-ci aux Américains. Il basait son argumentation sur I'ancienne écriture des naturels du Mexique et du Pérou, sur la ressemblance de leurs idoles avec celles de la Chine et sur de nombreuses identités entre ce dernier pays et la vieille Égypte. Il consacrait tout un chapitre à la réfutation de l'ouvrage de De Paw.

Mais ce sont là, chez les uns et les autres, opinions de gens qui voyagent dans les livres ; celle d'un père Prémare ${ }^{4}$, d'un père Fouquet, partisans, le premier, d'une origine égyptienne, le

\footnotetext{
${ }^{1}$ Lettres sur I'Origine des Sciences et sur celle des peuples de I'Asie. Seconde lettre.

${ }^{2}$ Lettres sur I'Atlantide, XXIVe lettre.

${ }^{3}$ Concorde de la Géographie, p. 75.

${ }^{4}$ Abel Rémusat a dit, du père Prémare, qu'il était le meilleur sinologue parmi tous les Jésuites qui se sont trouvés à Pékin au XVIII ${ }^{\mathrm{e}}$ siècle. (NouveauX mélanges asiatiques, p. 262.)
} 


\section{Les Chinois}

Essai de Psychologie ethnographique.

second, d'une origine asiatique occidentale ; celle aussi des missionnaires rédacteurs des Mémoires, bien éloignés d'une négation aussi péremptoire, doit être prise en plus grande considération, parce qu'ils ont, les uns et les autres, résidé longtemps au milieu des Chinois.

En ces matières, l'avis d'un homme qui a voyagé est plus précieux que celui des plus beaux esprits de bibliothèque. Ce qu'il a vu des populations et des monuments, ce qu'il sait de la situation géographique, de la nature des terrains, etc., lui donne une vue plus pénétrante, un jugement plus exact. C'est le cas de Sonnerat qui, de 1774 à 1781, visita par ordre du roi les Indes et la Chine. Il fait une observation dont on peut tirer, pour le cas qui nous occupe, une très utile conclusion, car il est évident que les premiers pays colonisateurs et civilisateurs sont ceux auxquels l'état du sol a permis une organisation plus précoce.

« Je n'examinerai point, dit-il, si la Chine fut peuplée par une colonie indienne, mais je puis assurer hardiment qu'après les bouleversements qu'essuya la terre, ce pays, coupé d'une infinité de rivières et de marécages, ne put sans doute devenir habitable que longtemps après I'Inde et la Perse. La situation de ces derniers pays favorisoit l'écoulement des eaux, tandis que l'autre n'a pu commencer à se dessécher qu'après une suite très longue d'années et de siècles ${ }^{1}$.

\footnotetext{
${ }^{1}$ Voyage aux Indes orientales et à la Chine, t. II, p. 228.
} 


\section{Les Chinois \\ Essai de Psychologie ethnographique.}

Tel était bien, en effet, l'état de la Chine après la grande catastrophe du déluge, si I'on s'en rapporte aux commentaires de Mencius sur les livres sacrés. A l'article 4 du chapitre $V$ il dit :

«Dans le temps de Yao, l'empire n'était pas encore tranquille. D'immenses eaux, débordant de toutes parts, inondèrent l'empire ; les plantes et les arbres croissaient avec surabondance ; les oiseaux et les bêtes fauves se multipliaient à l'infini ; les cinq sortes de grains ne pouvaient mûrir, etc.

\section{A l'article 9 du chapitre VI :}

«A l'époque de l'empereur Yao, les eaux débordées inondèrent tout le royaume. Les serpents et les dragons I'habitaient et le peuple n'avait aucun lieu pour fixer son séjour, etc.. ${ }^{1} \gg$

Pour John Barrow, membre scientifique de la mission de lord Macartney, l'écriture chinoise ne doit rien aux hiéroglyphes et les Célestes sont une race très distincte qui ne s'est mêlée à aucune autre. Les similitudes qui existent entre certaines de leurs idées religieuses et celles de l'Égypte et de la Grèce ont, d'après lui, été importées par des savants grecs qui accompagnaient Alexandre dans son expédition en Orient et par les Égyptiens et Grecs qui, lors des persécutions de Ptolémée Physcon, se réfugièrent en Perse et aux Indes. Son traducteur fait justement observer que si les Chinois ont emprunté quelque chose des

${ }^{1}$ Confucius et Mencius, traduction Pauthier. 


\section{Les Chinois}

Essai de Psychologie ethnographique.

Égyptiens, ils ont dû le faire à une époque beaucoup plus ancienne ${ }^{1}$.

Depuis lors, la pure sinologie, la sinologie en quelque sorte officielle, a définitivement rejeté ces hypothèses ; l'autonomie de la race et de la civilisation chinoises est devenue une sorte de dogme. Au début du XIXe siècle, Klaproth écrit à I'abbé Grosier, dont la querelle avec de Guignes fils n'est pas apaisée, qu'il partage sa foi en l'antiquité de la Chine, en l'authenticité de sa chronologie et de ses Annales 2 .

Abel Rémusat vient aussi à la rescousse de l'abbé Grosier qui, dit-il, « oppose, à des allégations sans preuves, des autorités et des raisonnements qui nous paraissent également irréfragables ». Il estime que le père jésuite, auteur du Mémoire sur l'Antiquité de la Chine, pourtant si précautionneux, si timide, a répondu victorieusement à toutes les difficultés soulevées sur I'histoire du Céleste Empire 3.

Les deux irréconciliables adversaires, Stanislas Julien et Pauthier, affichaient la même foi dans les traditions historiques de la Chine.

Ils eurent cependant là une nouvelle occasion de se quereller. D'une façon assez contradictoire avec cette parfaite orthodoxie sinophile, Pauthier avait exprimé I'opinion que les caractères chinois avaient une origine égyptienne ou phénicienne ; mais, au lieu de l'établir par une comparaison des écritures, comme l'avait

${ }^{1}$ Voyage en Chine, t. I, p. 442, et t. II, p. 232.

2 Mémoires relatifs à l'Asie, p. 414.

${ }^{3}$ Nouveaux mélanges asiatiques, t. I, p. 286. 


\section{Les Chinois}

Essai de Psychologie ethnographique.

fait de Guignes père à la suite de l'abbé Barthélemy, et comme il avait été également procédé pour les hiéroglyphes de I'Isis de Turin, il prétendait en voir la preuve dans un certain nombre de textes chinois traduits par lui. Ce sont ces traductions que Stanislas Julien attaqua, en en relevant impitoyablement les erreurs ${ }^{1}$. De Guignes fils avait déjà, par des traductions inexactes, dont l'abbé Grosier usa largement pour le combattre, discrédité le problème historique le plus passionnant qui soit.

Edouard Biot, le traducteur du Tchéou-li, s'en réfère entièrement, dans son Introduction, à la tradition chinoise.

« D’après les données authentiques, écrit-il, consignées dans les livres sacrés et dans les quatre livres sacrés qui forment la base de l'ancienne histoire chinoise, les premiers habitants de la Chine étaient des peuples sauvages et chasseurs, au milieu desquels s'avança, entre le $X X X X^{e}$ et le $X X V I I^{e}$ siècle avant notre ère, une colonie d'étrangers venant du nord-ouest. Cette colonie est généralement désignée, dans les textes, sous le nom de peuple aux cheveux noirs. Elle est appelée aussi les cent familles, et ses premières opérations présentent beaucoup d'analogie avec celles des planteurs qui vont défricher les forêts de l'Amérique septentrionale.

Cette tradition n'est d'ailleurs pas en contradiction avec les diverses hypothèses faites, elle est même d'accord avec elles, en ce sens qu'elle reconnaît que les premiers Chinois sont venus de

${ }^{1}$ De quelques Inventions archéologiques de M. Pauthier. 


\section{Les Chinois}

Essai de Psychologie ethnographique.

l'extérieur, d'une Asie plus occidentale - qui, d'ailleurs, s'ils étaient partis de plus loin, n'avait été qu'une étape - et toute la question est de savoir justement à quelle race, à quelle civilisation antérieure ils appartenaient.

Quelques hypothèses faites à cet égard sont encore à retenir. D'après celle de l'Anglais Terrien de la Couperie, le peuple qui serait venu coloniser et civiliser la Chine porterait le nom de Bak et serait parti de Chaldée. Après s'être arrêté dans la Bactriane, à laquelle il aurait donné son nom, ce peuple aurait ensuite franchi le Pamir par petits groupes, pour redescendre dans le pays des cinq fleuves, la Kachgarie de nos jours, et gagner peu à peu la contrée qui est maintenant la province du Kan-sou. Leur chef, Nakonte, ne serait autre que Hoang-ti ${ }^{1}$.

Le comte de Gobineau, comme on devait s'y attendre, rattache le Céleste Empire à son grand système du rôle prééminent de la race aryenne dans la civilisation universelle.

« Le pendant de ce qui arrive pour l'Égypte, dit-il, se rencontre en Chine. Une colonie ariane, venue de l'Inde, y apporta les lumières sociales. Seulement, au lieu de se mêler, comme sur les bords du Nil, avec des populations noires, elle se fondit dans des masses malaises et jaunes, et reçut, en outre, par le nordouest, d'assez nombreux apports d'éléments blancs, également arians, mais non plus hindous ${ }^{2}$.

${ }^{1}$ L'Empire du Milieu, par Élysée et Onésime Reclus, p. 59.

${ }^{2}$ Essai sur I'Inégalité des races humaines, t. I, p. 222. 


\section{Les Chinois}

Essai de Psychologie ethnographique.

Une étude plus récente du général Frey a cette originalité de renverser la proposition en ce qui concerne les relations de I'ancienne Égypte avec I'Extrême-Orient. La vallée du Nil aurait été colonisée par des Annamites, cette expédition se rattachant à l'une des grandes migrations des époques préhistoriques, antérieures à 8000 années, qui a pu s'effectuer soit par mer, soit par terre ${ }^{1}$. Le général soutient cette thèse, en l'appuyant sur l'identité du langage et des symboles religieux, qu'il s'efforce d'établir par de nombreux rapprochements. Il en conclut à la priorité de la race annamite, par conséquent tartare - celle-là était un rameau de celle-ci - et il se rapproche ainsi de I'opinion de Bailly et de celle de Bory de Saint-Vincent sur le point de départ nord-asiatique du premier peuple civilisateur du monde.

Il faut mentionner enfin, à titre documentaire, qu'un écrivain japonais a soutenu dans plusieurs Revues de son pays, en 1919, que la race japonaise, partie du nord de l'Afrique, avait subjugué la Grèce, I'Italie, I'Asie-Mineure, puis s'était étendue en Mongolie et au Japon. Il ajoutait, entre autres choses, que l'empereur Nintoku s'identifiait avec le pharaon Séti ${ }^{2}$. C'est là une allégation de journaliste mégalomane, sans base aucune et assez semblable à la prétention qu'ont eue les Allemands d'annexer à leur race tout ce qui émerge dans I'humanité, mais peut-être doit-on aussi y voir un écho du problème historique posé au XVIII ${ }^{\mathrm{e}}$ siècle à propos de la Chine.

Les Égyptiens préhistoriques identifiés avec les Annamites, librairie Hachette.

2 Voir l'Écho de Chine du 22 mars 1919. 


\section{Les Chinois}

Essai de Psychologie ethnographique.

S'il n'est pas une de ces diverses hypothèses sur l'origine des Chinois qui ait un caractère de certitude historique, la plupart sont néanmoins basées sur des analogies troublantes. Et, de fait, ces analogies sont indiscutables et nombreuses; non pas, selon l'expression de Michelet, que « la sotte imitation soit la loi de ce monde 1 », mais parce qu'il a dû y avoir, outre les civilisations de I'antiquité, une relation dont on ne percera sans doute jamais le mystère.

En dehors des similitudes d'écriture, admises même, on l'a vu, par les jésuites rédacteurs des Mémoires, notamment pour certains hiéroglyphes de I'Isis de Turin, on a relevé des identités significatives dans les conceptions religieuses. Dans cet ordre d'idées, une des constatations les plus étranges est celle que les missionnaires jésuites ont relevée sur l'existence, dans les livres sacrés de la Chine, des légendes hébraïques.

« Les premiers Chinois, disent les Mémoires, avaient connu les Patriarches d'avant le Déluge et apporté, ici, la foi et l'espérance du Messie, le culte religieux de la loi naturelle, l'attente d'une heureuse éternité, etc. La création du monde et de I'homme, l'état d'innocence, la chute d'Adam sont articulés aussi clairement qu'on peut le désirer dans nos anciennes chroniques (chinoises) ${ }^{2}$.

Le grand commentateur de ces livres sacrés, de ces King, Confucius, annonçait aux Cent familles que le saint par excellence devait naître en Occident.

${ }^{1}$ La Bible de I'Humanité, p. 358.

2 T. 1, p. 104, 105. 


\section{Les Chinois}

Essai de Psychologie ethnographique.

On retrouve ces mêmes traditions aux Indes et dans tous les pays d'ancienne civilisation. Ce sont elles qui avaient provoqué l'érection, dans Athènes, d'un autel au dieu inconnu, et qui avaient fait circuler, dans tout I'Orient, les bruits prophétiques dont parlent Suétone et Tacite.

Ces légendes hébraïques, ainsi répandues jusqu'à la Chine, ce sont celles même de la vieille Égypte.

« Les symboles des Égyptiens, a reconnu Saint-Clément d'Alexandrie, sont semblables à ceux des Hébreux.

« Les premiers Égyptiens, dit un égyptologue du commencement du XIXe siècle, n'étaient point idolâtres, mais la dégénération de leur culte, du temps de Moïse, les avait entraînés dans l'idolâtrie. Au milieu de cette dégénération générale, la pureté de la religion primitive s'était conservée dans l'intérieur des sanctuaires. Les prêtres, n'osant plus révéler cette religion à tout le peuple, en avaient fait ce qu'ils nommaient la sainte doctrine, et cette doctrine n'était enseignée par eux qu'aux hommes sur la discrétion et la sagesse desquels ils pouvaient compter. Moïse fut du petit nombre des élus ; il conçut l'idée d'effectuer, pour sa nation, ce que les prêtres n'osaient faire pour l'Égypte, c'est-à-dire d'initier, par une révélation générale, le peuple juif que l'exemple avait entraîné vers I'idolâtrie ${ }^{1}$.

Cette sainte doctrine était renfermée dans les ouvrages hermétiques d'Hermès Trismégiste qui est le Thoth égyptien.

${ }^{1}$ P. Lacour, Essai sur les hiéroglyphes égyptiens, Introduction, p. XIV. 


\section{Les Chinois}

Essai de Psychologie ethnographique.

Parmi ces livres, deux étaient consacrés à chanter les dieux et à donner des règles aux rois ; quatre traitaient de l'astrologie et dix, de l'art sacré, de la religion, du culte et du sacerdoce ${ }^{1}$. Les symboles et les légendes qui, comme il est dit plus haut, sont à la base de toutes les vieilles religions, y sont inscrits, non seulement ceux énumérés par les Mémoires, en ce qui concerne la Chine, mais encore la trinité, la triade sacrée d'Ammon-Râ, composée d'Ammon, le père, Maut, la mère, et Khons, le fils, dont Osiris, Isis et Morus sont les personnifications terrestres. Cette trinité se retrouve aux Indes, en Chine ${ }^{2}$ et dans la religion chrétienne. Et que dire d'Isis, qui venge le meurtre d'Osiris en faisant tuer, par son fils Horus, le meurtrier, Typhon, l'esprit du mal ? N'est-ce pas une première incarnation de la vierge Marie écrasant la tête du serpent ? Or, cette Isis, doublée de vierge Marie, existe en Chine sous le nom de Ching-Mou. Cette déesse est ordinairement placée au fond des temples, derrière l'autel, dans une espèce de niche fermée avec un écran de soie pour la dérober aux regards de la multitude. Tantôt elle a un enfant dans sa main, tantôt elle le tient sur ses genoux et elle a une auréole autour de sa tête. La tradition veut qu'étant encore vierge elle ait conçu et soit devenue enceinte pour avoir mangé une fleur de lien-houa. Au terme de sa grossesse, s'étant rendue à l'endroit où elle avait ramassé la fleur, elle y était accouchée d'un fils. Cet enfant, recueilli et élevé par un pauvre pêcheur, est devenu ensuite un grand homme et a fait des miracles. Le lien-houa

\footnotetext{
${ }^{1}$ Saint Clément d'Alexandrie, Stromates, I, VI.

${ }^{2}$ La trinité chinoise s'exprime très bien dans cette formule de Lao-tseu : «Tao est un par nature. Le premier a engendré le second ; deux ont produit le troisième ; les trois ont fait toutes choses. »
} 


\section{Les Chinois}

Essai de Psychologie ethnographique.

n'est autre que le lotus qui joue un si grand rôle dans la religion égyptienne où il est consacré à Osiris et à Isis, emblèmes du soleil et de la lune. John Barrow, qui relate dans son ouvrage ces singularités religieuses, y voit une preuve que les rites égyptiens ont pénétré dans I'Inde et en Chine dès la plus haute antiquité, ou bien qu'ils ont été apportés de l'Orient à l'Égypte ${ }^{1}$.

« Je crois, dit-il, qu'il est assez probable que, dans les premiers temps dont parlent les Annales de la Chine, on connoissoit, dans cet Empire, I'histoire d'Osiris et d'Isis. L'on sait qu'Osiris, roi d'Égypte, et époux d'Isis, était adoré sous la forme d'un bœuf, parce qu'il avait protégé l'agriculture et appris à employer le bœuf au labourage des terres.

La célèbre cérémonie chinoise, dans laquelle l'empereur prend la charrue et laboure un sillon, après s'être préparé à ce devoir solennel par trois jours de dévotions, lui paraît se rattacher à cette légende égyptienne. Et le savant voyageur ajoute :

« Le jour désigné par le tribunal des mathématiques, on sacrifie une vache au temple dédié à la Terre. Il y a des provinces où, le même jour, une vache d'argile, d'une grandeur démesurée, est promenée par une foule de gens de la campagne et accompagnée par les principaux officiers du gouvernement et par les autres habitants. Les cornes et les pieds de cette vache sont dorés et ornés de rubans. Quand les prosternemens sont faits et les offrandes déposées sur l'autel, la vache

\footnotetext{
${ }^{1}$ Voyage en Chine, t. II, p. 316 et suiv.
} 


\section{Les Chinois}

Essai de Psychologie ethnographique.

d'argile est brisée et distribuée au peuple. C'est ainsi que le corps d'Osiris, adoré ensuite sous la forme d'un bœuf, fut distribué aux prêtres par Isis. Les fêtes d'Isis furent longtemps célébrées en Égypte de la même manière que la fête du labourage se célèbre aujourd'hui en Chine. »

Le totémisme de la religion égyptienne, c'est-à-dire le système selon lequel, au temps des Pharaons, chaque divinité était symbolisée par un animal, existe également en Chine. Conformément à ce rite, les Égyptiens représentaient leurs dieux en plaçant, sur des corps de forme humaine, la tête de la bête qui était leur totem. Il n'est pas rare de voir encore, dans des pagodes chinoises, des idoles de ce genre. Marco Polo, qui en avait vu, les décrit en ces termes:

« Or sachiez que les ydoles du Catay (nord) et du Mangy (sud de la Chine) et celles de I'Inde sont tous d'une manière. Et y a telle ydole qui a chief de buef, et telle qui a chief de porc, de chien ou de mouton et de plusieurs autres façons, etc. Et quant aucun chrestien leur demande pourquoy ilz font leurs ydoles desguisées et, non semblables I'une aux autres, ilz leur respondent que leurs ancestres les orent si faites, et telles les laisseront à leurs enfans, et leurs enfans aux leurs ${ }^{1}$.

Les rites funéraires, qui touchent de si près à la religion, ont aussi des ressemblances remarquables, tant dans la conception

\footnotetext{
${ }^{1}$ Le livre de Marco Polo, rédigé en français sous sa dictée, par Rusticien de
} Pise (édition Pauthier). liv. III, chap. CLX. 


\section{Les Chinois}

Essai de Psychologie ethnographique.

de la vie, de la mort et de la survie de l'âme que dans les modes d'inhumation. On peut dire qu'hormis la momification, qui ne semble pas avoir jamais existé chez les Chinois, tout est identique. De même qu'en Égypte après la mort, un esprit inférieur, le $K a$, qu'on a appelé le double, reste avec le corps, dans la tombe, tandis que l'âme fait le grand voyage, pour aller comparaître devant Osiris, de même, en Chine, le p'ai, ou âme inférieure, descend en terre et le hoàn, âme supérieure, monte au ciel ${ }^{1}$. Le $K a$ égyptien et le $p^{\prime} a i$ chinois ont une vie matérielle et c'est pourquoi, ainsi que dans la vieille Égypte, on enterrait, avec le corps, à l'usage du $K a$, des simulacres de tous les objets dont il avait besoin pour sa deuxième existence et même de la nourriture. En Chine on voit encore, de nos jours, dans les enterrements, et pour la même raison, des animaux domestiques, des serviteurs, des vêtements, etc., le tout en papier, accompagner le défunt à sa dernière demeure 2 .

Chose également très curieuse, le cœur, dans un pays comme dans l'autre, joue un rôle éminent : il est le siège de la conscience. En Égypte, selon la croyance des temps pharaoniques, le cœur était placé, après la mort, dans un des plateaux de la balance d'Osiris, pour faire contrepoids à la déesse Vérité-Justice ${ }^{3}$. En Chine, la doctrine des Lettrés dit :

\footnotetext{
${ }^{1}$ Voir les Prolégomènes à l'étude de la Religion égyptienne, par Amélineau, et les Textes philosophiques chinois, traduits par le père Wieger.

2 Voir Morale et Usages, textes chinois traduits par le père Wieger : « Funérailles ».

${ }^{3}$ Amélineau, Prolégomènes, chap. V.
} 


\section{Les Chinois}

Essai de Psychologie ethnographique.

« Le cœur est la quintessence de la matière. De son union avec la norme résulte l'intelligence. La norme n'est consciente-percevante que dans le cœur.

« C'est dans le cœur que I'homme pense, c'est dans le cœur que résident les principes qu'il a reçus du ciel ${ }^{1}$.

C'est donc, là aussi, le cœur qui sera responsable, après la mort, devant le «Sublime Souverain du Ciel ».

D'autres usages relatifs aux funérailles sont encore semblables. Autrefois, en Égypte, elles n'étaient souvent célébrées, ainsi que l'établissent des textes fort anciens, qu'un an après la mort, et, dit Amélineau, « comme la chose a toujours lieu en Chine ». Dans ce dernier pays, en effet, l'enterrement ne s'effectue que bien après le décès, alors que, les cimetières n'existant pas, on a longuement cherché un lieu favorable à la sépulture, à l'aide de géomanciens intéressés à faire durer cette investigation ${ }^{2}$. En Chine également, comme jadis en Égypte, on choisit volontiers, pour établir cette dernière demeure, un lieu élevé d'où l'on a une belle vue. Les nécropoles pharaoniques s'étagent sur les falaises qui dominent la vallée du Nil, de même qu'à Canton, par exemple, la montagne des Nuages blancs est parsemée d'innombrables tombes.

Comme les Chinois, les Égyptiens étaient de grands constructeurs de canaux et de «grandes murailles ». Diodore de Sicile raconte que Sésostris fit creuser des canaux de

${ }^{1}$ Textes philosophiques chinois, p. 232, 233. - Morale et Usages, p. 137 et suiv. - Folk-lore chinois, textes traduits par le père Wieger : Introduction.

2 Morale et Usages : «Funérailles ». 


\section{Les Chinois}

Essai de Psychologie ethnographique.

communication depuis Memphis jusqu'à la mer d'Arabie. Mais le principal, dit l'historien, est qu'il mit tout le royaume à couvert des ennemis en fermant tout le côté de l'Égypte qui regarde I'Orient par un mur de quinze cents stades de longueur, qui coupait le désert depuis Péluse jus-qu'à Héliopolis, pour arrêter les courses des Syriens et des Arabes ${ }^{1}$.

Bien d'autres usages de Chine évoquent invinciblement la vieille Égypte. Parmi ceux-ci, la fête des Lanternes a été très controversée. Au XVIII siècle, M. de Mairan, surpris de la trouver pareille chez les Chinois à ce qu'elle était chez les Pharaons, d'après Hérodote 2, avait soumis ce point à son informateur habituel, le père Parennin, qui lui répondit par la négative. Il n'en reste pas moins que cette fête a le même but religieux dans le Céleste Empire que, jadis, sur les bords du Nil. La « raison sainte de ces illuminations », à laquelle fait allusion Hérodote, était une célébration en l'honneur d'Isis identifiée avec la lune, et c'est aussi en I'honneur de cet astre qu'elle se célèbre en Chine, pour la première lune de chaque nouvelle année. C'est I'interprétation que lui donnent de Guignes fils 3 et John Barrow ${ }^{4}$.

Il en est de même de la fête du Dragon. De Guignes observe 5 que le voyageur du XVII ${ }^{\mathrm{e}}$ siècle, Thévenot, rapporte les

${ }^{1}$ Histoire universelle, liv. I, section II.

${ }^{2}$ Histoire d'Hérodote, liv. II, LXII.

3 Observations sur quelques points concernant la religion et la philosophie des Égyptiens et des Chinois, dans les Mémoires de littérature du 24 janvier 1775.

${ }^{4}$ Voyage en Chine, t. II, p. 328.

5 Observations. 


\section{Les Chinois}

Essai de Psychologie ethnographique.

circonstances d'une réjouissance qui avait lieu sur le $\mathrm{Nil}$ et qui sont semblables à celles qui caractérisent cette fête en Chine : même époque du mois d'août et mêmes bateaux remplis de musiciens et ornés de figures de dragons ${ }^{1}$. De Guignes prétend même que c'était encore cette fête que les Égyptiens allaient, selon Hérodote, célébrer à Bubastis.

Et les allées monumentales de bêtes que I'on voit aux tombeaux impériaux, près de Pékin, comme à ceux des Mings, à Nankin, ne font-elles pas songer aux alignements de monstres accroupis des ruines de Karnak, à Louksor, sur le Haut-Nil ? Bien des statuettes de terre cuite que I'on a mises au jour, ces dernières années, en fouillant les plus anciennes tombes de Chine, dans le Ho-nan, rappellent singulièrement, par leur attitude hiératique, celles que I'on voit dans les collections d'égyptologie.

John Barrow, qui fait une énumération assez copieuse de ces similitudes, relève encore que, pour les éclipses de lune, les Égyptiens, ainsi, du reste, que les Grecs et les Romains, battaient du tambour, comme le font les Chinois, et sonnaient dans les trompettes pour secourir la déesse embarrassée ${ }^{2}$. Il signale que les Égyptiens faisaient couver les œufs artificiellement ainsi que les Chinois ${ }^{3}$. Ils avaient aussi le même

\footnotetext{
1 Thévenot, Voyage du Levan

2 Voyage en Chine, t. II, p. 21.

3 T. III, p. 57.
} 


\section{Les Chinois}

Essai de Psychologie ethnographique.

mode de décortiquer le riz et leur charrue était absolument semblable ${ }^{1}$.

Il ressort des dessins et peintures reproduits dans le livre de Champollion-Figeac sur l'Égypte ancienne que les Égyptiens avaient, pour élever l'eau, le même système de levier alourdi d'un poids à son extrémité que le voyageur peut voir fonctionner au long de tous les cours d'eau de Chine ${ }^{2}$. Le porteur de fardeaux se sert, comme les coolies célestes, du balancier en équilibre sur une épaule ${ }^{3}$. Quand il y a deux portefaix, il ont, chacun, une extrémité du balancier sur une épaule et le fardeau se balance au milieu, à l'exemple de ce qui se fait couramment en Chine ${ }^{4}$.

On vient d'inaugurer, au musée du Louvre, des salles d'Extrême-Orient où se trouve réuni un ensemble d'objets qui prouve, dit Le Temps, à quel point la vieille Chine se rencontre avec I'Égypte ancienne par ses croyances à une survie dans la tombe et ses habitudes funéraires, ainsi que dans les arts de la pierre et du bois 5 .

Outre ces similitudes de rites, d'usages et d'ingéniosité pratique, il y a une ressemblance morale profonde que Renan a saisie et qu'il a très bien définie dans l'étude qu'il consacra à

${ }^{1}$ T. III, p. 67 et 68.

2 Planche 55.

3 Planches 38, 43, 45 et 55.

${ }^{4}$ Planche 62.

${ }^{5}$ Le Temps, 10 mai 1920. 


\section{Les Chinois}

Essai de Psychologie ethnographique.

I'Égypte ancienne après son voyage avec Mariette ${ }^{1}$. Il ne paraît pas que la question de l'origine commune des deux peuples existe pour lui, il ne voit entre eux « aucune analogie de langue ni de race » et cependant, en traitant de la vieille Égypte, il ne cesse de penser à la Chine. Pour lui,

« l'Égypte et la Chine sont vraiment deux sœurs en histoire, en ce sens qu'elles ont suivi des lignes de développement parallèles.

Ailleurs, il dit :

« L'Égypte est une Chine, née mûre et presque décrépite, ayant toujours eu cet air à la fois enfantin et vieillot que révèlent ses monuments et son histoire.

Plus loin encore :

« La base de la civilisation égyptienne, comme de la civilisation chinoise, était l'opinion enracinée que le reste du monde était barbare, ou, en d'autres termes, qu'on était barbare quand on n'avait pas les manières et les idées regardées dans le pays comme celles d'un homme bien élevé.

De part et d'autre il voit

« une royauté de sages, une société gouvernée par une sorte d'académie des sciences morales et politiques, une nuée de fonctionnaires, une administration très développée, une notion fort limitée des droits de

\footnotetext{
${ }^{1}$ Mélanges d'histoire et de voyages, p. 27.
} 


\section{Les Chinois}

Essai de Psychologie ethnographique.

I'individu, un grand bon sens, une certaine douceur de mœurs, etc., avec cela nulle science, nulle philosophie, nulle critique, nul progrès : le règne absolu de la médiocrité.

On a l'impression qu'il regrette de ne pouvoir pousser plus loin cette comparaison parce qu'on ne connaît pas suffisamment le lointain passé de la Chine. Il y a là, pour lui, sans doute, une inconnue passionnante, une identité possible dont il vaut autant ne pas parler puisqu'on ne peut projeter sur elle aucune lumière.

« On n'osera parler avec assurance, dit-il, de la chronologie chinoise que quand les principes de la critique moderne y auront été appliqués : il y faudrait un sinologue qui fût à la fois un Wolf et un Mommsen.

Et qui serait en même temps, ajouterons-nous, un égyptologue comme Mariette. Les deux études devraient être étroitement unies. Souhaitons qu'elles le soient un jour ${ }^{1}$.

Les analogies avec les peuples de I'Orient, avec la Grèce et Rome, sont également nombreuses, et cela s'explique par le fait que tout ce monde ancien dut en grande partie sa civilisation, ses coutumes, les idées religieuses et morales qui forment l'âme, à l'Égypte, avec laquelle on vient de voir que la Chine a tant de

\footnotetext{
${ }^{1}$ Dans le premier volume de son Histoire générale de la Chine, récemment publiée, M. Henri Cordier donne un exposé très complet des diverses théories relatives aux origines chinoises et il conclut en estimant qu'il n'y a en ces matières que des hypothèses et que le problème est toujours posé. "Peutêtre, dit-il en terminant, faut-il chercher le lien qui rattache la Chine au reste de l'humanité dans une antiquité si reculée que les générations actuelles ne sauraient y remonter. Nous entrons dans le domaine de la préhistoire. »
} 


\section{Les Chinois}

Essai de Psychologie ethnographique.

parenté. Comme pour les Égyptiens, John Barrow en a donné une longue liste ${ }^{1}$. En voici quelques-unes signalées par lui :

Les Chinois ont la même conception du ciel que les Perses qui, selon Hérodote, considéraient le cercle entier des cieux comme le pouvoir gouvernant I'Univers et lui offraient des sacrifices sur les hautes montagnes.

Tous les peuples anciens ont eu d'ailleurs cette coutume d'adorer les dieux sur les lieux élevés. Lorsque Noé sortit de I'Arche, il bâtit un autel sur la montagne où elle s'était arrêtée et y sacrifia. Dieu commanda à Abraham de lui offrir en holocauste son fils unique, Isaac, sur une montagne du pays de Moria. Chez les Romains, Tacite, en parlant de cette coutume d'adorer les dieux sur les hauteurs, observe que plus les mortels peuvent se rapprocher du ciel, plus distinctement leurs prières sont entendues. Sénèque fait une remarque semblable.

Le culte des pénates est, chez les Chinois, identique à ce qu'il était chez les Grecs et les Romains, sauf qu'ils ne les représentent pas par des figures, mais par des tablettes avec inscription, devant lesquelles brûle un flambeau.

Le Men-chin, ou esprit de la porte des Célestes, est évidemment la même divinité que le Ganésa des Indous et le Janus des Romains.

Le culte des ancêtres existait ù Rome.

A certaines dates, comme en Chine, on y offrait des présents aux mânes des parents morts. Les Romains croyaient aussi,

\footnotetext{
1 John Barrow, Voyage en Chine, 3 vol.
} 


\section{Les Chinois}

Essai de Psychologie ethnographique.

d'ailleurs, à la survie matérielle de l'âme et ils pensaient que s'ils étaient privés de sépulture et d'offrandes, leur âme restait errante et privée de repos ${ }^{1}$. Cela, c'est de la pure Chine. Cette idée de la survie matérielle existait également chez les Étrusques 2.

Barrow rapporte la cérémonie, avec offrande et libations, à l'esprit du fleuve, qui fut célébrée par les Chinois, au confluent du Canal impérial et du Hoang-ho (fleuve Jaune), à bord des bateaux où se trouvaient les membres de la mission de lord Macartney. Cela faisait partie des rites que l'on observe à l'égard du génie de chaque rivière. Ce même culte était suivi chez tous les peuples anciens. Les Égyptiens révéraient le Nil. Hérodote constate une dévotion identique chez les Perses.

Il suffit de lire I'Iliade pour voir qu'elle existait aussi chez les Grecs. Élien fait une longue énumération des peuples qui honoraient ainsi les fleuves; il cite les Symphaliens, les Lacédémoniens, les Sicyoniens, les Phliasiens, les Argiens, les Psophidiens, les Héréens, les Chéronésiens, les Athéniens, les Syracusains, les Égestains et les Agrigentins. Ces derniers adoraient leur fleuve sous l'emblème d'un enfant parfaitement beau. Ils lui avaient consacré, au temple de Delphes, une statue en ivoire au bas de laquelle était écrit le nom du fleuve ${ }^{3}$.

\footnotetext{
${ }^{1}$ Voir Gaston Boissier, La Religion romaine, t. I, p. 267.

${ }^{2}$ Gaston Boissier, Nouvelles Promenades archéologiques, p. 87 et suiv.

${ }^{3}$ Histoires diverses, chap. XXXIII.
} 


\section{Les Chinois}

Essai de Psychologie ethnographique.

Il en est de même du trépied, vase à trois pieds, que l'on voit sur les autels d'ancêtres, en Chine, et qui a été en usage dans toutes les religions de l'Antiquité ${ }^{1}$.

En matière de pénalité, l'extension du châtiment à tous les membres de la famille du criminel, qui est appliquée dans la justice chinoise, se pratiquait dans la législation des anciens Grecs. Elle existait pareillement chez les Hébreux et Jéhova en avait donné l'exemple, comme il ressort de la tradition du péché originel que doit expier toute la descendance d'Adam.

On pourrait aussi faire des rapprochements pour l'astrologie, la divination, l'interprétation des phénomènes de la nature, à laquelle, même aujourd'hui, en Chine, sauf pour un très petit nombre, la science n'a aucune part.

Enfin, Barrow signale des similitudes moins importantes, mais curieuses : le souan-pan, machine à compter, qui est l'abacus des Romains, et un jeu, le tsoï-moï, qui consiste à deviner combien le partenaire a de doigts ouverts et qui est absolument pareil au micare digitis, auquel Cicéron fait souvent allusion dans le livre des Offices.

Ce qu'il y a peut-être de plus remarquable, c'est que la psychologie des Chinois a bien des traits communs avec celle des races de I'Orient méditerranéen. Le mensonge et la ruse jouent, chez eux, un rôle aussi important que chez les Grecs, et le geste de Minerve caressant le visage d'Ulysse, après une invention particulièrement ingénieuse 2 , est souvent reproduit par les

\footnotetext{
${ }^{1}$ Voir Hager, Panthéon chinois, p. 439 et suiv.

${ }^{2}$ L Odyssée, liv. XIII.
} 


\section{Les Chinois}

Essai de Psychologie ethnographique.

mères chinoises, heureuses que leurs enfants sachent déjà si bien mentir. Un médecin français eut un jour, à Canton, la surprise d'entendre une de ces mères se flatter de ce que son jeune fils était, à ce point de vue, fort bien doué. Par sa circonspection, si patiente et adroite, le roi d'Ithaque est vraiment digne d'être un héros chinois. Dans le Céleste Empire, en effet, la qualité éminente, celle qui est le plus louée, est la prudence, et le défaut le plus flétri : la témérité.

Une réglementation rituelle également rigide, associée à une pareille âpreté de réussite et de jouissance, aboutit, chez les Anciens et chez les Chinois, à une moralité de pure forme, de face, d'après laquelle il importe uniquement de cacher sous de belles apparences tous ses appétits. Cela crée entre eux une étrange ressemblance qui aide à les expliquer. C'est ainsi, par exemple, qu'on comprend mieux un Yuan Chi-kaï en pensant à Pompée. Et que de mandarins, dont les actions sont à l'encontre de leurs impeccables discours, évoquent le souvenir d'un Salluste ou d'un Sénèque.

De même, pour la conception de la dignité, qui nous paraît si bizarre et si contradictoire avec la sensibilité habituelle de leur face, quand de hauts fonctionnaires célestes, parfois même de grands personnages, acceptent avec une humilité déconcertante les châtiments les plus de nature à les déshonorer, comme, par exemple, il n'y a pas longtemps encore, la bastonnade du bambou. Ils remercient ceux qui leur ont infligé cette peine infamante. 


\section{Les Chinois}

Essai de Psychologie ethnographique.

Or, Nicolas de Damas rapporte, dans son livre des Mœurs des Nations, que les Perses qui étaient fouettés par ordre du roi l'en remerciaient comme d'une faveur. Selon Thucydide, les jeunes Lacédémoniens se glorifiaient du nombre de coups de verges qu'ils avaient reçus.

De telles identités de toute espèce doivent forcément faire supposer des relations que ne mentionne pas I'histoire, antérieures à elle sans doute, une lointaine parenté de civilisation, un lot commun de traditions, de réglementations, de coutumes et même de contes, comme cette Matrone d'Éphèse, du Satyricon de Pétrone, que I'on retrouve dans la Matrone du pays de Soung.

Au point de vue ethnique, il ressort de tout cela que le peuple chinois n'est pas plus que les autres d'un sang pur, au sens où I'entendait le comte de Gobineau. Il est, lui aussi, bien que dans une mesure moindre que les nations européennes, qui subirent tant d'invasions, le produit d'un métissage, et il est certain même que des afflux des races blanche et noire se sont déversés dans le grand fleuve de la fourmilière jaune. On s'en rend compte, quand on voyage en Chine, par la variété des types que I'on a sous les yeux. C'est ainsi que John Barrow rapporte avoir vu, à Pékin, des Mandchous qui ressemblaient beaucoup plus à des Grecs qu'à des Tartares, et il l'explique par un mélange qui a dû se produire autrefois avec les anciens Grecs de la Sogdiane ${ }^{1}$.

En définitive, on peut dire que les grandes civilisation ont une origine commune, et que si les Célestes paraissent si différents

${ }^{1}$ Voyage en Chine, t. I, p. 311. 


\section{Les Chinois}

Essai de Psychologie ethnographique.

des autres peuples, c'est que, pendant que ceux-ci, par suite d'un cours plus agité, évoluaient sans cesse, eux, maintenus par des rites rigides, dans un cadre que rien ne venait briser, gardaient les formes de la mentalité la plus ancienne. La Chine est une vieille Égypte qui a persisté et qui se trouve beaucoup plus loin de nous dans le temps que dans l'espace. 


\section{Les Chinois}

Essai de Psychologie ethnographique.

\section{Les relations avec le Monde ancien.}

Sur ces rapports avec I'Orient de la Méditerranée et I'Asie occidentale, on ne trouve rien dans les livres, et pour cause, car il s'agit de faits antérieurs aux époques historiques. Par la suite, il est vrai, I'histoire n'en dit pas davantage et il semble bien, comme le fait remarquer Barrow, que le monde ancien ait ignoré la nation chinoise. Hérodote, qui vivait en même temps que Confucius, n'en dit mot, et plus d'un siècle après, alors qu'Alexandre a renversé I'Empire des Perses et s'est enfoncé en Orient, vers la Bactriane et la Sogdiane, on ne semble pas connaître davantage le grand royaume qui existe au delà. Plus tard, des géographes : Ératosthènes, Strabon, Pline, Pomponius Méla, Ptolémée, ont mentionné un peuple des Sères, avec lequel se faisait un commerce de soie, de fourrures et de fer, trafic qui se pratiquait par la voie de terre, appelée route de la soie, et par la mer, à l'aide de bateaux qui venaient au golfe Persique et dans la mer Rouge.

Au XVIII siècle, au moment où la Chine excitait la curiosité des milieux lettrés et savants, la question se posa de savoir si ces Sères étaient les Chinois, et là-dessus encore les avis se partagèrent. Le sinologue de Guignes opina pour les Chinois, et il prétendait en trouver la preuve dans les Annales Célestes. Il y vit qu'An-toun (I'empereur Marc-Antonin, Marc-Aurèle, qui régnait en l'an 166 de l'ère chrétienne) envoya des ambassadeurs à l'empereur de Chine Oun-ti, dans le but de 


\section{Les Chinois}

Essai de Psychologie ethnographique.

réglementer et de rendre plus sûres ces relations commerciales ${ }^{1}$.

Aucun historien, grec ou latin, ne mentionne de pareilles relations officielles entre Rome et la Chine.

Le seul qui en parle, Florus, se borne à relater très succinctement que les Sères et les Indiens, «qui vivent sous le soleil », vinrent, pendant le règne d'Auguste, offrir aux Romains, en présents, des perles, d'autres pierres précieuses et jusqu'à des éléphants 2 . Cela, écrit plus de cent ans après la mort d'Auguste, n'a qu'un médiocre caractère d'authenticité.

Quant au commerce de la soie, John Barrow ne croit pas qu'il indique des relations avec les Chinois, parce que, dit-il, les Romains ne recevaient le peu de soie dont ils faisaient usage que de la Perse et non du pays des Sères ${ }^{3}$.

Pour tous les grands géographes du XVIII ${ }^{e}$ siècle, d'Anville, Gosselin, Mentelle, I'Anglais Pinkerton, la Sérique, dont parlent les anciens auteurs, était située au nord-ouest du Céleste Empire et les Grecs n'ont pas connu la Chine.

Hager est d'un avis contraire. Il a, sur ce point, la même opinion que de Guignes et il consacre toute une partie de son Parallèle entre le culte religieux des Grecs et celui des Chinois ${ }^{4}$ à établir que la Sérique des Anciens est bien la Chine. Il paraît

\footnotetext{
${ }^{1}$ Mémoire sur les liaisons et le commerce des Romains avec les Tartares et les Chinois, dans les Mémoires de littérature, XXXII.

${ }^{2}$ Florus, Abrégé de I'Histoire romaine, liv. IV, chap. XII.

${ }^{3}$ Voyage en Chine, t. II, p. 251.

${ }^{4}$ Le Panthéon chinois.
} 


\section{Les Chinois}

Essai de Psychologie ethnographique.

résulter de sa démonstration que si les historiens anciens n'ont pas fait mention de ce pays, les géographes, du moins, en ont connu l'existence et, certains même, la situation exacte. Ils pensaient que la terre était un bloc entouré d'eaux de toutes parts et ils plaçaient les Sères au milieu de la côte orientale de cette île immense. Pomponius Méla précise, en disant qu'ils sont au milieu et les Scythes et les Indiens aux deux extrémités ${ }^{1}$. C'est donc bien des Chinois qu'il s'agit et non des Tartares de D'Anville.

Le plus ancien de ces géographes, Ératosthènes, qui vivait à Alexandrie, à la cour de Ptolémée Évergète, au moment même où le fondateur de la dynastie Tsin unifiait, pour la première fois, par ses conquêtes I'Empire du Milieu, 220 ans avant JésusChrist, a appelé la capitale des Sères : Oívol, en latin, Thina, qui, selon Hager, venait du mot : Tsin, et est finalement devenu le nom même de ce pays.

Si l'existence de la Chine, sous le nom de Sérique, n'a donc pas été ignorée des Anciens, il n'en reste pas moins que ceux-ci ne connaissaient rien, ni de son passé déjà très long, ni de son organisation sociale, ni de sa civilisation égale à la leur.

On devine à quel point ces Sères étaient inconnus, quand on voit que la Géographie de Strabon, qui était en son temps une encyclopédie de ces matières, ne leur consacre qu'une demidouzaine de lignes. Et encore ce qu'elle dit, en les appelant Macrobiens, de leur faculté de vivre jusqu'à plus de deux cents

\footnotetext{
${ }^{1}$ De situ orbis, liv. I, chap. II.
} 


\section{Les Chinois}

Essai de Psychologie ethnographique.

ans, tient-il de la légende et n'a-t-il rien de commun avec la vérité scientifique ${ }^{1}$.

Pline I'Ancien, qui écrivait trois quarts de siècle plus tard, n'était pas tout à fait aussi ignorant de ce pays. Ce qu'il raconte de ses habitants tient en une page. Il parle de leurs forêts à laine (soie), et il ajoute qu'ils ont des « mœurs inoffensives, avec quelque chose de sauvage : ils fuient l'approche de tous les hommes, si ce n'est des marchands 2 ». A lui seul, ce détail montre bien qu'il s'agit des Chinois. Pline termine en disant qu'un nommé Amomète a écrit, sur ce peuple, un volume comme Hécatée sur les Hyperboréens. Il ne nous reste rien de cet ouvrage, mais il est à croire que s'il avait contenu des notions plus précises, Pline, qui le connaissait, n'aurait pas manqué d'en faire usage.

Il apparaît donc que les Sères ou Chinois n'ont eu avec les Anciens de l'époque historique que des relations commerciales, évitant, pour tout le reste, ainsi que le note Pline, tout contact avec les étrangers. Ils pratiquaient, comme nation, le conseil que Plutarque donne à I'homme dans son Traité de Morale : «Si tu veux être heureux, cache ta vie ». Ils la cachèrent si bien que, lorsque, des siècles plus tard, Marco Polo voulut initier ses contemporains aux merveilles de leur Empire, nul ne pouvait le croire. En France même, on n'eut quelque idée de leur importance et de leur civilisation que par les Mémoires des Jésuites missionnaires des $\mathrm{XVII}^{\mathrm{e}}$ et $\mathrm{XVIII}{ }^{\mathrm{e}}$ siècles. Et ne faut-il pas voir un reste de ce long mystère dans cet axiome, d'ailleurs

${ }^{1}$ Liv. XV, chap. I.

${ }^{2}$ Histoire naturelle, liv. VI, chap. XX. 


\section{Les Chinois}

Essai de Psychologie ethnographique.

faux, mais qui a cours encore aujourd'hui, que les Chinois sont tellement différents de nous que nous ne pourrons jamais les comprendre?

(a) 


\section{Les Chinois}

Essai de Psychologie ethnographique.

Tableau comparatif de quelques caractères chinois et hiéroglyphes égyptiens ${ }^{1}$.

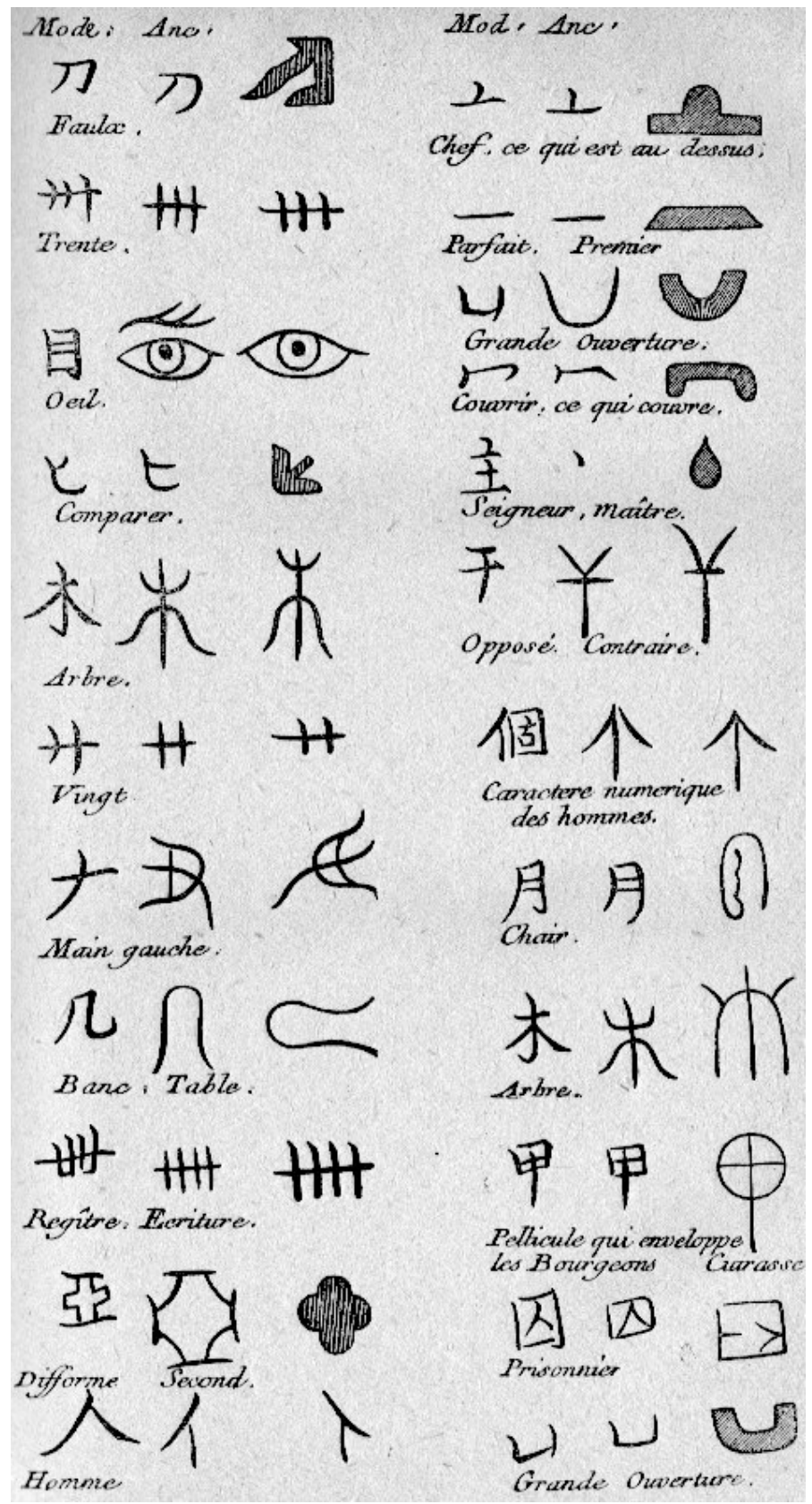

Ceci n'est qu'un partie du tableau comparatif publié par les Jésuites du XVIIIe siècle dans leurs Mémoires sur les Chinois, tableau qui était accompagné d'une reproduction des caractères et de la statue de I'Isis de Turin. 


\author{
Les Chinois \\ Essai de Psychologie ethnographique. \\ PSYCHOLOGIE \\ DES CHINOIS
}

TÉMOIGNAGES ET OPINIONS 


\section{Les Chinois}

Essai de Psychologie ethnographique.

I.

\section{Premières relations de voyages à la Chine.}

Il importe, pour donner la psychologie exacte d'un peuple, de dégager de ses caractéristiques ce qu'elles ont de permanent. Il y a donc lieu, avant de communiquer ses observations personnelles, de rechercher ce qu'ont pu en dire les voyageurs qui l'ont précédemment étudié. Il n'est pas indifférent non plus d'exposer, à la condition d'en pouvoir faire la critique, les opinions diverses, plus ou moins fondées, qui ont eu cours à son sujet. La confrontation de ces différentes manières de le voir aidera grandement à mettre les choses au point. Cette mise au point est d'autant plus nécessaire, en ce qui concerne les Chinois, que leur littérature, purement académique, et leur morale officielle, extrêmement rigoureuse, sont moins le miroir de la réalité que dans tout autre pays et ne peuvent par conséquent servir de repère. Quelles erreurs ne commettrait-on pas, du reste, si on voulait juger les peuples chrétiens d'après les Évangiles.

Par suite de leur soin, signalé plus haut, de se mettre à l'abri des regards étrangers, ces témoignages manquent tolalement pendant de nombreux siècles.

Les Arabes qui furent en Chine, Soleyman, au IX siècle, et Maçoudi, au $X^{e}$, ne nous ont laissé, pour cette cause sans doute, que des renseignements commerciaux. Marco Polo est, en 


\section{Les Chinois}

Essai de Psychologie ethnographique.

somme, le premier qui ait donné sur eux une contribution importante 1 . Malheureusement, s'il nous renseigne abondamment sur l'empereur Koubilaï-khan, auprès duquel il a vécu, sur sa bonne administration, sur le faste de sa capitale, Cambaluc (Pékin), ainsi que sur la beauté de quelques autres grandes villes et sur quelques coutumes générales, il ne nous dit à peu près rien de la vie privée, ni du caractère de ses sujets. Le psychologue ne trouve pas à glaner dans son récit, à d'autres égards si intéressant. On a encore moins des autres voyageurs du Moyen Age, les religieux Plan-Carpin, Rubruquis, Roderic de Pordenone, etc.

Un autre Arabe, Ibn Batouta, qui visita la Chine un demisiècle après le Vénitien, nous fait connaître des règlements de police, relatifs au séjour des étrangers, qui montrent bien toutes les précautions que I'on prenait pour leur surveillance, leur sécurité et aussi, probablement, surtout pour qu'ils n'emportent du Céleste Empire que de bonnes impressions.

« Lorsqu'un marchand musulman, dit-il, arrive dans une ville de la Chine, on lui laisse le choix de descendre chez un négociant de sa religion, désigné parmi ceux domiciliés dans le pays, au lieu d'aller à I'hôtellerie. S'il préfère la demeure chez le négociant, on compte toutes les valeurs qu'il possède, on les confie audit négociant choisi par lui, lequel prend sur l'argent de l'étranger

\footnotetext{
1 Marco Polo, de famille patricienne, né à Venise en 1251 , mort en cette même ville en 1324, est resté seize ans attaché au service de Khoubilaï-khan, empereur mongol de Chine. Il avait été amené dans ce pays par son père et son oncle, grands marchands vénitiens, qui avaient déjà fait un voyage en Extrême-Orient et avaient vécu à la Cour de ce souverain.
} 


\section{Les Chinois}

Essai de Psychologie ethnographique.

pour pourvoir aux besoins de celui-ci, mais d'une manière honnête. Quand il veut partir, on examine son argent, et, s'il en manque, le négociant chez lequel il demeure, et qui a reçu la somme en dépôt, est obligé de combler le déficit.

Dans le cas où le marchand qui arrive aime mieux se rendre à l'hôtellerie, on livre son argent au maître de I'hôtel à titre de dépôt. Ce dernier achète pour le compte de l'étranger ce que celui-ci désire, et s'il veut une concubine, il fait pour lui l'acquisition d'une jeune fille esclave. Il le met alors dans un appartement dont la porte s'ouvre sur l'intérieur de l'hôtellerie, et il fait la dépense pour I'homme et pour la femme. Quand le marchand étranger désire se marier en Chine, il le peut aussi très facilement ; mais pour ce qui est de dépenser son argent dans le liberti nage, cela ne lui est nullement permis. Les Chinois disent : «Nous ne voulons point que I'on entende rapporter dans le pays des musulmans qu'ils perdent leurs richesses dans notre contrée, que c'est une terre de débauche et de beautés fragiles et mondaines ».

La Chine est la plus sûre ainsi que la meilleure de toutes les régions de la terre pour celui qui voyage. On peut parcourir tout seul l'espace de neuf mois de marche sans avoir rien à craindre, même si l'on est chargé de trésors. C'est que dans chaque station il y a une hôtellerie surveillée par un officier, qui est établi dans la 


\section{Les Chinois}

Essai de Psychologie ethnographique.

localité avec une troupe de cavaliers et de fantassins, etc.. ${ }^{1}$

Certes, la Chine actuelle, pays de piraterie intense et de recherche du plaisir, ne ressemble guère, si du moins le voyageur arabe n'a pas été abusé, à celle qu'il a vue. Elle a bien changé depuis, sauf cependant sur le point capital de la face, que I'on veut toujours, à tout prix, sauver.

Il faut ensuite aller jusqu'au XVI ${ }^{\mathrm{e}}$ siècle pour trouver de nouveaux écrits sur le Céleste Empire. On a, de cette époque, les Voyages adventureux de Ferdinand Mendez-Pinto, venu en Chine après le malheureux envoyé du roi de Portugal, Thomas Pirès, que les Chinois avaient gardé en captivité après l'avoir torturé, et qui était mort depuis déjà quelque temps. Mais cette relation est un tissu d'aventures invraisemblables, et on ne peut rien en retenir de suffisamment authentique sur le caractère et la mentalité des Chinois.

Au siècle suivant, en 1655, le Conseil des Indes néerlandaises envoya des ambassadeurs, Pierre de Goyer et Jacob de Keyser, à Pékin. Le récit qui en fut fait par le maître d'hôtel, Nieuhoff, contient des détails piquants sur les mœurs chinoises, car il s'applique surtout à signaler les coutumes - et elles étaient nombreuses - qui allaient à l'encontre de celles de l'Europe. Il constate, ce que Pascal exprimera en une pensée lapidaire, que ce qui est ici convenable ne l'est pas ailleurs, et il en donne quelques exemples fort bizarres. On peut encore actuellement faire, dans ce genre, en Chine, des comparaisons très

${ }^{1}$ Traduction Defrémery et Sanguinetti, t. IV, p. 265. 


\section{Les Chinois}

Essai de Psychologie ethnographique.

surprenantes. Il signale la sévérité des peines qui vont parfois jusqu'à la mort, pour punir de simples infractions à l'étiquette. Il fait, à ce sujet, cette observation - qui garde encore aujourd'hui toute sa valeur - que les Chinois se troublent et s'irritent violemment pour des choses dont d'autres ne feraient que rire. Il dit que les Célestes, très peu accessibles à la pitié pour leurs semblables, sont très pitoyables aux animaux ; il cite le cas de gens qui achètent très cher des petits oiseaux pour leur rendre la liberté et il note que s'il n'y a pas un hôpital, dans toute la Chine, pour les hommes, il y en a une infinité pour les bêtes. La piété filiale est honorée, chez eux, par-dessus tout et les crimes contre elle sont punis des plus terribles châtiments. Leur goût de la tenue est tel, ils sont si « ennemis des badineries et des légèretés qu'ils réputent pour vauriens et fripons ceux qui crient, babillent et regardent çà et là par les rues ». L'auteur conte ensuite qu'ils sont tellement possédés de la passion du jeu que, non contents de jouer leur femme et leurs enfants pour un certain nombres d'années, ils se jouent assez souvent euxmêmes. Il leur reproche encore l'excès de la superstition la plus niaise qui fait, par exemple, que, s'ils rencontrent de bon matin un chien pommelé, ils tuent leur femme comme si elle était adultère. En outre, selon les circonstances, ils vendent leurs enfants, sur les marchés, comme des pourceaux ${ }^{1}$. Toutes ces remarques sont précieuses parce qu'elles sont très révélatrices de la nature du Chinois et de ses déconcertantes contradictions.

${ }_{1}^{1}$ L'Ambassade de la Compagnie orientale des Provinces unies vers l'Empereur de la Chine, Leyde, seconde partie, p. 37 et suiv., p. 52 et suiv. 


\section{Les Chinois}

Essai de Psychologie ethnographique.

C'était, dans tous les cas, la première fois qu'on faisait de lui un portrait aussi minutieux et aussi exact.

Vers la fin du $\mathrm{XVII}$ e siècle parurent successivement les notes chinoises des Jésuites missionnaires : pères de Semedo, Gabriel de Magalhaens et Louis Le Comte. Tous les trois font, certes, de grands éloges du pays qui leur donne l'hospitalité ; ils en admirent le Gouvernement, l'administration, les richesses, la culture et les mœurs. Ils montrent cependant plus de liberté d'esprit que leurs confrères du siècle suivant, et là où ceux-ci ne trouveront qu'à louanger, ils présentent des critiques qui, mieux que des éloges, permettent de pénétrer l'âme du Chinois. C'est ainsi que le père de Magalhaens fait, des Bacheliers et des Mandarins, les deux grands fléaux de la Chine, un portrait peu flatteur, qui est aussi vrai aujourd'hui qu'il l'était alors. Il dit que les premiers

« sont en grand nombre et souvent très pauvres et, se prévalans de leurs privilèges, deviennent hardis et insolens, exercent beaucoup de violences et de fourberies pour tirer de l'argent des pauvres et des riches, et perdent quelquefois le respect dû aux Présidens et aux Gouverneurs.

Pour les seconds,

« comme ils n'ont aucune connaissance du vray Dieu, ni des peines et des récompenses de l'autre vie, ils ne sont touchez d'aucun remords de conscience ; ils mettent tout leur bonheur dans les plaisirs, dans les dignitez et dans les richesses et, pour les acquérir, ils 


\section{Les Chinois}

Essai de Psychologie ethnographique.

violent sans aucun scrupule toutes sortes de droits divins et humains, foulant aux pieds la raison, la religion, la justice, les loix, l'honnesteté et les droits du sang et de I'amitié. Les officiers inférieurs ne songent qu'à tromper les Mandarins supérieurs, ceux-cy, les Tribunaux suprêmes et, tous ensemble, leur Roy. Ce qu'ils sçavent faire avec tant d'artifice et d'adresse, employant, dans leurs mémoires, des paroles si douces, si honnêtes, si humbles, si respectueuses et si flatteuses, et des raisons si bien colorées, et si désintéressées en apparence, que le pauvre Prince prend le plus souvent le mensonge pour la vérité. Ainsi le peuple, se voyant continuellement maltraité et accablé sans aucune raison, murmure et excite des séditions et des révoltes qui ont causé tant de ruines et de changements dans cet Empire. Toutefois, la méchanceté des magistrats ne doit point faire de tort à la bonté et à l'excellence des Loix de la Chine ${ }^{1}$.

Cela, vraiment, pourrait être écrit d'hier.

Le père Le Comte, après avoir énuméré les nombreuses qualités des Chinois, donne ensuite à entendre, par le pessimisme de ses constatations, que ce n'est là qu'une vaine apparence, qu'un trompe-l'œil :

« Je pourrais, en peu de mots, écrit-il, vous en faire le portrait (de la Chine), en disant qu'on y vit à peu près comme nous vivons en Europe : I'avarice, l'ambition,

\footnotetext{
${ }^{1}$ Nouvelle Relation de la Chine, p. 252 et suiv.
} 


\section{Les Chinois}

Essai de Psychologie ethnographique.

l'amour du plaisir ont beaucoup de part à tout ce qui s'y passe : on trompe dans le négoce, l'injustice règne dans les tribunaux, les intrigues occupent les princes et les courtisans. Cependant, les gens de qualité prennent tant de mesures pour cacher le vice, et les dehors sont si bien gardez, que si un étranger n'a soin de s'instruire à fond des choses, il s'imagine que tout est parfaitement réglé 1 .

Il est le premier à faire cette observation importante, souvent vérifiée depuis, que l'intelligence des Chinois est, en dépit de la bonne impression qu'on en reçoit tout d'abord, incapable de dépasser un niveau médiocre.

« On ne peut pas douter, explique-t-il, qu'ils n'ayent en effet de l'esprit, mais il me semble qu'on en connoist pas encore assez bien le caractère. A voir leurs bibliothèques, leurs universitez, le nombre prodigieux de leurs docteurs, leurs observatoires et le soin qu'ils prennent de bien observer, on jugeroit que cette nation est non seulement habile, mais encore parfaitement instruite en toutes sortes de sciences; qu'elle a de la pénétration, de l'invention, du génie pour tout. Cependant, quoyque depuis plus de quatre mille ans, on propose des récompenses aux sçavants, et que la fortune d'une infinité de gens dépende de leur capacité, ils n'ont pas eu encore un seul homme médiocrement profond en aucune science spéculative. Ainsi je crois

${ }^{1}$ Nouveaux Mémoires sur l'état présent de la Chine, t. I, p. 213. 


\section{Les Chinois}

Essai de Psychologie ethnographique.

pouvoir assurer, sans leur faire aucune injustice, que parmi les qualitez dont le Ciel a différemment enrichi les peuples de la terre, ils n'ont pas receu en partage cet esprit de pénétration et de subtilité si nécessaire à ceux qui s'appliquent à la connoissance de la nature ${ }^{1}$.

Notre auteur a même cette originalité d'aller à l'encontre de ce que I'on croit généralement et de ce qui est encore à présent bien établi, en ce qui concerne la probité commerciale des Célestes. Voici ce qu'il en pense :

« S'ils joignaient au travail et à l'industrie naturelle un peu de bonne foy, surtout à l'égard des étrangers, rien ne leur manqueroit de tout ce qui peut contribuer à former d'habiles négocians. Mais leur qualité essentielle c'est de tromper quand ils peuvent ; plusieurs ne s'en cachent point et j'ai ouï dire qu'il y en a d'assez effrontez, quand on les a surpris en faute, pour s'excuser sur leur peu d'habileté ; vous voyez, disentils, que je n'y entends pas finesse ; vous en sçavez plus que moy, mais peut-estre que je seray ou plus heureux ou plus adroit une autre fois.

Quand on leur preste, il faut bien prendre ses seuretez ; car pour leurs paroles, ceux qui les connoissent n'y font pas grand fond. Il s'en est trouvé qui empruntoienl une fort petite somme, promettant de rendre fort exactement le principal avec un gros intérêt. Ce qu'ils exécutoient ponctuellement au jour marqué, pour se

${ }^{1}$ Nouveaux Mémoires, t. I, p. 356. 


\section{Les Chinois \\ Essai de Psychologie ethnographique.}

faire la réputation d'hommes sincères. Ils en demandoient ensuite une plus grande qu'ils remettoient de mesme sans y manquer. Enfin ils continuoient des années entières ce commerce jusqu'à ce qu'ayant engagé les gens à se fier à eux, et à leur prester des sommes considérables, ils emportoient bien loin leur argent, et disparoissoient pour toujours ${ }^{1}$.

Il faut poursuivre encore ces citations, bien qu'elles soient déjà longues, car en vérité nul n'a tracé, des Chinois, un portrait aussi finement nuancé et aussi exact que celui que nous a laissé le père Le Comte. Leur adresse à tromper, leur patiente dissimulation et leur astuce, qui peuvent, en certaines circonstances, les rendre si redoutables, sont ainsi décrites par lui :

« Comme les Chinois ont du génie pour le négoce, ils en ont aussi beaucoup pour les affaires. Leur esprit s'est tourné depuis longtemps à la politique et à la négociation, non pas avec les estrangers qu'ils regardent comme des barbares ou comme leurs sujets et que l'ancienne fierté de l'Empire empesche de ménager : mais, entre eux, selon qu'ils sont liez d'interest, ou que leur fortune les $y$ engage. Ils s'appliquent continuellement à connoistre leur goust, leurs inclinations, leurs humeurs, leurs desseins ; et ils s'estudient d'autant plus qu'ils sont eux-mesmes plus cachez et plus dissimulez : ils ménagent tout le monde,

\footnotetext{
${ }^{1}$ Nouveaux Mémoires, t. I, p. 402 et suiv.
} 


\section{Les Chinois}

Essai de Psychologie ethnographique.

ils gardent mesme les bienséances avec leurs ennemis. Comme la voye de fait et le duel ne sont point establis dans l'État, toute leur vengeance est rarsonnée et secrette. On ne peut expliquer par combien de détours et de ressorts ils taschent de se détruire les uns les autres, sans qu'ils semblent y prendre aucune part. Ils sont non seulement dissimulez, mais encore patiens jusqu'à l'insensibilité, pour attendre le moment favorable de se déclarer, et de porter seurement leur coup ${ }^{1 .}$

${ }^{1}$ Nouveaux Mémoires, t. I, p. 406 et suiv. 


\section{Les Chinois}

Essai de Psychologie ethnographique.

\section{II \\ Les Jésuites et le XVIII ${ }^{\mathrm{e}}$ siècle.}

Dans la première moitié du XVIII ${ }^{\mathrm{e}}$ siècle, le jésuite du Halde s'attacha à faire connaître la Chine. Il pu blia, en quatre volumes in-folio, un grand ouvrage qui était la somme de tout ce que l'on savait de ce pays ${ }^{1}$. Il y joignit des récits de voyages, des travaux et des traductions diverses de ses confrères de la mission de Pékin. C'est là, par exemple, que Voltaire prit le sujet de l'Orphelin de la Chine, dans une pièce traduite par le père Prémare. En même temps qu'une œuvre de vulgarisation considérable, le père du Halde faisait là, par l'esprit d'admiration qui animait son travail, un véritable office de propagande 2 .

Cette propagande, continuée par la parution des Lettres édifiantes et des Mémoires sur les Chinois, où les Jésuites réfutaient les objections de ceux qui contestaient I'antiquité et les vertus de la Chine, - se basant d'ordinaire sur la « règle », qui est toujours parfaite en ce pays, - couronnée enfin par la Description de la Chine, du sinophile abbé Grosier, obtint le plus

\footnotetext{
${ }^{1}$ Description géographique, historique, chronologique, politique de l'Empire de la Chine et de la Tartarie chinoise, 1735.

2 Le père du Halde reconnaît cependant (Description, t. II) la rapacité et l'improbité commerciale des Chinois signalées par le père Le Comte.
} 


\section{Les Chinois}

Essai de Psychologie ethnographique.

grand succès. Le Céleste Empire entra dans les préoccupations des milieux littéraires au point qu'il n'est pas un écrivain sérieux de l'époque qui n'en ait parlé une fois ou l'autre, et l'art chinois lui-même, mis à la mode, connut la plus grande vogue ${ }^{1}$.

L'engouement fut tel qu'un jour, où Louis XV se plaignait des nombreux abus qui régnaient en France, son ministre, Bertin, lui proposa, comme remède infaillible, « d'inoculer aux Français l'esprit chinois ». Le roi trouva cette idée si lumineuse qu'il approuva tout ce que son ministre crut devoir lui suggérer pour I'exécuter. Grimm, qui raconte cette histoire, ajoute :

« L'esprit de la nation ne paraît pas à la vérité se ressentir infiniment de I'heureuse révolution que devait produire l'idée ingénieuse de $M$. Bertin ; mais on se souvient encore qu'il y eut un moment où toutes nos cheminées furent couvertes de magots de la Chine, et la plupart de nos meubles dans le goût chinois ${ }^{2}$.

Néanmoins, les opinions émises varièrent et furent loin d'être unanimement favorables. Des voyageurs ayant visité la Chine en avaient rapporté des impressions opposées à celles des Jésuites ; certains même accusèrent les missionnaires de partialité et l'influence de ces derniers s'en trouva gravement atteinte.

Le plus grand écrivain du siècle, Voltaire, se signala entre tous par son admiration pour les Chinois. Ce qui visiblement lui plaît surtout, chez eux, c'est leur religion rationaliste, sans

\footnotetext{
${ }^{1}$ Voir à ce sujet : La Chine en France au XVIII siècle, par Henri Cordier.

${ }^{2}$ Correspondance, novembre 1785.
} 


\section{Les Chinois}

Essai de Psychologie ethnographique.

merveilleux, et dont il juge évidemment par les préceptes théoriques des Canoniques exposés dans I'ouvrage de Du Halde :

« Jamais la religion des empereurs et des tribunaux, remarque-t-il dans l'Essai sur les mœurs, ne fut déshonorée par des impostures, jamais troublée par les querelles du sacerdoce et de l'empire, jamais chargée d'innovations absurdes, qui se combattent les unes les autres avec des arguments aussi absurdes qu'elles, et dont la démence a mis à la fin le poignard aux mains des fanatiques, conduits par des factieux. C'est par là surtout que les Chinois l'emportent sur toutes les nations de l'Univers ${ }^{1}$.

L'indifférence des Célestes en matière de religion les a en effet gardés du fanatisme, mais de là à l'esprit philosophique que leur prête Voltaire il y a loin, car il n'est peut-être pas de pays au monde où le merveilleux et la superstition jouent un plus grand rôle.

On retrouve encore dans d'autres passages de l'Essai sur les mœurs 2, dans le Dictionnaire philosophique 3 et surtout dans ses Lettres ${ }^{4}$ au contempteur des Chinois, de Paw, un vif éloge du vieil Empire. Il s'en constitue même le défenseur contre ceux qui le critiquent. Il prétend

\footnotetext{
${ }^{1}$ Introduction, XVIII.

${ }^{2}$ Chap. I et chap. CXCV.

${ }^{3}$ Article De la Chine.

${ }^{4}$ Lettres chinoises, indiennes et tartares, à M. de Paw, par un Bénédictin, V. lettre.
} 


\section{Les Chinois}

Essai de Psychologie ethnographique.

« détruire les imputations vagues qu'on trouve dans I'Esprit des lois, contre ce Gouvernement, le plus ancien qui soit au monde ${ }^{1}$.

Il estime aussi peu sérieux les reproches formulés dans la relation du voyage de I'amiral Amson ${ }^{2}$. Il termine une lettre à de Paw, en disant :

« Vous avez vaillamment combattu ceux qui ont voulu faire passer les Égyptiens pour les pères des Chinois : laudo vos. Mais si vous regardez encore les Chinois avec mépris, in hoc non laudo 3.

Pourtant, il reconnaît, chez eux, cette espèce d'infirmité intellectuelle dont parle le père Le Comte et qui les a arrêtés à une limite que les peuples occidentaux, bien que très en retard sur eux, ont depuis longtemps franchie ${ }^{4}$.

« Il semble, dit-il, que la nature ait donné à cette espèce d'hommes, si différente de la nôtre, des organes faits pour trouver tout d'un coup tout ce qui leur était nécessaire, et incapables d'aller au delà. Nous, au contraire, nous avons eu des connaissances très tard, et nous avons tout perfectionné rapidement 5 .

\footnotetext{
${ }^{1}$ Essai sur les mœurs, chap. I.

${ }^{2}$ Idem.

${ }^{3}$ VII ${ }^{\mathrm{e}}$ lettre.

${ }^{4}$ Le père Parennin lui-même reconnaît cette infériorité, dans une lettre du 11 août 1730 à M. de Mairan (Lettres édifiantes).

${ }^{5}$ Essai sur les mœurs, chap. I.
} 


\section{Les Chinois}

Essai de Psychologie ethnographique.

Il répète cela dans le Dictionnaire philosophique ${ }^{1}$, dans le Siècle de Louis $X I V{ }^{2}$ et dans la préface de sa pièce de théâtre : L'Orphelin de la Chine, où cette impossibilité de perfectionnement, qu'il leur attribue pour les sciences, est étendue, par lui, au théâtre et à tous les arts.

Diderot, dans son article de l'Encyclopédie, après quelques considérations élogieuses sur le Gouvernement et le peuple chinois, fait la même constatation d'infériorité littéraire.

«Plus on leur accordera d'ancienneté, dit-il, plus on aura de reproches à leur faire sur l'imperfection de leur langue et de leur écriture.

Il ajoute qu'ils ne sont ni de grands orateurs, ni de grands poètes et que leurs drames sont bien imparfaits.

Grimm, que nous avons trouvé parmi les partisans de la haute antiquité de la Chine, exprime néanmoins une opinion identique :

« Le tableau d'un tel peuple, écrit-il, sans doute est un assez beau tableau, mais de siècle en siècle, c'est toujours le même ; les progrès que fait ce peuple sont insensibles, où plutôt il n'en fait aucun ${ }^{3}$.

Il termine en reprochant à l'abbé Grosier de n'avoir tenu, dans sa Description, aucun compte des relations des derniers voyageurs,

${ }^{1}$ Article De la Chine.

${ }^{2}$ Chap. XXXIX.

${ }^{3}$ Correspondance, Lettre du 27 juin 1786. 


\section{Les Chinois}

Essai de Psychologie ethnographique.

« qui prouvent clairement combien les missionnaires de la Compagnie de Jésus avaient mis d'exagération dans leurs calculs.

Avec Montesquieu on a la note absolument opposée à celle de Voltaire. Après avoir lu la relation du voyage de l'amiral Amson, il s'était écrié :

- Ah ! je l'ai toujours dit que les Chinois n'étaient pas si honnêtes gens qu'ont voulu le faire croire les Lettres édifiantes ${ }^{1}$.

Ayant rencontré $M$. de Mairan, qui était sous I'influence de sa correspondance avec le père Parennin, il en discuta avec une telle vivacité qu'il écrivit à l'abbé de Guasco pour le prier de voir si son interlocuteur s'en était blessé et, dans ce cas, d'arranger les choses.

Ce jugement défavorable aux Célestes apparaît nettement dans I'Esprit des Lois. On y lit, par exemple :

« Ils ont un désir si excessif du gain qu'aucune nation commerçante ne peut se fier à eux ${ }^{2}$.

Et plus loin :

«Ce qu'il y a de singulier, c'est que les Chinois, dont la vie est entièrement dirigée par les rites, sont néanmoins le peuple le plus fourbe de la terre. Cela paroit surtout dans le commerce, qui n'a jamais pu leur inspirer la bonne foi qui lui est naturelle. Celui qui

\footnotetext{
${ }^{1}$ Annotation d'une lettre écrite à l'abbé de Guasco en 1755.

${ }^{2}$ Liv. XIX, chap. X.
} 


\section{Les Chinois}

Essai de Psychologie ethnographique.

achète doit porter sa propre balance, chaque marchand en ayant trois, une forte pour acheter, une légère pour vendre et une juste pour ceux qui sont sur leurs gardes. « C'est la nécessité et peut-être la nature du climat qui ont donné à tous les Chinois une avidité inconcevable pour le gain ; et les lois n'ont pas songé à l'arrêter. Tout a été défendu, quand il a été question d'acquérir par la violence ; tout a été permis, quand il s'est agi d'obtenir par artifice ou par industrie. Ne comparons donc pas la morale des Chinois avec celle de l'Europe. Chacun, à la Chine, a dû être attentif à ce qui lui étoit utile; si le fripon a veillé à ses intérêts, celui qui est dupe devoit penser aux siens. A Lacédémone, il était permis de voler ; à la Chine, il est permis de tromper ${ }^{1}$.

Jean-Jacques Rousseau est encore plus dur. Parlant du peuple chinois, dans la Nouvelle Héloïse, il dit :

« Autant de fois conquis qu'attaqué, il fut toujours en proie au premier venu et le sera jusqu'à la fin des siècles. Je l'ai trouvé digne de son sort, n'ayant pas le courage d'en gémir. Lettré, lâche, hypocrite et charlatan ; parlant beaucoup sans rien dire, plein d'esprit sans aucun génie, abondant en signes et stérile en idées ; poli, complimenteur, adroit, fourbe et fripon ; qui met tous les devoirs en étiquettes, toute la morale

\footnotetext{
${ }^{1}$ Liv. XIX, chap. XX.
} 


\section{Les Chinois}

Essai de Psychologie ethnographique.

en simagrées, et ne connaît d'autre humanité que les salutations et les révérences.

Helvétius, à son tour, prononce ce verdict sévère :

« Le despotisme de la Chine est, dit-on, fort modéré. L'abondance de ses récoltes en est la preuve. En Chine, comme partout ailleurs, on sait que, pour féconder la terre, il ne suffit pas de faire de bons livres d'agriculture, qu'il faut encore que nulle loi ne s'oppose à la bonne culture. Aussi les impôts à la Chine, dit à ce sujet $M$. Poivre, ne sont portés sur les terres médiocres qu'au trentième du produit. Les Chinois jouissent donc presque en entier de la propriété de leurs biens. Leur gouvernement, à cet égard, est donc bon. Mais jouit-on pareillement à la Chine de la propriété de sa personne ? L'habituelle et prodigieuse distribution qui s'y fait de coups de bambou prouve le contraire. C'est l'arbitraire des punitions qui, sans doute, y avilit les âmes et fait de presque tout Chinois un négociant fripon, un soldat poltron, un citoyen sans honneur ${ }^{1}$.

Le président de Brosses rapporte, dans une de ses lettres d'Italie 2, des anecdotes que lui a contées le père Fouquet, sur la tyrannie odieuse que I'empereur Khang-hi faisait peser sur son entourage, anecdotes qui confirment l'appréciation d'Helvétius. L'usage des châtiments que I'on considérerait en Europe comme

\footnotetext{
${ }^{1}$ De I'Homme, section V, note 14 .
}

${ }^{2}$ Lettres familières, lettre XLVI. 


\section{Les Chinois}

Essai de Psychologie ethnographique.

une intolérable atteinte à I'honneur n'est, du reste, pas contesté par les admirateurs les plus systématiques de la Chine.

« L'empereur, reconnaît le père du Halde, fait quelquefois donner une bastonnade à des personnes de grande considération et ensuite les revoit et les traite comme à l'ordinaire 1.

L'érudit hollandais de Paw, à qui Voltaire voulut inculquer sa sinophilie, avait publié, en français, un ouvrage : Recherches philosophiques sur les Égyptiens et les Chinois, qui est un véritable réquisitoire contre ces derniers.

«On ne verra point ici, disait-il dans sa préface, les Chinois dépeints suivant les idées du vulgaire, mais suivant les faits. Et il faut convenir qu'ils perdent infiniment à être jugés de cette manière-là.

Il les passe ensuite au crible de la critique la plus serrée et il ne leur fait grâce d'aucune des nombreuses tares qu'il leur découvre, sans qu'aucun éloge vienne atténuer l'effet de cet impitoyable éreintement. Les missionnaires de Pékin y répondirent par une réfutation qui tient plus de 200 pages compactes du deuxième volume de leurs Mémoires. Quand ils sont gênés pour nier les graves travers reprochés au peuple dont ils se sont constitués les thuriféraires et les défenseurs, il leur arrive - pour l'improbité, par exemple - de s'en tirer en disant que, si les Chinois sont ainsi, c'est qu'ils n'ont pas le frein de la

${ }^{1}$ Description de la Chine, t. II, p. 157. 


\section{Les Chinois}

Essai de Psychologie ethnographique.

Conscience et de la Religion pour contenir leur cupidité dans les bornes de la justice ${ }^{1}$.

Après les ouvrages systématiquement bienveillants des missionnaires, du moins des rédacteurs des Mémoires, dont I'indulgence et même la partialité s'expliquent pour un pays qui était en somme devenu le leur et qu'ils espéraient gagner à leur foi, les récits plus désintéressés des voyageurs laïques vinrent donner une vision plus exacte de la Chine et rectifier I'opinion sur ce pays. C'est à cela certainement, de l'aveu même de Montesquieu, que sont dues les critiques que l'on vient de lire. Du reste, les auteurs de ces relations ne se sont pas fait faute, comme on va le voir, de reprocher aux Jésuites la peinture audacieuse qu'ils ont faite des Célestes et de leur gouvernement.

La mission que Pierre Ier de Russie envoya à Pékin, en 1719, fut la première en date, au XVIII ${ }^{\text {e }}$ siècle. Deux de ses membres, le médecin anglais Bell et le Suédois Lange, en ont laissé, chacun, un récit. Celui du premier est insignifiant, mais celui du second, animé d'un esprit très critique et aussitôt connu en France, contrebalança, dans les milieux littéraires français, I'influence du grand ouvrage du père du Halde qui parut vers la même époque.

Vint ensuite le voyage autour du monde de l'amiral anglais Amson, qui rapporta de Chine une impression détestable. Sa narration n'est qu'une longue énumération des fourberies et des filouteries diverses qu'il eut à subir de la part des Chinois de Canton, des mandarins aussi bien que du peuple. Il en raconte

${ }^{1}$ T. II, p. 373. 


\section{Les Chinois}

Essai de Psychologie ethnographique.

quelques-unes qui, en effet, dénotent une malice incroyable. Il termine en disant que toute la morale si vantée des Chinois, en dépit de ce que racontent les missionnaires catholiques, ne se manifeste que par une tenue et une bienséance apparentes, derrière lesquelles il n'y a que dissimulation et friponnerie.

« Les magistrats sont corrompus, le peuple voleur, les tribunaux dominés par l'intrigue et la vénalité 1 .

Le naturaliste français Sonnerat, qui fit son voyage «par ordre du roi », nous a laissé, des Célestes, une appréciation aussi mauvaise. Après avoir reproché aux Jésuites de nous avoir, dans un but intéressé, induits en erreur, il montre quelle est I'infériorité des Chinois en toutes matières, entremêlant ce sévère examen de phrases comme celles-ci, qui indiquent en quelle médiocre estime il tient ce peuple :

«Qu'on cesse donc de vanter ces mœurs si douces, ce gouvernement si sage où I'on achète le droit de commettre des crimes, où le peuple gémit sous le joug de l'oppression et de la misère 2 !

«Cette nation, quoique très ancienne, ne cherche point à réformer ses abus ; les hommes n'ont point de génie, point d'activité dans l'imagination, tout se fait machinalement et par routine ${ }^{3}$.

\footnotetext{
${ }^{1}$ Voyage autour du monde, liv. III, chap. IX et X.

${ }^{2}$ Voyage aux Indes orientales et à la Chine, t. II, p. 256.

${ }^{3}$ Voyage aux Indes orientales et à la Chine, t. II, p. 260.
} 


\section{Les Chinois}

Essai de Psychologie ethnographique.

« Les Chinois sont frippons, fiers, insolens et lâches ; dix Européens, armés seulement d'un bâton, en feroient fuir mille, et s'ils ne nous accordent aucune liberté, c'est parce qu'ils connoissent leur foiblesse ${ }^{1}$.

Il fait ici allusion aux conditions humiliantes que les Célestes imposent pour permettre de commercer avec eux et c'est pourquoi il dit en terminant :

« La cupidité seule peut faire supporter aux Nations européennes des injures pareilles et les soumettre à la merci d'un peuple aussi méprisable par son caractère que par son ignorance 2 .

Le récit du passage de La Pérouse en Chine, au cours de son voyage autour du monde, débute par cette même réflexion qui clôt celle de Sonnerat :

«Comme, explique-t-il, on est aussi éloigné de la Chine à Macao qu'en Europe, par l'extrême difficulté de pénétrer dans cet empire, je n'imiterai pas les voyageurs qui en ont parlé sans avoir pu le connoître, et je me bornerai à décrire les rapports des Européens avec les Chinois, l'extrême humiliation qu'ils y éprouvent, la foible protection qu'ils peuvent retirer de l'établissement portugais sur la côte de la Chine, l'importance, enfin, dont pourroit être la ville de Macao pour une nation qui se conduiroit avec justice, mais avec fermeté et dignité, contre le gouvernement peut-

${ }^{1}$ Ibid., p. 283.

2 Ibid., p. 284. 


\section{Les Chinois}

Essai de Psychologie ethnographique.

être le plus injuste, le plus oppresseur et en même temps le plus lâche qui existe dans le monde ${ }^{1}$.

Puis vient, à la fin de 1792, la grande mission officielle anglaise de lord Macartney, qui eut d'ailleurs un échec complet et dont il reste plusieurs relations. La moins intéressante, celle où il y a le moins à glaner d'indications psychologiques, est, comme il convient, celle du secrétaire de l'ambassade, sir Georges Staunton, rédigée d'après les papiers de lord Macartney. C'est la narration prudente et réservée à l'excès d'un diplomate qui, professionnellement, se préoccupe beaucoup plus des conséquences politiques de ce qu'il écrit, que de la recherche stricte de la vérité. Cet état d'esprit le prédisposait davantage à la louange et à I'admiration qu'à la critique. En Chine, où tout a toujours été machiné en vue de produire le meilleur effet sur les étrangers, cette tendance pouvait aisément se satisfaire. Sir Staunton n'y a pas manqué. A diverses reprises, il note la tenue parfaite et la décence des foules chinoises.

«On ne néglige, en Chine, dit-il avec componction, aucun moyen pour exciter à faire de bonnes actions, et empêcher qu'on en fasse de mauvaises ; et l'on emploie également l'espoir de la louange et la crainte du blâme. Il y a un registre public, nommé le Livre du mérite, dans lequel on inscrit tous les exemples frappans d'une conduite estimable, et dans les titres d'un homme, on mentionne particulièrement le nombre de fois que son nom a été inséré dans ce livre. Ces règlements sont

${ }^{1}$ Collection des Voyages anciens et modernes autour du monde, Voyage de La Pérouse, p. 304. 


\section{Les Chinois \\ Essai de Psychologie ethnographique.}

faits principalement pour les mandarins auxquels l'empereur ne confie l'autorité que pour qu'ils I'employent à faire le bonheur du peuple ${ }^{1}$.

Nous voici fixés sur ces excellents mandarins et ces bienheureux Chinois. En bon puritain anglais, il s'extasie surtout sur la décence; il écrit :

« La délicatesse des Chinois s'offense à la vue des ouvrages de l'art qui imitent le corps humain, soit nud, soit couvert seulement des draperies qui suivent et déploient ses contours. Aussi cette délicatesse a retardé, parmi eux, les progrès de la peinture et de la sculpture, du moins en ce qui a rapport à ces deux sujets ${ }^{2}$.

A défaut de ce que I'on sait de la salacité naturelle aux gens de ce pays, un fait qu'on lira plus loin et qui est rapporté par Hüttner, autre membre de cette même ambassade, montrerait combien, à cet égard, sir Staunton s'est abusé ou a abusé ses lecteurs.

Ce parfait diplomate ne constate de fâcheux que la défiance extrême dont la mission eut à souffrir de la part de ses hôtes et leur orgueil national excessif qui amena des difficultés et des vexations fort désagréables. C'est ainsi que l'ambassade anglaise fut annoncée partout comme venant payer le tribut à l'Empereur Kien-Long, et cela fut écrit en gros caractères chinois sur les caisses contenant les présents. En outre, lord Macartney eut

\footnotetext{
${ }^{1}$ Voyage en Chine, t. III, p. 344.

${ }^{2}$ Ibid., t. I, p. 83.
} 


\section{Les Chinois}

Essai de Psychologie ethnographique.

toutes les peines du monde à éviter de faire les prosternations rituelles à deux genoux, le front touchant le sol. Il put s'en tirer en mettant seulement un genou à terre, ce qui était déjà assez humiliant pour un représentant de la fière Albion.

La courte relation de Hüttner est aussi riche d'observations que les quatre volumes de Staunton sont insignifiants et vides. Hüttner, précepteur des fils de ce dernier et n'étant pas un personnage officiel, pouvait, lui, dire les choses comme il les avait vues. C'est ce qui donne plus de prix à son témoignage. Il mentionne à diverses reprises, avec des exemples à l'appui, l'indélicatesse et l'improbité profondes des mandarins. Du Chinois en général, il signale la duplicité, la cruauté, la lâcheté, I'esprit de fraude et de rapine. Les gens de Canton surtout lui ont laissé une impression fort mauvaise.

« Il faut, dit-il, employer la plus grande circonspection, si on ne veut pas être trompé en faisant des affaires avec les habitants de cette ville. On accuse la nation en général de manquer de probité, de s'applaudir même de ses fraudes, et de les regarder comme très ingénieuses. Dans ce sens, les habitants de Canton sont très ingénieux, et peu de personnes auront quitté cette ville sans en avoir été convaincus à leurs dépens ${ }^{1}$.

Le cannibalisme en Chine ayant toujours été nié avec indignation par certains, il y a lieu de relever qu'Hüttner affirme son existence de la façon la plus nette.

${ }^{1}$ Voyage à la Chine, p. 200. 


\section{Les Chinois}

Essai de Psychologie ethnographique.

«Ce dont nous avons vu plusieurs fois des exemples, dit-il, est I'horreur de voir, dans les famines, beaucoup de pauvres manger leurs enfants ; ce qui est assez connu, quoique les Chinois n'en conviennent pas ${ }^{1}$.

Il note le goût et la science des plaisirs chez les Célestes,

« car, explique-t-il, dans ce pays, comme dans toute I'Asie, les plaisirs de la volupté sont devenus une étude et une branche de commerce ${ }^{2}$.

Et il donne, à ce sujet, d'intéressants détails.

Quant à la décence et à la moralité si admirées par ce bon sir Staunton, voici un trait qui les ramène à leur exacte valeur :

« Dans I'un de ces palais (impériaux), raconte Hüttner, parmi d'autres chefs-d'œuvre de l'art, on voyait deux statues de garçons, en marbre, d'un excellent travail ; ils avaient les pieds et les mains liés, et leur position ne laissait point de doute que le vice des Grecs n'eût perdu son horreur pour les Chinois. Un vieil eunuque nous les fit remarquer avec un sourire impudent. Il est difficile de dire si l'Empereur ne vient que rarement dans cette chambre, comme plusieurs le croient, ou s'il ne désapprouve pas ces indécences ; quoi qu'il en soit, il est très dévot 3 .

${ }^{1}$ Ibid., p. 237.

${ }^{2}$ Voyage à la Chine, p. 147.

${ }^{3}$ Ibid. , p. 96. 


\section{Les Chinois}

Essai de Psychologie ethnographique.

Une étude, faite, un siècle plus tard, par un médecin français, répond, en ce qui concerne les mœurs de la Cour de Chine, à la question ainsi posée ${ }^{1}$.

La contribution de Barrow, qui était, lui aussi, attaché à I'ambassade Macartney, est exceptionnellement intéressante. Il ne s'agit plus de simples impressions de voyageur, mais d'une enquête méthodique de savant. Ses observations, d'ordre psychologique, sont nombreuses et appuyées de faits. En voici l'essentiel :

L'impression générale que lui font les Chinois est complexe, mais, en définitive, mauvaise. Il dit :

« Le caractère général de la nation chinoise est un étrange composé d'orgueil et de bassesse, de gravité affectée et de frivolité réelle, de civilité raffinée et d'indélicatesse grossière. Avec un grand air de simplicité et de candeur dans la conversation, les Chinois portent l'art et la ruse à un degré contre lequel un Européen ne peut jamais être bien en garde 2 .

L'attitude de la foule, accourue sur le passage de la mission, lui paraît cependant digne d'éloges. «Son maintien étoit doux, bienveillant et gracieux. » Les physionomies « avoient un air d'innocence et de simplesse qui annonçoit un caractère heureux et une âme contente ${ }^{3}$. » Ces manières irréprochables sont dues

\footnotetext{
${ }^{1}$ Superstition, crime et misère en Chine, par le Dr Matignon.

2 Voyage en Chine, t. I, p. 344. Voir encore : t. I, p. 147, t. II, p. 103, 123, 224.

${ }^{3}$ Voyage en Chine, t. I, p. 132.
} 


\section{Les Chinois}

Essai de Psychologie ethnographique.

à des règles sévères et à tout un cérémonial imposés par l'éducation et soumis à la surveillance du gouvernement (ministère des rites) ${ }^{1}$. Cette étiquette rigide a d'ailleurs le grave inconvénient de déformer et de figer le caractère de la jeunesse. « Un enfant chinois de la première classe est inanimé, formaliste, inactif, et s'attache constamment à affecter la gravité de la vieillesse ${ }^{2}$. Tout cela, c'est la façade chinoise, derrière laquelle se cachent « l'injustice, la tyrannie et l'oppression, d'une part, et la crainte, la dissimulation et la désobéissance, de I'autre ${ }^{3}$.

Ce souci de garder les apparences, de sauver la face, est pour beaucoup, sans doute, dans l'habitude invétérée du mensonge ${ }^{4}$, chez les Célestes, et aussi probablement à la source d'un autre de leurs défauts les plus sérieux : la vanité. La vanité et le mensonge vont, chez eux, de pair ${ }^{5}$. Cette vanité individuelle se transforme en toute occasion en un insupportable orgueil national, dont il faut tenir compte dans les renseignements qu'ils donnent sur leur pays. Tout est faussé ou exagéré par eux, dans le but de paraître supérieur aux autres nations ${ }^{6}$.

Par ailleurs, cette réglementation rigoureuse de la conduite et des moindres gestes de l'existence les rend méfiants,

\footnotetext{
${ }^{1}$ Ibid., t. I, p. 298.

${ }^{2}$ Ibid., t. I, p. 241.

${ }^{3}$ Ibid., t. II, p. 129.

${ }^{4}$ Ibid. , t. I, p. 317.

${ }^{5}$ Ibid., t. I, p. 72.

${ }^{6}$ Voyage en Chine, t. II, p. 48, 203.
} 


\section{Les Chinois}

Essai de Psychologie ethnographique.

malveillants et jaloux à l'égard les uns des autres, et c'est ce qui a dû empêcher, entre eux, la vie de société telle qu'elle existe en Europe et qui exige une confiance mutuelle ${ }^{1}$ !

Une observation curieuse, parce qu'elle dément toutes les idées actuellement reçues sur l'absence de nerfs des Chinois, est celle que Barrow fait plusieurs fois sur leur nervosité excessive, dans laquelle il voit la cause de leur faiblesse de caractère et de leur lâcheté 2 . Pour la même raison, et contrairement encore à ce qu'on croit aujourd'hui, bien loin d'être insensibles à la douleur, ils la redoutent à tel point que l'exercice de la chirurgie est à peu près impossible en Chine ${ }^{3}$.

Lui aussi il signale le goût très vif des Célestes pour les plaisirs de l'amour ${ }^{4}$, de toutes sortes d'amour. Et il confirme, pour les Chinois en général, les mœurs particulières, dont la vue de deux statues, dans une salle du palais de Kien-Long, avait donné le soupçon à Hüttner.

«Un Chinois, dit-il, trouve si peu honteux et si peu indélicat de se livrer à cette dépravation, que la plupart des principaux officiers de l'État n'hésitent pas à I'avouer publiquement. Ils sont sans cesse accompagnés par un porte-pipe, qui est ordinairement un garçon fort joli, de l'âge de quatorze à dix-huit ans, et toujours parfaitement bien mis. Lorsque quelqu'un de

${ }^{1}$ Ibid., t. I, p. 328.

${ }^{2}$ Ibid., t. I, p. $301 ;$ t. II, p. 213 ; t. III, p. $18,148$.

${ }^{3}$ Ibid., t. I, p. 119 et 120.

${ }^{4}$ Voyage en Chine, t. I, p. 249 et 250. 


\section{Les Chinois}

Essai de Psychologie ethnographique.

ces officiers nous faisoit remarquer les jeunes gens qui suivoient les autres, il ne manquoit pas de faire des signes et des mouvemens trop expressifs pour qu'on pût s'y méprendre ${ }^{1}$.

Le théâtre est en harmonie avec cette obsession des plaisirs charnels. Parlant d'un drame qui avait alors beaucoup de succès, Barrow dit qu'il est impossible de concevoir « rien de plus obscène, de plus indécent et de plus dégoûtant 2 .

Tout cela n'empêche d'ailleurs pas les Chinois d'être très exigeants quant à la vertu des femmes et des jeunes filles; ils punissent avec la dernière rigueur leurs écarts de conduite, ayant même, dans ce cas, le droit de les vendre comme esclaves ${ }^{3}$.

Un autre vice des Chinois, auquel ils se livrent avec excès, c'est le jeu. Ainsi que l'avait déjà mentionné le Hollandais de Nieuhoff, Barrow dit qu'on prétend qu'ils mettent souvent pour enjeu leurs femmes et leurs enfants ${ }^{4}$.

La cruauté est parmi les caractéristiques les plus indiscutables de ce peuple. Elle se manifeste de bien des manières ; entre autres, par le goût des combats de bestioles dressées dans ce but, combats de coqs, de cailles, de grillons, de sauterelles, les plus petits de ces animaux étant ceux qui se battent avec le plus

\footnotetext{
${ }^{1}$ Ibid., t. I, p. 252.

2 Ibid., t. I, p. 371.

3 Ibid., t. I, p. 251.

${ }^{4}$ Ibid., t. I, p. 267.
} 


\section{Les Chinois}

Essai de Psychologie ethnographique.

d'acharnement et qui, par cette raison, sont très appréciés ${ }^{1}$. Cette inhumanité se traduit surtout par l'indifférence vis-à-vis des souffrances et des risques de mort dont les Chinois sont témoins, sans qu'ils fassent rien pour aider les victimes à se soulager ou à se sauver. Il est vrai que cela s'explique par une loi horrible qui, à elle seule, est la plus éclatante preuve de cruauté d'une race. D'après cette loi, on est tenu pour responsable de la mort - et en Chine, on sait ce que cela veut dire, - de toute personne que I'on a soignée ou secourue ${ }^{2}$.

La manifestation la plus éclatante de cette inhumanité est dans l'usage très fréquent de la vente, de l'abandon et de la suppression des enfants. Barrow rapporte que

« I'une des obligations essentielles de la police de Péking, c'est d'employer tous les matins, de bonne heure, un certain nombre de personnes à faire leur ronde avec des charrettes, et à ramasser tous les enfants jetés dans les rues pendant la nuit. L'on ne fait jamais de recherches sur les parens qui ont exposé ces faibles et innocentes créatures. On met ces enfans dans les charrettes et on les porte dans une voirie hors de l'enceinte de la ville où I'on entasse, dit-on, pèle-mêle, non seulement ceux qui sont morts, mais ceux qui vivent encore 3 .

\footnotetext{
${ }^{1}$ Voyage en Chine, t. I, p. 267, 268.

${ }^{2}$ Voyage en Chine, t. I, p. 276 et suiv.

${ }^{3}$ Ibid., t. I, p. 282, 287.
} 


\section{Les Chinois}

Essai de Psychologie ethnographique.

« Certains attribuent l'infanticide à la croyance de ce peuple à la métempsycose. Ils disent que les parens voyant que ceux de leurs enfans qui vivront seront réduits à la pauvreté, croient qu'il vaut mieux faire en sorte que l'âme des enfans s'échappe tout d'un coup pour chercher un plus heureux asile que de la laisser languir dans un corps condamné à la misère et à l'infortune ${ }^{1}$.

La grande tare, celle que le père Le Comte a dénoncée et que tous les voyageurs du XVIII ${ }^{\text {e }}$ siècle signalent, c'est I'improbité. Barrow dit :

« Un marchand chinois trompe toutes les fois qu'il en trouve l'occasion, par la raison qu'on le croit incapable d'agir avec honnêteté. Un paysan chinois vole dès qu'il peut espérer qu'il ne sera pas découvert, parce qu'il sait qu'en cas qu'il le soit, il n'aura d'autre punition que des coups de bambou, auxquels il est journellement exposé 2 .

Chose curieuse, il fait une exception pour les grands marchands de Canton, les Hongs, qui sont en rapport d'affaires avec les étrangers et sur lesquels ses devanciers en Chine ont pourtant donné de si mauvais renseignements.

En revanche, les mandarins, les ministres et les princes sont, d'après lui, encore plus fripons que les autres Chinois. Il raconte une friponnerie particulièrement basse dont s'est rendu coupable un prince de sang, petit-fils de l'empereur. Il en cite une autre due, cette fois, au premier ministre. Et il constate que

\footnotetext{
${ }^{1}$ Voyage en Chine, t. I, p. 290.

${ }^{2}$ Voyage en Chine, t. I, p. 302.
} 


\section{Les Chinois}

Essai de Psychologie ethnographique.

« la crainte qu'inspire aux Chinois en place la possibilité d'une révélation de leurs torts est le seul frein qui arrête leur rapacité 1 .

Parmi les fonctionnaires de l'Empire, la vénalité et le péculat sont universellement pratiqués. Ils s'exercent de toutes façons : en vendant la justice, en fermant les yeux sur l'importation de I'opium qui est interdite, en se partageant les sommes affectées par l'Empereur au soulagement des misères publiques 2. Et, pour couronner ce beau tableau des mœurs administratives, la Cour de Pékin est complice dans toutes ces extorsions ${ }^{3}$.

Il existe cependant de bons Chinois ; Barrow en cite trois dont il loue les qualités très séduisantes : ce sont les deux fonctionnaires et l'interprète qui avaient été attachés à l'ambassade par le gouvernement chinois ${ }^{4}$.

Barrow note encore l'extrême saleté des Chinois, des mandarins aussi bien que des hommes du peuple. Tous ont des poux et les habitudes les plus malpropres ${ }^{5}$. Les appartements des palais impériaux sont également très mal tenus, pleins de détritus et de poussière. L'ambassade, logée dans l'appartement d'un ministre d'État, dut, pour pouvoir s'y installer, le nettoyer à fond 6 .

\footnotetext{
${ }^{1}$ Ibid., t. I, p. 302 et suiv. ; t. III, p. 143 et suiv.

${ }^{2}$ Ibid., t. I, p. 257; t. II, p. 155 ; t. III, p. 135.

${ }^{3}$ Ibid. , t. III, p. 145.

${ }^{4}$ Voyage en Chine, t. I, p. 130 et suiv.

${ }^{5}$ Ibid., t. I, p. 127.

${ }^{6}$ Ibid. , t. I, p. 183.
} 


\section{Les Chinois}

Essai de Psychologie ethnographique.

Au point de vue intellectuel, I'infériorité des Chinois, déjà reconnue, se trouve confirmée. Elle est due, entre autres causes, à une incuriosité profonde de tout ce qui est pour eux nouveau et, par conséquent, étranger à leur routine ${ }^{1}$. Ils n'ont aucune idée de la recherche scientifique et toutes les notions qu'ils ont des choses sont empiriques et puériles 2. Par contre, ils possèdent un don remarquable d'imitation et ils peuvent, avec un modèle, exécuter les travaux les plus difficiles. Il est vrai qu'en copiant ainsi, les Célestes ne font point usage de leur jugement. Ils rendent avec soin les défauts, les taches, originales ou accidentelles, parce qu'ils ne sont qu'imitateurs serviles et qu'ils ne sentent nullement le mérite et la beauté des ouvrages qu'on expose à leurs regards ${ }^{3}$.

Plusieurs fois, au cours de sa relation, le savant anglais reproche aux Jésuites missionnaires les faux renseignements qu'ils ont répandus sur la Chine. Dès le début, il déclare :

« Les volumineux mémoires des missionnaires catholiques en Chine ne sont pas toujours exacts et j'aurai, dans le cours de cet ouvrage, plus d'une fois occasion de relever leurs erreurs ${ }^{4}$.

«Ces hommes pieux, dit-il plus loin, pouvoient avoir des motifs particuliers pour présenter les Chinois sous le point de vue le plus favorable. Dans les portraits

\footnotetext{
${ }^{1}$ Ibid., t. I, p. 98; t. II, p. 55; t. III, p. 4.

${ }^{2}$ Ibid., t. II, p. 99 et suiv.

${ }^{3}$ Voyage en Chine, t. II, p. 54, 77.

${ }^{4}$ Ibid., t. II, p. 4.
} 


\section{Les Chinois}

Essai de Psychologie ethnographique.

qu'ils faisoient de cette nation, plus ils la montroient grande, puissante, savante et polie, plus ils relevoient la gloire qu'ils avoient eue de lui faire adopter le christianisme. Peut-être aussi croyoient-ils qu'il étoit de leur prudence de ne parler que d'une manière avantageuse d'un peuple dont ils avoient besoin de conserver la protection, et dont leur vie même dépendoit 1 .

« C'est avec raison, ajoute-t-il, qu'on peut supposer qu'en général les missionnaires tâchoient de dire la vérité ; mais tantôt ils en supprimoient une partie, tantôt ils s'exprimoient comme s'ils avoient craint que leurs écrits ne fussent renvoyés en Chine, et traduits dans la langue du pays.

Il remarque ailleurs, à propos de quelques vérités dites par le père Le Comte, que ce missionnaire,

« en quittant la Chine pour ne plus y retourner, avoit moins de ménagement à garder dans ses récits que les autres missionnaires qui sont condamnés à y passer leur vie ${ }^{2}$.

Barrow reproche surtout aux Jésuites d'avoir attribué aux Chinois des connaissances qui leur faisaient absolument défaut.

« Il est difficile, écrit-il, de deviner le motif qui a pu induire le père Amiot à dire - «que les Chinois, pour

${ }^{1}$ Ibid., t. I, p. 48.

${ }^{2}$ Voyage en Chine, t. I, p. 107 et 260. 


\section{Les Chinois}

Essai de Psychologie ethnographique.

rendre leur gamme parfaite, n'ont pas craint de la soumettre aux pénibles opérations de la géométrie et aux calculs les plus longs et les plus rebutants de la science des nombres ». - Cependant le père Amiot n'ignoroit pas que les Chinois n'avoient pas la moindre idée de la géométrie et que leur arithmétique ne s'étendoit pas au delà de leur souan-pan.

Un autre jésuite a énoncé une assertion aussi hardie et aussi peu fondée que celle du père Amiot :

« Le système musical des Chinois, dit-il, a été emprunté d'eux par les Grecs et les Égyptiens, avant le temps $d^{\prime}$ Hermès et d'Orphée ${ }^{1}$.

Au sujet de la circulation du sang :

«Quoique les Jésuites ne se soient fait aucun scrupule d'affirmer qu'on la connoissoit en Chine longtemps avant qu'elle fût découverte en Europe, il n'en est pas moins certain que les Chinois n'en ont pas la moindre idée ${ }^{2}$.

Il exprime enfin sa surprise de l'indifférence indulgente avec laquelle les missionnaires parlent du grand commerce de filles qui se fait à Sou-tchéou-fou et de l'usage des Chinois d'acheter des concubines, pour avoir un fils, et de se débarrasser ensuite d'elles, quand ce désir est satisfait.

\footnotetext{
${ }^{1}$ Voyage en Chine, t. II, p. 69.

${ }^{2}$ Ibid., t. II, p. 106.
} 


\section{Les Chinois}

Essai de Psychologie ethnographique.

«Comment, s'exclame-t-il, ces saints hommes peuventils accorder un trafic infâme avec toutes les vertus qu'ils ont attribuées aux Chinois ${ }^{1}$ ?

Cette espèce de polémique rétrospective, ouverte par le voyageur anglais avec les missionnaires du XVIII ${ }^{\mathrm{e}}$ siècle, a l'avantage d'éclairer certains côtés obscurs de la psychologie chinoise et de contribuer à mettre au point bien des opinions qui avaient gratuitement cours à leur sujet.

Un sous-officier, attaché à l'ambassade de lord Macartney, le sergent-major Holmès, a publié, lui aussi, ses impressions de voyage. Celles-ci ne nous apprennent rien qui n'ait été déjà dit, mais elles vérifient, sur quelques points, par leur témoignage sans prétention, ce que nous ont appris les autres. Holmès note, parmi les choses qui l'ont le plus frappé, l'infanticide des filles considéré comme une chose normale 2 , la friponnerie foncière des Chinois 3 , leur ignorance grossière 4 , leur vanité et leur dissolution 5 ; enfin la méfiance extraordinaire qu'ils ont des étrangers 6 .

Un an après le retour de lord Macartney, la compagnie des Indes orientales hollandaises, qui avait envoyé, au XVII ${ }^{e}$ siècle,

\footnotetext{
${ }^{1}$ Voyage en Chine, t. II, p. 382 et suiv.

${ }^{2}$ Voyage en Chine et en Tartarie, t. II, p. 7.

${ }^{3}$ Ibid., t. II, p. 14.

${ }^{4}$ Ibid., t. II, p. 35.

${ }^{5}$ Ibid., t. II, p. 63, 64.

${ }^{6}$ Ibid., t. II, p. 12, 15, 27, 35.
} 


\section{Les Chinois}

Essai de Psychologie ethnographique.

la mission dont il est parlé plus haut, déléguait une nouvelle ambassade à Pékin.

La relation, rédigée par Moreau de Saint-Méry, d'après le journal tenu par Everard Van Braam, deuxième ambassadeur, ne révèle rien d'inédit sur les Chinois. Elle confirme ce que I'on sait déjà de leur hostilité secrète, de leur méfiance, de la saleté inimaginable des appartements impériaux et des gens de la Cour ${ }^{1}$, de leur ignorance 2 et du trafic des filles. Sur ce dernier point, l'auteur dit qu'

« il est évident qu'à la Chine toutes les femmes sont un objet de commerce ${ }^{3}$.

Ce qu'il y eut de plus intéressant dans ce voyage, c'est qu'il mit en pleine lumière le caractère des Célestes ; il démontra que leur arrogance, bien loin de s'adoucir, si on se soumet à leurs usages et si on s'efforce de leur plaire, s'accroît au contraire jusqu'à l'insolence la plus intolérable. Un missionnaire de Pékin ayant écrit que l'insuccès de l'ambassade Macartney devait être attribué, entre autres causes, au refus des Anglais de faire les prosternations rituelles devant I'Empereur, les Hollandais avaient décidé de se soumettre à toutes les formalités de ce genre. Leur bonne volonté à cet égard fut mise à une rude épreuve. Selon ce que raconte Van Braam lui-même, non seulement ils durent s'agenouiller devant l'Empereur, en touchant la terre avec le

${ }^{1}$ Voyage de l'ambassade de la Compagnie des Indes orientales hollandaises, t. I, p. 187, 197, 255.

${ }^{2}$ Ibid., t. I, p. 236, 319.

${ }^{3}$ Ibid., t. II, p. 115 et 116. 


\section{Les Chinois}

Essai de Psychologie ethnographique.

front neuf fois, toutes les fois qu'ils le virent ; mais, depuis leur arrivée à Canton, au cours de leur traversée de la Chine par la voie intérieure, ils durent se livrer à cette cérémonie humiliante toutes les fois qu'ils se trouvèrent, dans un monument quelconque, en présence de sa tablette. Bien plus, à Pékin, ils s'agenouillaient également devant les ministres, quand ils avaient affaire à eux. Si le souverain leur envoyait des raisins, de la pâtisserie, un aliment quelconque, ils devaient pareillement se prosterner. La relation est pleine de ces génuflexions.

Bien loin d'être amadoués par cette soumission à leurs rites extravagants, les Chinois accablèrent les envoyés hollandais du plus outrageant mépris. En voici un exemple :

« Il était à peu près huit heures, dit Van Braam, lorsque nous sommes rentrés à notre hôtel. Environ trente minutes après on nous a apporté pour déjeuner un présent de l'Empereur, consistant en un plat de viande bouillie froide, et en une assiette de boules farineuses également bouillies. Ce présent paraîtra encore plus incroyable si je le détaille davantage. La viande consistait en un morceau de côtes sur lesquelles il n'y avait point un demi-pouce d'épaisseur d'une chair maigre ; en un petit os de l'épaule où il n'y avait presque pas de chair, et en quatre ou cinq autres ossemens fournis par le dos ou par les pattes d'un mouton, et qui semblaient avoir été déjà rongés. Tout ce dégoûtant ensemble était sur un plat sale et 


\section{Les Chinois}

Essai de Psychologie ethnographique.

paraissait plutôt destiné à faire le régal d'un chien que le repas d'un homme, etc... ${ }^{1}$

Cette avanie et bien d'autres encore qu'essuya cette ambassade montrent de la manière la plus claire la conduite à ne pas tenir dans ce pays.

De Guignes fils avait demandé et obtenu d'accompagner la mission hollandaise à Pékin. Son récit ne présente rien de particulier ; il répète la narration de Van Braam, mais il la fait suivre d'observations qu'il avait prises sur les Chinois au cours de ce voyage et pendant les dix ans qu'il avait antérieurement passés à Macao. On peut y puiser de précieuses indications. Le portrait en pied, notamment, qu'il fait du Chinois, en traitant de son caractère, est à citer entièrement.

« Les Chinois, dit-il, sont actifs et laborieux ; ils n'ont pas un grand génie pour les sciences, mais ils ont de l'aptitude pour les arts et le commerce ; ils sont souples et plians, quoiqu'orgueilleux, et méprisent les autres nations, auxquelles ils se croient fort supérieurs.

« Ils sont intéressés et enclins à tromper ; j'ai vu des paysans faire avaler du sable à des poules, pour qu'elles pesassent davantage. Pendant notre voyage, les Chinois garnissoient de papier l'intérieur des pièces de soie qu'on nous donnoit, pour les faire paroître plus épaisses ; et à Péking, les mandarins donnèrent à $M$. Van Braam du faux gin-seng pour du vrai. Les Chinois

${ }^{1}$ Voyage de l'ambassade de la Compagnie des Indes orientales hollandaises, t. I, p. 254. 


\section{Les Chinois}

Essai de Psychologie ethnographique.

se font une telle habitude de la fraude, qu'ils ne croient pas faire mal ; c'est adresse, suivant eux. Ils aiment le jeu et la débauche; et sous un extérieur grave et décent, ils savent mieux que personne cacher leurs vices et leurs penchans déréglés : la preuve est qu'on trouve chez eux des gens qui composent des pièces dont le sens, à la simple lecture, n'exprime que de la morale, tandis que le son des mêmes mots signifie des choses obscènes. Humbles dans leurs discours, minutieux dans leurs écrits, polis sans sincérité, ils masquent, sous un dehors froid, un caractère vindicatif ; ils ne s'aiment pas même entre eux, et cherchent à se nuire. Cruels lorsqu'ils sont les plus forts, et lâches dans le danger, ils sont attachés à la vie ; il en est cependant quelquefois qui se donnent la mort ; mais le suicide est plus commun parmi les femmes que parmi les hommes ; chez elles, c'est l'effet de la jalousie et de la colère, ou l'envie de susciter à leurs maris quelques mauvaises affaires.

«Ce n'est pas que, dans un aussi vaste empire, il ne se trouve des gens doux, honnêtes et désintéressés, mais il y en a moins qu'ailleurs. La forme du gouvernement s'y oppose : obligés de vivre dans une crainte continuelle, sans cesse occupés à cacher leur bien, toujours forcés de tromper, comment une pareille contrainte n'étoufferoit-elle pas chez eux les germes d'un heureux caractère ! Je rendrai cependant justice aux Chinois sur leur respect pour leurs parens et les 


\section{Les Chinois \\ Essai de Psychologie ethnographique.}

vieillards ; ce respect est même si grand, qu'il se transmet du père qui vient de mourir, au fils aîné que les frères regardent alors comme le père et le chef de la maison.

« Ils sont aussi très respectueux pour les morts, mais ils seroit à désirer qu'ils eussent en même temps plus d'humanité pour les vivans. Lorsque des soldats poursuivent une personne mandée par un magistrat, ils emploient toutes sortes de moyens pour s'en saisir, et la maltraitent quelquefois très rudement, sans s'inquiéter si elle est innocente ou coupable. Un jour qu'ils avoient arrêté des voleurs, se trouvant dépourvus de cordes pour les attacher, ils leur percèrent les mains avec un bambou et les emmenèrent dans cet état. Un trait récent, et qui donne une idée de la barbarie des Chinois, c'est qu'en 1786, lorsque la disette régnoit dans le Chantong, on y mangea de la chair humaine ${ }^{1}$ : ceci n'est pas une histoire inventée à plaisir, c'est un fait certain ; d'ailleurs, ce n'est pas la première fois. A la même époque, dans la partie septentrionale du Houkouang, trente personnes furent enterrées toutes vives par des gens affamés à qui elles avoient refusé du riz.

« On objectera peut-être que ce sont des cas extraordinaires : cela est vrai ; mais ils font voir que le caractère national, retenu par la sévérité des lois, se

${ }^{1}$ D'après une lettre du père Raux, missionnaire à Pékin, à M. de Guignes. 


\section{Les Chinois}

Essai de Psychologie ethnographique.

fait reconnoitre lorsque certaines circonstances lui rendent toute son énergie. On a dit avec raison que le Chinois est vindicatif; il attend avec patience le moment favorable pour accuser son ennemi auprès des mandarins ; mais souvent celui-ci, aussi adroit, réussit, avec des présens, à faire retomber sur son accusateur le châtiment qu'on lui préparoit à lui-même : de là naissent des haines éternelles, qui se terminent quelquefois par I'incendie de I'habitation d'un des deux adversaires. Cette conduite ne doit pas étonner chez un peuple qui n'est arrêté que par la crainte, et non par des principes de vertu et de saine morale. Les livres de Confucius existent ; mais le peuple ne les lit pas, I'homme instruit qui les a lus ne s'en livre pas moins à ses passions lorsque l'intérêt le domine ; et chez les Chinois l'intérêt est un mobile tout puissant.

« Après avoir parlé du Chinois du côté moral, il est bon de l'examiner du côté physique. C'est un être dont les sens ne sont émus que par des impressions fortes; aussi est-il enchanté de sa musique qui est très bruyante. Des exhalaisons qui nous répugnent n'affectent pas son odorat.

« En mangeant, ils se servent avec adresse de petits bâtons pour prendre les morceaux, mais ils avalent le riz gloutonnement : ils boivent indistinctement dans toutes les tasses, sans s'embarrasser si quelqu'un s'en est servi auparavant. En sortant de table, ils prouvent 


\section{Les Chinois}

Essai de Psychologie ethnographique.

de toutes les manières qu'ils ont bien dîné. La seule chose qu'on ne puisse leur reprocher, c'est de se montrer ivres. Je n'en ai jamais rencontré dans cet état ; et même si le vin les a un peu échauffés au point que leur visage soit rouge ou enflammé, ils ont l'air embarrassé lorsqu'on les regarde : aussi vont-ils rarement alors dans les rues. En un mot, peu de peuples prennent autant de soin pour cacher leurs défauts et paroître sous des dehors réservés ${ }^{1 .}$

Ce portrait du Céleste est complété, plus loin, à propos de la politesse, par les lignes suivantes :

« Ces usages, ces devoirs, cette politesse rendent les Chinois minutieux à l'excès : I'habitude où ils sont, dès I'enfance, d'être respectueux envers leurs supérieurs, et cette contrainte continuelle dans laquelle ils vivent, les portent à la crainte et à la défiance ; et de la défiance à la fourberie il n'y a qu'un pas : aussi voit-on que les Chinois cachent, sous une apparence honnête et polie, un caractère faux et dissimulé 2 .

En outre, dans le cours de son ouvrage, de Guignes note que les marchands sont méprisés en Chine ${ }^{3}$ et que, contrairement à ce qu'on avait précédemment écrit, les enfants ne prennent le métier de leur père que si la nécessité les y contraint ${ }^{4}$. Il

\footnotetext{
${ }^{1}$ Voyages à Péking, Manille et I'Ile de France, t. II, p. 161 et suiv.

${ }^{2}$ Ibid., t. II, p. 258.

${ }^{3}$ Ibid. , t. II, p. 444 et 453.

${ }^{4}$ Ibid., t. II, p. 454.
} 


\section{Les Chinois}

Essai de Psychologie ethnographique.

confirme le goût hautement avoué des Chinois pour les jeunes garçons ${ }^{1}$. Il dit qu'ils mangent toutes sortes de bêtes malpropres : chiens, rats, vers; cependant ils ont honte de s'alimenter du chien et ils se cachent pour préparer cette cuisine ${ }^{2}$. Au sujet de l'infanticide, il prend la défense des Chinois. Il dit qu'ils aiment généralement leurs enfants et qu'ils ne les exposent, ne les vendent, et ne les tuent que lorsqu'ils y sont poussés par la famine et l'extrême misère ${ }^{3}$.

${ }^{1}$ Ibid., t. II, p. 285.

${ }^{2}$ Ibid., t. II, p. 276.

${ }^{3}$ Ibid., t. II, p. 285 et suiv. 


\section{Les Chinois}

Essai de Psychologie ethnographique.

\section{III}

\section{Relations de voyageurs contemporains.}

Une vingtaine d'années plus tard, en 1816, à la suite d'incidents répétés entre les factoreries anglaises et les autorités de Canton, I'Angleterre, à la demande expresse de la Compagnie des Indes, envoya à Pékin une nouvelle ambassade avec, à sa tête, lord Amherst. Un de ses membres, Ellis, en a écrit la relation. D'après ce qu'il raconte, cette mission se heurta à des difficultés plus grandes encore que celles qu'avait eues à surmonter la mission de lord Macartney, et son résultat fut moindre puisqu'elle ne vit même pas l'empereur, Kia-k'ing, fils de Kien-Long.

Les Chinois exigeaient que l'ambassadeur exécutât les agenouillements rituels et - ce qui donne une indication sur leur véracité - ils prétendirent que lord Macartney s'y était soumis ; pour le prouver, ils montrèrent un extrait des registres du tribunal du Lipou qui en rendait compte ${ }^{1}$. A peine arrivé dans la capitale, lord Amherst, avant reçu, de l'empereur, l'invitation d'avoir à se présenter de suite devant lui et ayant répondu en demandant un peu de temps pour prendre un repos nécessaire et pour se préparer, le souverain, irrité, fit donner l'ordre à I'ambassade de quitter immédiatement Pékin. Ce qui fut fait.

${ }^{1}$ Voyage en Chine ou Journal de la dernière ambassade anglaise à la Cour de Pékin, t. I, p. 438 et 302. 


\section{Les Chinois}

Essai de Psychologie ethnographique.

Au cours de son récit et des observations dont il le fait suivre, I'auteur fait quelques constatations qui sont à retenir. S'il parle de la tenue parfaite de la foule sur le passage des Étrangers, il remarque, dans les Chinois d'un rang supérieur, le mélange d'arrogance et de bassesse que tous les voyageurs ont mentionné ${ }^{1}$. Ils changent d'attitude si on leur oppose un air ferme et résolu, car ils sont bons physionomistes ${ }^{2}$. C'est pour cela, sans doute, que les querelles qu'ils ont entre eux, malgré qu'ils paraissent animés d'une fureur extrême, se terminent de la manière la plus pacifique. Toutefois, lorsqu'ils se déterminent enfin à se battre, c'est toujours de la façon la plus cruelle ${ }^{3}$. La justice est vénale et corrompue ${ }^{4}$. En somme, malgré tout ce que I'on a écrit, les qualités morales des Chinois sont très incertaines. Les maximes de leurs philosophes et leurs lois sont irréprochables, mais il y a loin de la théorie à la pratique 5 .

Par leur long séjour dans le pays, les missionnaires auraient pu renseigner exactement sur ce pays. Malheureusement,

« ils ont porté des jugements aussi faux qu'exagérés sur le rang comparatif que la Chine tient parmi les nations, jugements qu'ils ont puisés dans les écrits et les exposés des Chinois euxmêmes ${ }^{6}$.

\footnotetext{
${ }^{1}$ Ibid., t. I, p. 55 et 252.

${ }^{2}$ Ibid. , t. I, p. 137.

${ }^{3}$ Ibid. , t. I, p. 268.

${ }^{4}$ Ibid., t. II, p. 352.

${ }^{5}$ Ibid., t. II, p. 353.

${ }^{6}$ Ibid. , t. II, p. 347.
} 


\section{Les Chinois}

Essai de Psychologie ethnographique.

Par suite de leur ignorance de la force des nations occidentales et de leur propre faiblesse, les Chinois persistèrent dans l'attitude arrogante et hostile qui devait tôt ou tard amener un conflit. Cela advint un demi-siècle plus tard, en 1841. Les Anglais se présentèrent devant Canton, qui paya une rançon ; puis ils prirent Amoy, Ningpo, Shanghai. Au mois d'août 1842, la flotte anglaise se trouvait devant Nankin. Des négociateurs chinois se présentèrent et signèrent un traité par lequel on donnait Hong-kong aux Anglais et cinq ports étaient ouverts au commerce étranger. Plus tard, pour ne pas remplir les conditions de ce pacte, les Chinois dirent qu'il n'avait pas été soumis à I'Empereur et I'appelèrent le faux traité de Nankin.

Les Américains, voulant avoir une situation égale, dépêchèrent une ambassade qui signa un traité, en 1844. La France envoya aussi, dans le même but, une mission diplomatique dirigée par $M$. de Lagrené. Le premier secrétaire de cette ambassade, M. de Ferrière-le-Vayer, a laissé un livre sur cette mission. Il n'y a rien à retenir de cet ouvrage si ce n'est qu'il signale chez les fonctionnaires chinois une politesse exquise et une amabilité parfaite qui avaient remplacé l'arrogance et la grossièreté d'antan. La révélation de leur faiblesse avait changé les Célestes dont la conduite, en cette circonstance, fut d'une dissimulation bien remarquable.

A la date d'octobre 1844, M. de Ferrière-le-Vayer écrivait :

« Ki-Yng (le vice-roi de Canton) est venu, ce matin, à la légation, accompagné de Pan-se-Tchen et de Tchaô. Il a déployé une grande bonhomie. C'était une visite 


\section{Les Chinois}

Essai de Psychologie ethnographique.

d'amitié. Il a désiré voir madame de Lagrené et ses petites filles. Il a joué avec les enfants et les a comblés de caresses et de cadeaux ${ }^{1}$.

Dans le même temps, Ki-Yng mandait, au Gouvernement de Pékin :

« Les Barbares anglais ayant été amadoués, les Barbares américains et français sont aussi venus cette année. Je les ai également traités de manière à les mettre en belle humeur. Nés et élevés dans des pays étrangers, ces Barbares sont incapables de comprendre les choses de l'Empire du Milieu. Ils aiment à se réunir en grand nombre, pour manger et boire ensemble. Je leur ai fait I'honneur de leur donner des repas, et j'ai ensuite été invité par eux dans leur résidence. Tous se sont disputés à qui m'offrirait à manger et à boire. Ces Barbares ont une grande affection pour leurs femmes. C'est au point que le Barbare américain Parker, et le Barbare français Lagrené, ont amené les leurs. Quand j'allai chez eux pour traiter d'affaires, soudain ces femmes parurent, pour me saluer. Je fus très mal à I'aise, tandis qu'elles étaient charmées. On voit par là qu'il est impossible d'exiger quoi que ce soit de ces Barbares, en fait de cérémonial, et qu'il est inutile d'essayer d'éclairer leur stupidité. Ils m'ont aussi offert quelques petits présents, des vins, des parfums, etc. Je leur en ai fait à mon tour, de considérables, d'après ce

${ }^{1}$ Une Ambassade française en Chine, p. 261. 


\section{Les Chinois \\ Essai de Psychologie ethnographique.}

principe qu'il faut rendre beaucoup quand on a reçu peu. Ces Barbares affublent maintenant leurs personnes et leurs pays de caractères chinois honorables, auxquels ils n'ont pas le moindre droit. Il ne faut pas se disputer avec eux ; pour si peu de chose. Mieux vaut leur concéder tous les détails insignifiants, pour assurer le succès des négociations importantes ${ }^{1}$.

Quant à la véracité chinoise, on peut en juger par la façon vraiment curieuse dont les Annales impériales relatèrent ces événements. On y lit :

«En 1844, les Américains et les Français conclurent aussi des traités de commerce. Depuis longtemps ces deux nations trafiquaient à Canton. Ennemies des Anglais, elles étaient respectueuses et dociles à l'égard de la Chine. Quand les Anglais se révoltèrent à Canton et gênèrent le commerce, ces deux nations furent très ennuyées et se plaignirent à leurs souverains, lesquels envoyèrent des vaisseaux de guerre et des délégués qui négocièrent des traités. Les Anglais ayant voulu les faire soumettre à des formalités et à des droits, les Américains et les Français se fâchèrent très fort : Nous ne sommes pas, protestèrent-ils, les tributaires des Anglais ! Ce n'est pas nous qui avons fait des misères à la Chine ! Pourquoi les Anglais seraient-ils plus favorisés que nous ? Alors le délégué chinois Ki-Yng concéda aux

\footnotetext{
${ }^{1}$ Textes historiques, traduction et notes du père Wieger, p. 2094.
} 


\section{Les Chinois}

Essai de Psychologie ethnographique.

Américains et aux Français les mêmes droits qu'aux Anglais ${ }^{1}$.

Comme le père Wieger le note entre parenthèses, c'est amusant, mais c'est aussi une indication dont il faut se souvenir pour l'appréciation du caractère chinois.

Une douzaine d'années plus tard, en 1856, les Chinois, ayant oublié la leçon, non seulement n'observent pas les traités signés, mais ils adoptent une attitude violemment hostile ; ils brûlent des factoreries anglaises à Canton, mettent à mort un missionnaire français au Koangsi, etc. Pour régler ces affaires, la France envoie, en 1857, I'ambassade du baron Gros, et l'Angleterre, celle de lord Elgin. Ce fut le point de départ de I'action militaire combinée des deux puissances qui aboutit, en octobre 1860, à la prise de Pékin, où un traité fut signé qui ratifiait les précédents, ouvrait cinq ports et donnait aux nations étrangères le droit d'avoir des ministres plénipotentiaires résidant dans la capitale de l'Empire.

Un secrétaire de lord Elgin, Laurence Oliphant, a publié une relation de cette ambassade et, du côté français, un attaché à la mission du baron Gros, le marquis de Moges, a laissé également un récit de son voyage en Chine. Ce qui est surtout mis en lumière par l'un et par l'autre, c'est la fausseté et la mauvaise foi avec lesquelles, au cours de ces premiers contacts un peu rudes avec les puissances étrangères, les Chinois s'efforcèrent d'éluder tous leurs engagements.

${ }^{1}$ Textes historiques, p. 2091. 
Au cours de cette guerre, les Chinois donnèrent en outre une preuve éclatante de leur perfidie et de leur cruauté, en gardant comme prisonniers et en martyrisant les parlementaires qu'on leur avait envoyés sur leur demande.

«Quand nous eûmes été tous liés, a raconté l'un de ceux-ci, on versa de l'eau sur les cordes, afin de les resserrer. On nous emporta et nous déposa dans une cour, où nous restâmes gisants trois jours entiers, exposés au froid durant la nuit et au soleil durant le jour. A la fin du second jour, ou nous donna deux pouces carrés de pain et un peu d'eau. Durant le jour venait se jouer de nous qui voulait. Le soir, un factionnaire était placé à côté de chacun de nous. Si nous disions un mot, ils nous piétinaient et nous frappaient à coups de pied sur la tête. Si nous demandions à manger ou à boire, ils nous remplissaient la bouche d'ordures. Le reste ne peut pas se raconter. M. Anderson mourut après neuf jours de délire. Les liens avaient fait éclater ses mains, les vers pullulaient dans ses plaies, la gangrène $s^{\prime} y$ mit et découvrit les os de l'avant-bras. Son cadavre resta couché durant trois jours parmi les survivants ${ }^{1}$.

A partir de ce moment, M. de Lagrené ayant obtenu, du gouvernement de Pékin, des décrets levant l'interdiction dont avait été frappée la religion chrétienne, les missionnaires se répandirent et circulèrent plus ou moins librement dans les dix-

\footnotetext{
${ }^{1}$ Textes historiques, traduction et notes du père Wieger, p. 2108.
} 


\section{Les Chinois}

Essai de Psychologie ethnographique.

huit provinces, D'autre part, la création, dans les concessions récemment accordées, de véritables villes européennes attira de nombreux étrangers. Des relations régulières et permanentes s'établirent ainsi entre la Chine et le monde extérieur. De ce fait, les livres publiés sur le Céleste Empire se multiplièrent. Il ne saurait être question de les passer tous en revue ; il faudra se borner à l'examen des mieux renseignés et de ceux qui, à tort ou à raison, ont, chez nous, fortement influencé l'opinion sur ce pays.

Les ouvrages notamment du père Huc, qui parcourut la Chine et voyagea au Thibet, de 1844 à 1846, renferment toutes sortes d'indications que I'on ne peut passer sous silence. Il relève les fausses idées qu'on se fait, en Europe, sur l'unité du peuple chinois et sur son invariabilité.

« Il y a sans doute, dit-il, un certain fond qu'on retrouve partout et qui constitue le type chinois. Ces traits caractéristiques peuvent se remarquer dans la physionomie, le langage, les mœurs, les idées, le costume et certains préjugés nationaux ; mais, dans tout cela, il existe encore des nuances si profondes, des différences si bien tranchées, qu'il est bientôt facile de s'apercevoir si I'on a affaire à des hommes du Nord ou du Midi, de l'Est ou de l'Ouest ${ }^{1}$.

Ce qui importe, ici, c'est justement ce « certain fond » qui constitue la psychologie générale du Chinois, sur laquelle le père Huc a si puissamment contribué à porter la lumière. Voici

${ }^{1}$ L'Empire chinois, t. II, p. 51. 


\section{Les Chinois}

Essai de Psychologie ethnographique.

quelques-unes de ses observations qui ont une portée collective indéniable :

La plus significative, peut-être, et qui avait été déjà signalée par d'autres voyageurs, c'est cette impressionnabilité spéciale qui fait que, très fier, très arrogant et d'une apparence d'abord inflexible, le Chinois devient aussitôt faible et craintif si on lui oppose une attitude ferme et une résolution inébranlable. Le père Huc en donne de nombreux exemples. Une aventure qui lui arriva au Setchoan est topique à cet égard ${ }^{1}$. Elle se termine par cette réflexion :

« La crainte de se compromettre est d'ailleurs, en Chine, un sentiment presque universel, et qu'on peut exploiter avec beaucoup de facilité. Chacun cherche d'abord à se mettre à l'abri, et puis advienne que pourra. Une certaine prudence, qu'il serait mieux peutêtre d'appeler pusillanimité, est une des grandes qualités des Chinois. Ils ont une expression dont ils se servent à tout propos et qui caractérise très bien ce sentiment. Au milieu des difficultés et des embarras, les Chinois se disent toujours : «Siao sin », c'est-à-dire : Rapetisse ton cœur.

La note suivante donne la valeur réelle de la politesse chinoise :

« Il est d'usage, en Chine, qu'on se fasse les invitations les plus pressantes; mais c'est à condition qu'elles

${ }^{1}$ L'Empire chinois, t. I, p. 248 et suiv. Voir aussi dans Le Voyage en Tartarie, t. I, p. 469 et 474 ; t. II, p. 18 et 19. 


\section{Les Chinois}

Essai de Psychologie ethnographique.

seront refusées ; les accepter serait la preuve d'une très mauvaise éducation.

Comme de juste, une anecdote très amusante illustre cette remarque ${ }^{1}$.

Une des observations les plus exactes est celle qui dit que les vices des Célestes sont les mêmes que ceux des autres peuples, mais poussés à l'extrême. Tel est le cas de la passion du jeu. Quand les Chinois n'ont plus d'argent, ils jouent leurs habits et, s'ils les perdent, ils se retirent nus. Ils vont jusqu'à jouer leurs doigts qu'ils se coupent mutuellement avec un horrible stoïcisme.

« Il n'est pas de village et de hameau qui n'ait sa maison de jeu et ses joueurs de profession ${ }^{2}$.

Une constatation encore plus importante a trait à I'indifférence des Chinois en matière de religion.

« Indifférentisme, dit le père Huc, radical, profond, et dont il est impossible de se former une idée exacte Iorsqu'on n'a pas eu occasion de l'étudier sur les lieux. Les Chinois sont tellement enfoncés dans les intérêts temporels, dans les choses qui tombent sous les sens, que leur vie entière n'est que le matérialisme en action ${ }^{3}$.

Ce sont des positivistes.

\footnotetext{
${ }^{1}$ L'Empire chinois, t. I, p. 307 et suiv.

${ }^{2}$ Ibid., t. II, p. 372 et suiv.

3 Ibid., t. I, p. 473.
} 


\section{Les Chinois}

Essai de Psychologie ethnographique.

«Peu leur importent I'origine, la création et la fin du monde ; peu leur importent les longues élucubrations philosophiques. Ils ne prennent du temps que ce qu'il leur faut pour la vie; de la science et des lettres, que ce qu'il leur faut pour remplir leurs emplois ; des plus grands principes, que les conséquences pratiques, et de la morale, que la partie utilitaire et politique ${ }^{1}$.

Ainsi absorbés par le culte des intérêts matériels, sans idéal, les Chinois ont la justice qui leur convient.

« Le rotin et le bambou sont la seule garantie de I'accomplissement du devoir ${ }^{2}$.

On peut ajouter qu'ils ont, pour les leur dispenser, les mandarins qu'ils méritent. L'un d'eux faisait l'admiration du missionnaire et de son compagnon, par l'entrain avec lequel il réglait les procès. Mais il eut le soin de les avertir lui-même

« qu'il avait besoin d'argent et qu'un procès bien conduit était la meilleure manière de s'en procurer ». Ces sentiments peu élevés sont dans le cœur de tous les mandarins, et ils les manifestent ouvertement et sans scrupule. L'administration de la justice est devenue un véritable trafic ${ }^{3}$.

Ils s'humanisent, d'ailleurs, dans la poursuite des délits, si ceux qui les commettent savent, par des présents, s'acquérir

${ }^{1}$ Ibid., t. II, p. 201.

${ }^{2}$ L'Empire chinois, t. II, p. 292.

${ }^{3}$ Ibid., t. I, p. 143 ; t. II, p. 292. 


\section{Les Chinois}

Essai de Psychologie ethnographique.

leur indulgence ${ }^{1}$. Mais il en est de délicats, à qui il faut conserver la face, en leur donnant sans en avoir l'air ${ }^{2}$.

Cette rapacité des mandarins, jointe à la bizarre législation qui rend responsable du suicide celui qui en est la cause ou I'occasion, fait que le nombre de ceux qui se donnent la mort en Chine est considérable.

« Il suit de là que, lorsqu'on veut se venger d'un ennemi, on n'a qu'à se tuer, et l'on est assuré de lui susciter, par ce moyen, une affaire horrible ; il tombe immédiatement entre les mains de la justice qui, tout au moins, le torture et le ruine complètement, si elle ne lui arrache pas la vie. La famille du suicidé obtient ordinairement, dans ces cas, des dédommagements et des indemnités considérables. En tuant son ennemi, le meurtrier expose, au contraire, ses propres parents et ses amis, les déshonore, les réduit à la misère et se prive lui-même des honneurs funèbres, point capital pour un Chinois ${ }^{3}$.

Ce peuple antique, avec beaucoup de tares et de travers odieux, a des côtés d'une très vieille civilisation raffinée, au regard de laquelle nous sommes vraiment, à ce point de vue, des Barbares. L'un des plus dignes d'admiration est le respect que tous ont, en Chine, pour la parole écrite.

\footnotetext{
${ }^{1}$ Ibid., t. II, p. 376.

${ }^{2}$ Ibid., t. II, p. 377.

${ }^{3}$ L'Empire chinois, t. I, p. 304.
} 


\section{Les Chinois}

Essai de Psychologie ethnographique.

« On a grand soin de ne pas employer à des usages profanes le papier qui contient des caractères imprimés ou tracés au pinceau. On conserve avec respect celui qui est écrit, on évite de le fouler aux pieds et de lui laisser contracter des souillures. Les enfants mêmes ont cette habitude. Nous ne pensons pas que les Chinois attachent à cette pratique aucune idée superstitieuse. Il nous a semblé qu'ils entendaient simplement honorer de cette manière la pensée humaine, qui s'incarne en quelque sorte et se fixe dans l'écriture ${ }^{1 .}$

Il y a près de quarante ans un ouvrage sur la Chine eut un vif succès de curiosité. Il étudiait justement une région, le Fou-kien, dans laquelle venait d'opérer l'escadre de I'amiral Courbet, au cours de la guerre que nous soutenions à ce moment-là contre le Céleste Empire. Bien loin d'être une diatribe contre nos ennemis jaunes, c'était, en leur honneur, un véritable dithyrambe qui dépassait, dans ce genre, tout ce que les Jésuites du XVIII ${ }^{e}$ siècle avaient pu écrire. Ce livre avait pour titre : la Cité chinoise, et, pour auteur, un ancien consul de France en Chine, Eugène Simon.

C'était l'époque de la conquête du Tonkin et la disposition d'esprit de notre auteur apparaît bien dans la manière dont il la juge. Il la déplore et, selon lui, le mieux, pour les Tonkinois, serait qu'on leur laissât « les libertés et la douceur du régime chinois »2. A son avis, il eût été préférable d'abandonner aux

\footnotetext{
${ }^{1}$ Ibid. , t. I, p. 237.

${ }^{2}$ La Cité chinoise, p. 165.
} 


\section{Les Chinois}

Essai de Psychologie ethnographique.

Célestes le soin de l'exploitation industrielle du Tonkin, et il estime que, «s'il était un moyen possible de remettre les choses en l'état, il faudrait s'empresser de l'adopter $\gg 1$.

Cela n'est pas écrit dans le but d'appuyer la polémique anticoloniale qui sévissait alors à Paris, mais dans l'intérêt de la civilisation.

« L'état le plus civilisé, dit Eugène Simon, est celui dans lequel, sur une surface de territoire donnée, le plus grand nombre d'hommes possible ont su se procurer et se distribuer le plus également et au meilleur marché possible la plus grande somme de bien-être, de liberté, de justice et de sécurité. J'exposerai d'abord la situation de la Chine à ces différents points de vue, puis je dirai par quels moyens elle y est arrivée ${ }^{2}$.

On est de la sorte tout de suite fixé sur la tendance de l'ouvrage. C'est l'expression d'un véritable culte de latrie, dont tout esprit critique est absent. Par exemple, pour la population qui, d'après quelques-uns, ne dépasse pas 300 millions d'habitants et que la «géographie » récente du père jésuite Richard, de Shanghaï, fixe à 410 millions, dont on n'a en somme aucun dénombrement certain, la Cité chinoise l'évalue, sans la moindre hésitation ni réserve, au chiffre de 530 millions ${ }^{3}$. Il en sera de tout ainsi.

\footnotetext{
${ }^{1}$ Ibid., p. 168.

${ }^{2}$ La Cité chinoise, p. 3.

${ }^{3}$ Ibid., p. 24.
} 


\section{Les Chinois}

Essai de Psychologie ethnographique.

Il n'est pas de peuple plus libre que le peuple chinois. Il n'y a, chez lui, « ni caste judiciaire, ni caste sacerdotale, ni caste enseignante, ni caste militaire »1. Des mandarins, pas un mot.

Ce peuple est du reste souverain. Il se charge de châtier les fonctionnaires qui ne le servent pas convenablement ; qu'une sécheresse survienne et les préfets et sous-préfets sont révoqués. Huit jours de plus et le gouvernement doit partir à son tour.

«Si les fléaux se prolongent ou sont trop fréquents, I'Empereur est remplacé, sa dynastie congédiée. Tous payent de la perte de leurs emplois ou de leur trône ce que le peuple a payé de son bien-être, le cultivateur de sa récolte ${ }^{2}$.

« Le souffle vigoureux et régulier sorti des larges poumons de la nation chinoise fait fonctionner tous les organes ; la pensée énergique et saine, émanée de I'Académie (des Han-lin) comme de son cerveau, va porter partout le sentiment et la vie ${ }^{3}$.

L'infanticide, que tous les voyageurs ont signalé, « est beaucoup moins fréquent en Chine qu'en France ${ }^{4}$. De même pour l'abandon et l'exposition des enfants. Du reste, il existe, dans le Céleste Empire, des orphelinats et des établissements charitables purement chinois, supérieurs à ceux des missions, et

\footnotetext{
${ }^{1}$ Ibid., p. 19.

${ }^{2}$ La Cité chinoise, p. 145.

${ }^{3}$ Ibid., p. 157.

${ }^{4}$ Ibid., p. 25.
} 


\section{Les Chinois}

Essai de Psychologie ethnographique.

« qui pourraient servir de modèles, sous bien des rapports, à des pays où l'on sacrifie plus à l'apparence, au faste des monuments, qu'à la commodité des malades ${ }^{1}$.

Sur la vente des filles, plaie des dix-huit provinces dans les temps de famine, et en tous temps, du Kiang-sou et du Kouangtoung, complet silence. En revanche, I'ancien consul déclare:

«Sens être aussi apparente qu'en Europe, la place de la femme chinoise dans la civilisation est au moins aussi considérable. La femme, c'est la maison, en Chine comme dans tous les pays civilisés, et peut-être plus réellement qu'ailleurs. C'est elle qui, par le mariage, rend I'homme citoyen et lui donne toute sa valeur. On ne I'accable pas autant qu'en France de flatteries et d'adulation, mais on la respecte davantage, et on le lui prouve en l'épousant, en la laissant moins souvent tomber dans la misère et dans I'abandon ${ }^{2}$.

Du caractère, de la psychologie du Chinois, il n'est pas question ; on reste, même avec la Famille Ouang Ming-tse, dans les généralités d'un exposé de doctrine. Une affirmation est cependant à retenir, sur la rareté des névroses en Chine ${ }^{3}$, parce qu'elle sera reprise par d'autres sous la forme de l'axiome : les Chinois n'ont pas de nerfs.

\footnotetext{
${ }^{1}$ La Cité chinoise, p. 21 et 25.

${ }^{2}$ Ibid., p. 59.

${ }^{3}$ Ibid., p. 347.
} 


\section{Les Chinois}

Essai de Psychologie ethnographique.

Tel est cet ouvrage qui affichait hautement la prétention de donner, du Céleste Empire, un tableau documentaire. L'auteur disait, en effet, en tête de sa Préface, que, n'ayant pu étudier la Chine dans ses livres d'origine, il l'avait étudiée sur le vif, c'està-dire dans les faits. Or, il cite largement une Encyclopédie chinoise, publiée en 1747 : le Tchi-Pen-Ti-Kang ${ }^{1}$ et il se réfère ailleurs aux Rites des Tchéou, traduits par Ed. Biot, d'une façon qui montre que son esprit en était fortement influencé. C'est en réalité le cas curieux d'auto-suggestion d'un homme qui, sous l'impression de lectures et, aussi, de certaines séductions incontestables d'un pays très original, ne voit pas la réalité et y substitue son rêve ; déformation, du reste, connue par les Européens de Chine et qu'on appelle là-bas : I'enchinoisement.

Une étude, parue vers le même temps et qui - contrairement au travail d'Eugène Simon, qu'on ne peut goûter qu'à la condition de tout ignorer de ce dont il parle - jouit d'un grand crédit auprès des Européens de Chine, est le Chinese Characteristics du missionnaire américain Arthur H. Smith. Elle contient de nombreuses indications accompagnées d'exemples sur ]a sensibilité de la face, sur la politesse, sur l'indifférence du temps perdu et du confort, sur le génie de l'imprécision, le manque de sincérité, la méfiance mutuelle et l'antipathie pour les étrangers, etc., qui confirment d'une manière fort intéressante ce qui a été déjà dit.

Tout un chapitre est consacré à la facilité du Chinois, dont a parlé le père Huc, de passer instantanément, selon l'attitude

${ }^{1}$ Ibid., p. 92 et suiv. 


\section{Les Chinois}

Essai de Psychologie ethnographique.

qu'on lui oppose, de l'extrême énergie arrogante à la plus grande douceur, particularité de caractère que Smith qualifie très exactement de flexible inflexibility. Un autre chapitre tend à établir que les Célestes n'ont pas de nerfs : the absence of nerves. Un autre, enfin, parle plus justement de leur endurance exceptionnelle, de leur résistance au mal, qui est due à une grande vitalité physique.

Le livre de l'ancien président du Conseil d'administration de la concession française, à Shanghaï, E. Bard : Les Chinois chez eux, d'une période encore plus récente, mais qui précède cependant l'actuelle modernisation, est marqué du même esprit de stricte observation. Sur bien des points, il donne de piquantes et utiles notations. Ainsi, pour la politesse :

« Il est de règle absolue que l'on doit parler de soi et de tout ce qu'on possède dans les termes les plus humbles, tandis que tout ce qui touche l'interlocuteur n'est mentionné qu'avec les épithètes les plus pompeuses ». Un père à qui on demande combien il a de « précieux fils » répond qu'il possède « seulement cinq stupides petits porcs $\gg 1$.

Pareillement, un refus ou une vérité désagréable doivent être enveloppés de circonlocutions évasives.

« Notre habitude de répondre carrément non quand c'est non, est, pour les Chinois, le comble de la brutalité.

\footnotetext{
${ }^{1}$ Les Chinois chez eux, p. 12 et suiv.
} 


\section{Les Chinois}

Essai de Psychologie ethnographique.

Sur le peu de goût de la précision :

« Lorsqu'on discute un marché avec un Chinois, il n'y a pas d'effort qu'il ne tente pour qu'il reste place à l'équivoque. Il est extrêmement difficile de les enfermer dans un dilemme d'où ils ne puissent pas sortir. C'est, d'ailleurs, là toute leur malice, en affaires comme en diplomatie ${ }^{1 .}$

Avec une semblable disposition d'esprit, le mensonge n'est pas considéré comme déshonorant, mais comme une preuve d'habileté.

« Cela fait partie de l'éducation, et si on prend un Chinois en flagrant délit de mensonge, on peut lui dire qu'il ment; il ne se fâche pas ; il se contente de remarquer en riant que vous êtes plus habile que lui 2.

Le mépris du temps :

« Le temps n'a positivement aucune valeur pour le Chinois, non seulement le sien, mais celui des autres. En quatre ans de séjour en Chine, nous n'avons pas connu un Chinois exact à un rendez-vous que nous lui donnions. Nous n'en avons jamais entendu un offrir la moindre excuse de son retard. Cela ne lui paraît pas nécessaire ${ }^{3}$.

Sur la probité si vantée des Célestes :

${ }^{1}$ Ibid., p. 23.

${ }^{2}$ Les Chinois chez eux, p. 25.

3 Ibid., p. 29. 


\section{Les Chinois}

Essai de Psychologie ethnographique.

« Le Chinois connaît la valeur d'un engagement et généralement il le respecte. Pour qu'un Chinois se dérobe à l'exécution d'un contrat, il faut que les circonstances l'aient réellement mis dans l'impossibilité de faire honneur à sa parole ou à sa signature. Comme faire des affaires, pour lui, c'est jouer, il s'est fait un tempérament de joueur, et il est un beau joueur, au rebours du Japonais, aussi joueur que lui, mais joueur de la plus entière mauvaise foi. Il y a cependant une ombre au tableau ${ }^{1}$.

Voici l'ombre :

«Une longue expérience des affaires en Chine nous permet d'affirmer que jamais un marchand chinois n'hésitera à livrer une marchandise fraudée ou inférieure s'il croit pouvoir le faire impunément. Nous avons constaté les fraudes les plus invraisemblables, les moins profitables à leurs auteurs, pratiquées pour l'amour de l'art. Nous avons trouvé, dans des cocons de vers à soie, des grains de plomb de chasse introduits à grand peine par un trou imperceptible, soigneusement recousu, et la soie ramenée sur le petit trou. Nous avons trouvé, dans les plumes d'oiseaux, des aiguilles introduites pour augmenter le poids. Le duvet de canard est additionné de plumes de poulet coupées aux ciseaux. Tout ce qui permet l'addition d'eau et de boue, pour augmenter le poids, en est largement additionné :

${ }^{1}$ Ibid., p. 227. 


\section{Les Chinois}

Essai de Psychologie ethnographique.

le coton, la laine, le duvet, les peaux, etc. On trouve des briques, des pièces de fer dans les balles de marchandises.

Tout négociant qui se respecte a une balance, sorte de romaine comme celles des portefaix de Marseille, graduée de deux façons : I'une pour acheter, I'autre pour vendre.

Payer en fausse monnaie n'est pas non plus considéré comme répréhensible. Certains produits, sur certains marchés, ont deux cotes : I'une en fausses sapèques, I'autre en bonnes sapèques ${ }^{1}$.

Sur les Mandarins :

« Les grades, en principe, doivent s'obtenir gratuitement par les examens, c'est-à-dire que I'on est gradué du premier, deuxième ou troisième degré et, par suite, susceptible de remplir un emploi parmi ceux affectés à chacun des grades, mais il faut payer pour obtenir un emploi. Cela ne dispense pas de forts cadeaux à ceux de qui dépend la nomination ${ }^{2}$.

La charge ainsi acquise ne rapportant que des appointements dérisoires, elle doit donc, par d'autres moyens, être fructueuse. Le Mandarin rendant la justice, on sent tout le parti qu'il peut en tirer.

\footnotetext{
${ }^{1}$ Les Chinois chez eux, p. 234 et suiv.

${ }^{2}$ Ibid., p. 111 et suiv.
} 


\section{Les Chinois}

Essai de Psychologie ethnographique.

« Nulle part, le fossé qui sépare la théorie de la pratique n'est plus large qu'en cette matière. Les lois chinoises sont dans l'ensemble relativement modérées et humaines; de nombreuses précautions sont prises pour prévenir ou corriger les abus, et cependant l'administration de la justice n'offre guère qu'un tableau de corruption, d'extorsion et de cruelle injustice ${ }^{1}$.

Les impressions de voyage de Marcel Monnier, qui eurent un vif succès, justifié par le pittoresque des descriptions, la variété des renseignements et la saveur des anecdotes, sont, au point de vue psychologique, en dépit d'un réel effort de pénétration, moins heureuses, parce que, sans cloute, insuffisamment nuancées. C'est peut-être, par exemple, un peu sommaire de dire que le Chinois n'a pas de nerfs ${ }^{2}$, qu'il est médiocrement imaginatif 3 , et de vanter sa probité commerciale ${ }^{4}$.

Un médecin, le docteur Matignon, qui était attaché à la Légation de France, à Pékin, lors des événements de 1900, a réuni, sous le titre de Superstition, Crime et Misère en Chine, quelques études ayant, la plupart, fait l'objet de communications à I'Académie de médecine. C'est dire la valeur d'observation scientifique qu'elles présentent. L'une d'elles éclaire singulièrement les mœurs de Bas-Empire de la Cour chinoise, qui avaient déjà été signalées par les voyageurs du XVIII $I^{e}$ siècle :

\footnotetext{
${ }^{1}$ Les Chinois chez eux, p. 168.

${ }^{2}$ Le Tour d'Asie. L'Empire du Milieu, p. 356.

${ }^{3}$ Ibid, p. 359.

${ }^{4}$ Ibid, p. 362.
} 


\section{Les Chinois}

Essai de Psychologie ethnographique.

John Barrow, Hüttner et de Guignes. Une autre, sous le titre de : Hystérie et Boxeurs, établit ce fait que le Chinois, contrairement à ce que d'autres ont prétendu, est un nerveux, plus qu'un nerveux : un hystérique.

«Plusieurs fois, dit-il, il m'est arrivé de formuler devant des « globe-trotters », qui collectaient fiévreusement des notes et impressions aussi rapides que légères, cette opinion que l'hystérie était très répandue en Chine et qu'une étude approfondie de ce mal nous permettrait de pénétrer un peu plus avant que nous ne l'avons fait jusqu'à l'âme chinoise. A cette hypothèse - qui est maintenant pour moi une certitude, - il m'était presque toujours fait la même réponse : « Le Chinois hystérique ! Allons donc ! Le Céleste si patient, si calme, qui ne court jamais, tenace, résistant, travailleur, dur au mal, n'est pas un nerveux ! » Cette réponse était I'indice d'une ignorance aussi absolue de I'hystérie que du caractère des Chinois ${ }^{1}$.

Il n'est pas douteux que le docteur Matignon ait raison et qu'il y ait là une des clefs les plus sûres pour expliquer ce qu'il y a d'incompréhensible dans la mentalité et dans la conduite des Célestes.

Dans leur grand ouvrage : L'Empire du Milieu, Elisée et Onésime Reclus se sont inspirés de la plupart de ces travaux, pour le portrait qu'ils ont tracé du Chinois. En dépit des renseignements contradictoires dont ils ont dû se servir, ce

${ }^{1}$ Superstition, crime et misère en Chine, p. 393. 


\section{Les Chinois}

Essai de Psychologie ethnographique.

portrait est assez exact. Pourtant, celui qui a vécu en Chine, qui y a suivi les événements et les multiples manifestations de ces dernières années, ne lit pas sans surprise des passages comme celui-ci :

« Dans les écoles, surtout, le caractère chinois se montre à son grand avantage. Jamais, pour ainsi dire. les élèves ne se permettent de troubler I'ordre quasi religieux des classes ou de négliger le travail qui leur a été demandé. Ils se montrent tels qu'ils seront pendant toute leur vie : dociles, avisés, laborieux, infatigables ; d'une gravité au-dessus de leur âge, ils n'en sont pas moins gais et dispos. Ils ne rient pas aux éclats comme l'enfant mongol ; comme lui, ils ne se laissent pas emporter par la colère ; ils ont déjà pleine conscience de leur dignité $d^{\prime}$ hommes civilisés ${ }^{1}$.

On ne saurait être plus violemment en contradiction avec la réalité, sur la plupart de ces points.

Un journal de Shanghaï, L'Écho de Chine, a justement publié récemment une lettre de Ning-po qui est à cet égard très édifiante. Après avoir raconté une mutinerie d'une école secondaire de Shaoshing (Tchékiang), au cours de laquelle la police avait arraché le directeur des mains de ses élèves qui voulaient lui faire un mauvais parti, ce correspondant écrivait :

« Cette affaire avait eu des précédents à Ning-po, où le directeur de l'École normale avait dû, pour éviter les coups dont on le menaçait, renvoyer deux élèves qui ne

${ }^{1}$ L'Empire du Milieu, p. 114. 


\section{Les Chinois}

Essai de Psychologie ethnographique.

plaisaient pas aux autres. Les exigences des élèves augmentent de jour en jour, ils en sont arrivés à exiger que le choix des professeurs leur soit confié ${ }^{1}$.

De nombreuses correspondances, adressées à ce même grand journal français d'Extrême-Orient, constituent, du reste, au point de vue spécial qui fait l'objet de ce livre, une précieuse mine de renseignements. Leurs auteurs, missionnaires, pour la plupart, installés aux quatre coins de cet immense pays, continuent ainsi, mais avec beaucoup plus d'exactitude, dans le réel, cette fois, et non plus dans le théorique, l'enquête commencée au XVIII ${ }^{e}$ siècle par leurs prédécesseurs.

Ces missionnaires, qui connaissent admirablement les Chinois, ont généralement, de ceux-ci, une opinion peu favorable. C'est ainsi que l'un d'eux, sinologue réputé et auteur de savants travaux sur l'Empire céleste, le père Wieger, dit, dans la préface de ses Textes historiques, parlant des Chinois à travers les âges :

«Étudiez ces caractères, toujours singuliers, rarement nobles, ordinairement puérils et vulgaires, trop souvent vils, immondes, bestiaux ou féroces. Si vous vivez longtemps en Chine, vous verrez toutes ces figures repasser sur la scène de la vie. Même rôle, même jeu, mêmes passions, même intrigue, même dénoûment : les noms seuls changent. Il ne se peut plus rien de neuf chez ce peuple suranné.

${ }^{1}$ L'Écho de Chine hebdomadaire du 15 janvier 1921. 


\section{Les Chinois}

Essai de Psychologie ethnographique.

@ 


\section{Les Chinois}

Essai de Psychologie ethnographique.

\section{LE CHINOIS}

TEL QU'IL EST 


\section{Les Chinois}

Essai de Psychologie ethnographique.

\section{La sensibilité chinoise. Ses manifestations contradictoires. L'instinct grégaire. La conception païenne de la vie. Le sentiment artistique. La nervosité.}

Il est généralement admis que les Célestes ont une sensibilité très médiocre et une absence complète de nerfs. Pour si indiscutée qu'elle soit, au point d'être passée à l'état d'axiome, cette opinion est erronée et bien des observations faites au cours de mes voyages la démentent catégoriquement. Il importe d'autant plus de rétablir la vérité à ce sujet que c'est précisément dans leur sensibilité particulière, et surtout dans leur nervosité, que I'on trouve I'explication de ce qui semble tout d'abord, chez eux, le plus singulier et le plus incompréhensible.

Bien des choses ont pu faire croire à cette insensibilité du Chinois : en première ligne, son attitude devant la mort, dont il n'a pas l'épouvante parce que sa conception de la survivance matérielle de l'esprit le préserve de toute angoisse à cet égard ; ensuite, sa faculté de résistance aux pires infortunes, son indifférence absolue du confort ; le fait aussi que des spectacles, des odeurs, des contacts, des incommodités, qui provoquent notre plus vif dégoût, ne le gênent nullement ; enfin, son impassibilité coutumière, due à un très lointain atavisme rituel. 


\section{Les Chinois}

Essai de Psychologie ethnographique.

Par suite de ces diverses apparences, la première impression du voyageur est conforme au préjugé courant. Plus tard, un regard attentif non seulement permet de rectifier ce jugement superficiel, mais impose même peu à peu une conviction diamétralement opposée. Le fils de Han, le rejeton des « Cent Familles », apparaît alors tout autre qu'on le décrit d'ordinaire. Malgré la vieillesse décrépite de sa race et l'attitude imperturbable et glacée, qui est habituellement la sienne, on lui découvre une réelle fraîcheur d'âme et une grande vivacité d'impressions. Nul ne goûte la vie avec plus d'ivresse. Il aime d'ailleurs les bêtes, les enfants, tout ce qui, comme lui, s'abandonne à l'instinct avec force et plénitude. C'est bien ainsi qu'on le comprend, quand on le voit, à la fin du jour, sortir de sa maison, une cage à la main. Presque tous les soirs, en effet, il va, quelquefois assez loin, au bord de la rivière, sur le rivage de la mer, ou au sommet d'une colline, pour faire jouir de I'heure et respirer le bon air à son oiseau favori. Que de fois I'ai-je aperçu, dans cette posture, un peu de tous les côtés de la Chine, écoutant, ravi, les trilles de son petit prisonnier.

Il y a certainement entre les Célestes et les bêtes une entente que nous ignorons. C'est dû sans doute à ce qu'ils sont, eux aussi, très près de la nature. Cela crée, entre les uns et les autres, un lien fraternel dont nous n'avons pas idée. Les Chinois pourraient dire, comme saint François d'Assise : « Mon frère le moineau ». J'en ai eu, un jour, sous les yeux, la plus gracieuse révélation. C'était, sur une place, à Shanghaï, dans la cité. Un 


\section{Les Chinois}

Essai de Psychologie ethnographique.

groupe d'enfants stationnait là, ayant, chacun, à la main, une baguette au bout de laquelle un oiseau était perché. L'une de ces petites bêtes ailées, ayant brisé le fil qui la retenait, s'était envolée sur un toit voisin et tous les bambins l'appelaient de loin, en lui montrant la boîte à mil. L'oiseau s'est avancé, tout sautillant, jusqu'au bord de la toiture, il a regardé un instant le groupe qui lui tendait les mains, puis il a pris son vol et il est venu se poser sur la baguette de son jeune maître qui n'en a pas semblé autrement surpris. L'incident était évidemment aussi coutumier que naturel. On ne saurait dire le charme intraduisible et bien chinois de cette petite scène.

Le Céleste ne borne pas aux animaux ce sentiment affectueux. Il l'éprouve également, en dehors même de la famille, pour son semblable. Il n'est pas d'homme qui ait plus que lui le culte et le besoin de l'amitié. On sait, par ce qui en a été dit souvent, ce qu'on entend, en Chine, par une « amitié jurée » et ce que celle-ci comporte de fidélité, de dévouement, d'assistance, entre deux individus, quelque diverses que puissent être par la suite leur situation sociale et leur fortune. Comme tous ceux, d'ailleurs, qui ont une sensibilité purement instinctive, les Célestes ne sont pas enclins à l'isolement, ils ont l'instinct grégaire ; ils aiment, dans la grouillante foule, sentir la chaleur du contact ; ils sont de ces Orientaux qui vont en se tenant par la main.

Sur certains points, sur ce qui le touche de plus près notamment, cette sensibilité du Chinois est celle de la sensitive. C'est ainsi qu'il est troublé et détourne la tête $s^{\prime}$ il vient à 


\section{Les Chinois}

Essai de Psychologie ethnographique.

rencontrer sa femme dans la rue, il feint de ne pas la voir et jamais, dans tous les cas, il ne la reconnaît ni ne la salue.

En toutes ces matières, sa délicatesse dépasse tout ce que nous pouvons imaginer. Même avec des courtisanes, sa galanterie est affinée à l'extrême ; au lieu d'affirmer brutalement son désir, il fait une cour très réservée, avec accompagnement de cadeaux, et cela dure parfois longtemps. Ces filles sont, du reste, à cet égard, d'une susceptibilité qui oblige à ces précautions. A un banquet offert par des « soyeux » chinois de Canton à des Européens qui m'avaient emmené avec eux, chaque convive avait, assise derrière lui, une de ces petites hétaïres, à laquelle de temps en temps il donnait une poignée de graines de pastèques prises sur la table. Voulant simplement être agréable à celle que j'avais ainsi près de moi et qui était fort gracieuse, je joignis, vers la fin du repas, à la poignée de graines, un dollar. J'avais fait la chose très discrètement et personne ne l'avait vue; elle ne me l'en rendit pas moins, toute rougissante de honte. J'avais évidemment agi, à ses yeux, comme un Barbare.

La littérature, du moins dans le roman et la poésie, en harmonie avec cette manière de se conduire, est le plus souvent d'une inspiration véritablement éthérée. Eckermann rapporte, dans ses Entretiens 1, qu'elle faisait I'admiration de Goethe, qui trouvait la nôtre lourde et grossière, comparée à celle-là. Certains contes l'enchantaient, par exemple : celui de la jeune fille dont les pieds étaient si légers, si gentils, qu'elle pouvait se

${ }^{1}$ Entretiens de Goethe et d'Eckermann, traduction J.-N. Charles, p. 114. 


\section{Les Chinois}

Essai de Psychologie ethnographique.

balancer sur une fleur sans la froisser ; celui du jeune homme dont la conduite fut si morale, si honnête, qu'il eut I'honneur, à trente ans, de parler à l'empereur ; celui de ces deux amoureux qui se montrèrent si chastes pendant un long entretien que, contraints une fois de passer la nuit dans une même chambre, ils employèrent toutes les heures à causer sans s'approcher.

D'une délicatesse extrême est aussi le soin de ne pas se servir, pour un emploi trivial, des papiers portant de l'écriture. On le préserve de toute souillure et, pour cela, il existe, dans bien des villes, de grands récipients de bronze, dressés généralement sur les places qui précèdent les pagodes; on y jette, pour les brûler, les papiers écrits ou imprimés qui traînent sur le sol. Ce respect de l'écriture est vraiment une chose supérieure et raffinée, digne d'admiration.

Ce qui est, pour nous, particulièrement déconcertant, c'est que ces caractéristiques, si remarquables chez le Chinois, ont en lui, et aussi fortement marqués, leurs contraires. Cet être si doux, si ami des hommes et des bêtes, si sensible, à la façon de notre XVIII $^{\mathrm{e}}$ siècle et de Jean-Jacques, est, en certaines circonstances, pour les uns et les autres, d'une inimaginable cruauté. Il n'y a pas de pays où l'art et le goût de faire souffrir soient poussés aussi loin. Celui-là même qui comble un oiseau d'attentions et de gâteries, a, dans des cages minuscules, des grillons qu'il dresse pour des combats affreux et sa joie est encore extrême de plumer, par exemple, jusqu'au dernier duvet un poulet vivant, pour le faire ensuite courir, devant lui, dans cet état. Mais c'est à l'égard de I'homme surtout que ce génie se 


\section{Les Chinois}

Essai de Psychologie ethnographique.

manifeste. Le supplice et la mise à mort d'un missionnaire, en Mandchourie, pendant les événements boxers, en sont une preuve éclatante. D'après ce que me raconta, plus tard, un de ses confrères, le père M..., procureur de la mission de QuangCheng-tzé, voici comment fut traité ce malheureux : Comme il était assez corpulent, les habitants de sa localité, qui s'étaient emparés de sa personne, le mirent à nu, et, lui ayant ficelé les mains et les pieds, ils le suspendirent à un bambou de coolie, pour le porter, ainsi qu'on fait d'un porc gras, à travers les rues de la ville. La population, qui faisait la haie, le piquait au passage de petits coups de couteau, calculés pour le faire souffrir sans I'achever. Cet amusement dura plusieurs jours. Quand on en fut las, pour finir, on lui fit scier le cou par un enfant de huit ans, avec un coutelas à dessein ébréché.

Cette cruauté n'est pas due seulement à la xénophobie ; à toutes les époques troublées, entre eux-mêmes, les Chinois s'ingénient pareillement. Ils n'ont pas notre respect de la vie humaine et la pitié paraît leur être totalement inconnue. L'assassinat est, pour eux, un acte légitime et, dans les polémiques des journaux, cette menace fait partie de la discussion. Un article du Tientoupao, en décembre 1912, commençait par cette phrase : «L'assassinat n'est pas toujours un crime, comme on le croit généralement ». Cela, joint à ce qu'ils n'ont aucun sens de la légalité et du droit des gens, fait qu'ils résolvent certains cas avec une sauvagerie expéditive. En 1913, la mission catholique de Nan-ning, au Kouang-Si, ayant demandé l'autorisation de construire un hôpital, pour y recueillir les lépreux, nombreux dans cette région, les autorités 


\section{Les Chinois}

Essai de Psychologie ethnographique.

préférèrent se débarrasser de ceux-ci d'une manière plus radicale. Elles firent creuser un puits au fond duquel on jeta du bois imprégné d'essence inflammable. On rabattit sur ce brasier, à coups de baïonnette, tous les lépreux que l'on put trouver et qui furent ainsi brûlés vifs en présence d'une foule nombreuse. L'informateur de I'Agence Reuter, qui faisait connaître cet exploit, ajoutait que les autorités s'enorgueillissaient de s'être débarrassées aussi promptement de ces malades contagieux.

Cette inhumanité est si naturelle au Chinois qu'elle est souvent dénuée de toute malice. Un petit fait que me conta un missionnaire de Souatao le montre bien sous ce jour, dans toute son ingénuité. Ayant appris qu'une famille avait vainement tenté de noyer une petite fille de douze ans, qui était idiote et qui avait, chaque fois, réussi à se sauver, il s'était rendu chez les parents et leur avait proposé de leur acheter cette malheureuse enfant. Ils la lui vendirent pour très peu de chose et le père, honnête homme, simple, le dissuadait d'abord de conclure un aussi mauvais marché : «Elle n'est bonne à rien, lui disait-il, qu'à vous manger du riz ».

La si délicate pudeur, mentionnée plus haut, a également sa contre-partie d'une invraisemblable crudité, obscène et grossière. Une dame, du monde diplomatique de Pékin, me dit, un jour, qu'il était assez difficile d'inviter à dîner des Chinois parce qu'ils avaient l'habitude de tenir des conversations très scabreuses dans les termes les plus inconvenants.

Dans le même ordre de faits, un interprète me rapporta que, Iorsqu'il était à Yun-nanfou, le fantaï Li King-chi, neveu de Li 


\section{Les Chinois}

Essai de Psychologie ethnographique.

Hung-chang et promu par la suite vice-roi, lettré du type le plus vieille Chine, étant venu voir le consul, lui tint, au cours d'une causerie familière, sur son bon état de santé, des propos d'une scatologie répugnante. Cela le plus naturellement du monde, comme une de ces choses dont on a coutume de parler.

Le même fonctionnaire, lancé sur ce chapitre de l'obscénité chinoise, me raconta encore que la fille d'un banquier de cette même capitale provinciale se livra très ostensiblement, au cours d'une réunion, sur la personne d'un étranger de marque, à une investigation particulièrement audacieuse. Il est certain que, dans la pensée de cette jeune Chinoise, ce geste n'avait pas le caractère de provocation effrontée qu'il aurait eu chez nous. C'était simplement le mouvement de curiosité un peu espiègle d'une enfant terrible.

Évidemment, les Célestes n'ont pas nos idées sur ce point. Les allusions aux actes sexuels, leur reproduction par l'image, qui, pour le puritanisme occidental, font l'impression d'une obscénité révoltante, ne sont pas, à leurs yeux, immorales. Aussi cela s'étale-t-il partout, en toute liberté. Je me rappelle avoir vu des marchands de gravures de l'érotisme le plus accusé, le plus cynique même, et dont la vente serait, chez nous, sévèrement interdite, montrer leur marchandise au coin des rues, devant un cercle d'amateurs au premier rang desquels il y avait, sans que cela offusquât personne, des enfants.

Le plus extraordinaire, pour notre mentalité à nous, c'est que ces dessins ont souvent un but pédagogique ; il s'agit d'instruire 


\section{Les Chinois}

Essai de Psychologie ethnographique.

la jeunesse; on en fait des albums destinés à l'instruction des jeunes filles des meilleures familles.

Les Chinois ont toujours eu la spécialité de cette imagerie spéciale. Casanova fait dire à une des héroïnes de ses Mémoires, qui se vantait de son insensibilité :

« Je ne suis pas si facile à recevoir une impression, car j'ai un cabinet que le duc a fait tapisser en tentures chinoises dont les personnages représentent une foule d'attitudes amoureuses. Nous y allons quelquefois et je t'assure qu'elles ne me causent pas la moindre sensation ${ }^{1}$.

Il en est de même dans tout l'Extrême-Orient. En ce qui concerne le Japon, le Journal des Goncourt s'exprime en ces termes:

« Ces images ne seraient pas, comme on l'a cru jusqu'ici, des images à l'usage des maisons de prostitution, elles seraient destinées à faire l'éducation des sens des jeunes mariés ; et dans un volume, illustré par la fille d'Hokousaï, racontant le mariage et ses épisodes, on voit, roulée près du lit des jeunes époux, une série de makimono qui doivent être une collection de ces images ${ }^{2}$.

Les journaux chinois sont pleins d'annonces que les étrangers poursuivent en justice sur le territoire de leurs concessions. De

\footnotetext{
${ }^{1}$ Édition Garnier, t. V, p. 255.

2 T. VIII, p. 128.
} 


\section{Les Chinois}

Essai de Psychologie ethnographique.

même pour les négociants qui affichent, sur les murailles, des réclames impudiques. En voici un cas récent rapporté par l'Écho de Chine ${ }^{1}$ :

« Mardi dernier, y lit-on, le nommé Zung Yu-tze, directeur de la droguerie connue sous le nom de Tieh Thien Daung Drug Firm, a passé devant la Cour mixte internationale pour exhibition de gravures obscènes en guise d'annonces.

« L'avocat du prévenu déclara : « Mon client m'a informé que ces annonces étaient placardées dans les concessions depuis dix ans et que si les étrangers les considéraient comme immorales, elles ne passaient pas pour telles aux yeux des Chinois.

Dans les journaux, ces annonces sont principalement faites par les pharmaciens. Il s'agit surtout de recettes destinées à rendre la vigueur sexuelle, et cela est indiqué de la manière la plus précise et la plus crue. Le plus usité de ces remèdes est, du reste, à base de semence humaine. Cela n'est pas nouveau, puisque John Barrow parle d'une véritable science de la pharmacopée chinoise, ignorée des Européens, et qu'il appelle : la spermatologie 2 .

Le théâtre aussi «brave I'honnêteté » avec une verve qui égale, si elle ne la dépasse, celle des Latins. Je le constatai, un soir que j'étais allé dans une salle de spectacle indigène de la Concession française, à Shanghaï. Au cours de la pièce comique

${ }^{1}$ Écho de Chine hebdomadaire, 17 mai 1919.

${ }^{2}$ Voyage en Chine, t. III, p. 46. 


\section{Les Chinois}

Essai de Psychologie ethnographique.

qu'on jouait, une scène eut un grand succès. C'était un dialogue fort vif entre un personnage à grosses moustaches et à lunettes et une petite femme, gracieuse et mignarde, qui devait être, du reste, selon l'usage, un jeune garçon. Sans comprendre la teneur littérale des propos qu'ils échangeaient, il n'était pas difficile, aux gestes, d'en deviner la signification très égrillarde. L'acteur, en effet, à chacune de ses phrases, lancées avec un entrain irrésistible, visait tour à tour, de la main, certaines parties du corps de son interlocutrice. Celle-ci, à chaque tentative, donnait de petites tapes sur les doigts de l'insolent, en se cachant le visage derrière l'éventail.

Le public, composé d'hommes, de femmes et d'enfants en grand nombre, qui, tous, se bourraient de bananes, de pastèques et de pâtisseries, s'esclaffait de ces plaisanteries «salées », bien loin de se douter de ce que notre morale morose pouvait trouver là de repréhensible. Un gamin d'une dizaine d'années, non loin de moi, ne cessait de rire, d'un rire qui faisait disparaître ses yeux et fendait sa bouche jusqu'aux ÿ oreilles. C'était obscène et familial, c'était bien chinois et, en somme, charmant.

Les appétits sensuels sont à coup sûr la manière dont se manifeste surtout la sensibilité des Célestes. Leur conception de la vie est à cet égard celle du paganisme ancien. Un état social identique en permet d'ailleurs la même réalisation. En Chine, comme dans la Rome des Césars, la fréquence des disettes et de l'extrême misère du plus grand nombre, ainsi que l'existence de I'esclavage, facilitent singulièrement la recherche de tous les 


\section{Les Chinois}

Essai de Psychologie ethnographique.

plaisirs à ceux qui disposent de la puissance et de la richesse. De là, sans doute, la similitude des mœurs. A cet égard, il est intéressant de rapprocher ce que le docteur Matignon rapporte de l'éducation des «Sian-kon », auxquels on enseigne la musique, la poésie et l'art des répliques vives et spirituelles, de ce que Martial et Stace disent des jeunes esclaves alexandrins qu'ils appellent : «les doctes enfants du Nil ».

Tout un commerce de filles et de garçons est ainsi suscité par les besoins de villes comme Pékin, Canton et Shanghaï. Il est alimenté par la vente des enfants qui a lieu en tous temps, mais surtout aux époques de famine, et aussi par leur enlèvement. L'un des crimes les plus fréquents, dont les tribunaux des concessions étrangères ont à juger, est le vol d'enfants. Ce même vol est l'une des principales opérations des bandes de pirates des rivières du Sud, dans la région cantonnaise, où il se pratique sur une échelle très vaste ${ }^{1}$.

Les Chinois ont un naturel si salace que beaucoup d'entre eux, surtout dans la classe des lettrés et des riches marchands, sont en proie à une obsédante érotomanie. Un étranger de Shanghaï, dont le caractère sérieux engageait pourtant peu à de telles confidences, en correspondance avec un secrétaire de légation depuis peu en Europe, me dit qu'il ne recevait, de lui, que des histoires de «petites femmes », avec, à l'appui, des photographies ou des cartes postales très suggestives. Visiblement, la capitale dans laquelle il se trouvait, pourtant riche en ressources diverses, précieuses pour l'étude de la

1 Voir le Céleste Empire avant la Révolution, p. 80 et suiv. Bien loin d'améliorer cette situation, la révolution l'a encore aggravée. 


\section{Les Chinois}

Essai de Psychologie ethnographique.

civilisation occidentale, n'intéressait le jeune diplomate qu'à ce point de vue-là.

Pour toutes ces raisons probablement, la seule science que possèdent à un degré supérieur les Célestes, est celle du plaisir et des moyens propres à l'accroître, en le renouvelant, particulièrement des aphrodisiaques. Leur pharmacopée est à ce sujet aussi curieuse qu'abondante. $\mathrm{Si}$, en toutes autres matières, ils se sont arrêtés à mi-chemin, pour celle-là, ils sont allés jusqu'au bout. De même, rien ne les arrête dans l'exercice de leur passion dominante : Jeu, opium, voluptés charnelles ; ils s'y adonnent tout entiers, sans restriction ni limite prudente, jusqu'à la ruine matérielle complète ou la dernière usure physique. C'est certainement en Chine qu'on voit les plus impressionnantes têtes de viveurs.

Le petit peuple a les mêmes penchants et il y satisfait dès que I'envie lui en vient, sans se préoccuper de I'heure. Une promenade dans le Foochow road de la concession internationale de Shanghaï, qui est le quartier de la fête chinoise, permet de s'en rendre compte. Certes, c'est principalement le soir que I'affluence y est énorme, dans une véritable ruée au plaisir, mais en plein jour, on est surpris d'y voir les maisons de thé, les théâtres, les concerts de chanteuses et d'autres lieux plus secrets, pleins de chalands. Le Chinois, dont la vie quotidienne se soumet à tant de petites règles méticuleuses, est, à cet égard, un fantaisiste qui n'admet aucune contrainte. 


\section{Les Chinois}

Essai de Psychologie ethnographique.

Ce qui contredit encore cette opinion que le Chinois n'a pas de sensibilité, c'est son instinct d'art et de poésie. Incontestablement, à ce point de vue, la moyenne des Célestes est supérieure à la nôtre. Il n'est pas d'autre pays où les boutiques soient, comme partout en Chine, de véritables bijoux d'orfèvrerie précieuse. A l'intérieur des maisons les plus modestes, généralement autour de l'autel des ancêtres, il y a toujours quelques peintures en kakémonos : paysages, fleurs, feuillage de bambous, cigognes volant à tire d'ailes vers une lune rouge, et souvent même un décor de boiseries finement sculptées, laquées et dorées, reproduisant des sujets de légendes ou un entrelacs de feuilles et de fruits. Chez nous, à niveau égal, par quels horribles chromos ne satisfait-on pas ce goût de décoration, quand il existe. Dans la rue, les enseignes commerciales, avec la zébrure élégante et capricieuse de leurs caractères si originaux, sont, à elles seules, une fête pour les yeux.

Que dire aussi de la musique qui accompagne les moindres actions, de l'appel prolongé des colporteurs entre deux sonorités de gongs, du chœur des mariniers levant la voile rectangulaire ou poussant, debout, la longue rame, vraie évocation de l'antique ; du cri même des coolies portant les lourds fardeaux sur un rythme à deux voix du plus mélodieux effet ?

A ce sentiment artistique, inné, s'ajoute, - bien qu'on ait dit que le Chinois est médiocrement imaginatif, - l'imagination la plus rêveuse et la plus portée aux fantasmagories. Callery et Yvan ont bien vu cela. 


\section{Les Chinois}

Essai de Psychologie ethnographique.

« Les Chinois ne se lassent pas, disent-ils, de contempler les œuvres de la nature, à condition, toutefois, que leur imagination pourra y découvrir quelque forme indécise, quelque image bizarre. Les touristes du Céleste Empire font, devant les rochers du Kouang-Si, un travail de contemplation analogue à celui auquel se livrent certains individus devant les tabatières de buis. Ils veulent absolument qu'elles soient peuplées $d^{\prime}$ images que leurs yeux prévenus seuls y découvrent ${ }^{1}$.

Grâce à cette propension à la rêverie, alimentée par l'imagination la plus fantaisiste, le Chinois peut passer des heures, immobile et contemplatif, dans sa boutique aussi bien que devant un coin de belle nature. Les colorations d'un caillou, les veines d'un fragment de marbre, suffisent pour mettre en mouvement cette merveilleuse faculté créatrice. Il verra, dans I'un, toutes les somptuosités d'un soleil couchant et, dans l'autre, des cimes de hautes montagnes où les masses sombres des sapins se profilent sur la blancheur des neiges. Le caillou sur un socle de bois dur, travaillé à jour, et le marbre dans un cadre de luisant ébène, placés de manière à ce que son regard les rencontre, seront, pour lui, d'inépuisables motifs de rêve. De là, ses jardins de rocailles et de grottes factices, de lacs lilliputiens et de bosquets minuscules, où tout est proportionné de telle sorte que l'esprit peut y vagabonder comme sur les plus vastes horizons. Du reste, devant un panorama de vraies montagnes et les masses profondes de forêts réelles, il découvrira, dans leurs

${ }^{1}$ L'Insurrection en Chine, p. 98. 


\section{Les Chinois}

Essai de Psychologie ethnographique.

lignes capricieuses, toutes sortes d'images fantastiques, à commencer par le dragon. Et c'est pourquoi, sans doute, l'art des dessinateurs et peintres célestes, bien loin d'être basé, comme celui des nôtres, sur l'observation la plus exacte des choses et de leur atmosphère, reste dans le domaine de l'irréel.

Peut-être faut-il aussi penser à tout cela pour comprendre l'irrésistible attrait qu'a, pour les hommes de cette race, ce dispensateur par excellence de rêve : I'opium.

Après ce que I'on sait de la psycho-physiologie en général, on ne peut guère supposer que l'être dont nous parlons n'a, ainsi qu'on le prétend, pas de nerfs. Non seulement il en a, mais c'est même un névrosé, le $D^{e}$ Matignon, on l'a vu, dit : un hystérique.

Étant donnée l'opinion courante, je fus, au début, très surpris par les manifestations diverses de cette nervosité. Aussi les observai-je de mon mieux à cet égard, tontes les fois que j'en eus l'occasion. Quand les Chinois montent, par exemple, dans un train, sur un quai de gare et, bien plus encore, quand ils s'embarquent sur un bateau fluvial, dont l'arrêt est fort court, j'ai vu cela souvent sur le Yangtsé et dans les rivières du Sud, ils se précipitent, comme affolés, passent les uns sur les autres, se piétinent, avec des cris affreux. On dirait, chaque fois, un mouvement de panique, et c'est exactement ce qui dut se passer sur l'Athos, coulé, au cours de la dernière guerre, par une torpille, en Méditerranée.

«Sauf un contingent de travailleurs chinois, raconta un correspondant de journal, qui perdirent la tête et se 


\section{Les Chinois}

Essai de Psychologie ethnographique.

noyèrent faute de discipline, presque tous les passagers, y compris des compagnies sénégalaises admirables de sang-froid et d'héroïsme, purent être recueillis sur les torpilleurs d'escorte ${ }^{1}$.

On ne peut s'imaginer à quel point d'invraisemblance peuvent atteindre ces réactions nerveuses. Tel est le fait, que j'ai relaté dans les Scènes de la Vie révolutionnaire en Chine ${ }^{2}$, de la fuite générale de deux partis en lutte, dans une petite ville du Yangtsé, devant un appareil de photographie braqué par des missionnaires. Les uns étaient des pirates, mais l'autre parti, composé d'habitants avec lesquels marchaient les missionnaires, savait pourtant à quoi s'en tenir sur ceux-ci et sur leur machine : il n'en fut pas moins emporté par la frayeur communicative de ses adversaires. L'anecdote est authentique et a été racontée par le Père Courtois, dans l'Écho de Chine, pendant la Révolution. Au mois d'octobre 1913, lors de l'élection de Yuan Chi-kaï à la présidence de la République, un photographe ayant voulu prendre, aussitôt après le scrutin, une photographie de l'Assemblée, la petite explosion de magnésium provoqua, parmi les représentants, une panique indescriptible. Tous se précipitèrent, en se piétinant et en hurlant, vers les portes.

Ce que j'ai aussi toujours remarqué, c'est l'incapacité du Chinois à se conduire dans la rue. Cet homme, si adroit de ses mains, pour certains travaux exécutés tranquillement chez lui, est, dehors, au milieu des autres passants, fort maladroit de sa

${ }^{1}$ Le Temps, $1^{\text {er }}$ août 1917.

${ }^{2}$ Les Angoisses d'une petite ville. 


\section{Les Chinois}

Essai de Psychologie ethnographique.

personne. Il va, tête baissée, il fait des crochets brusques ou se retourne sans se préoccuper de savoir s'il n'y a aucun inconvénient. Personne n'est plus susceptible que lui de se jeter devant une voiture ou sous un tramway. Ce genre d'accidents est fréquent dans les concessions de Sanghaï ou les véhicules de toutes sortes abondent. Cela indique qu'a aucun moment il n'a le sang-froid nécessaire et qu'il n'agit que par réflexes.

Une querelle entre deux Chinois est un spectacle fort curieux qui ressemble à une crise de delirium tremens, et, quand ils en viennent à se battre, c'est le plus souvent avec les griffes, comme les femmes et les chats. A Pékin, pendant le mouvement constitutionnel de $1910-11$, et à Shanghaï, pendant la Révolution, les rares étrangers qui ont eu l'occasion d'assister à des réunions publiques, - au cours desquelles, parfois, quelque exalté se faisait une incision pour écrire une lettre au sang ou même se coupait un doigt, - en sont revenus avec l'impression pleine de malaise de s'être trouvés au milieu des sujets d'une étrange Salpêtrière.

A Canton, à cette même époque, l'énervement était tel parmi les innombrables volontaires qui parcouraient en armes les rues étroites de la cité marchande, qu'au moindre bruit insolite les fusils partaient tout seuls, faisant des victimes un peu de tous les côtés.

Les faits de cannibalisme qu'on relève chez les Chinois sont certainement dus à cette frénésie morbide. Ces supra-nerveux poussent l'exaspération et la haine de l'ennemi jusqu'à le manger. On mange volontiers le foie parce qu'on croit s'assimiler 


\section{Les Chinois}

Essai de Psychologie ethnographique.

ainsi le courage dont cet organe passe pour être le siège, mais, dans les cas de grande surexcitation, on dévore la chair de n'importe quelle autre partie du corps.

L'agent consulaire de France, à Hokéou, poste chinois qui fait face à notre poste frontière de Laokay, dans le haut Tonkin, $M$. D..., m'a rapporté avoir vu des soldats faire un repas de ce genre avec le foie de révolutionnaires exécutés, lors de la rébellion du Yunnan, en 1904. J'ai mentionné ailleurs cette anthropophagie d'après des correspondances d'un missionnaire de Setchoan à I'Écho de Chine ${ }^{1}$ et aussi d'après ce qui me fut raconté à moimême à Hankéou, dans la période des combats qui suivirent la révolution ${ }^{2}$. Un autre correspondant écrivait au même journal, au cours du conflit qui éclata à cette époque entre le Thibet et la Chine républicaine, que les Thibétains avaient « habillé » avec sa propre peau, puis « dépouillé » et « vidé » le préfet chinois de Batang. Puis il continuait ainsi :

«En guise de représailles, les soldats républicains ont mis à mort leurs prisonniers, après leur avoir infligé mille tourments que Néron, malgré sa diabolique imagination, n'aurait jamais inventés, et leur ont octroyé, comme sépulture, le hideux tombeau de leurs anthropophages estomacs ${ }^{3}$.

Ces pratiques abominables semblent naturelles aux Célestes ; ils en parlent couramment. Au moment de la

\footnotetext{
${ }^{1}$ La Fin des Mandchous, p. 172.

2 Scènes de la Vie révolutionnaire en Chine, p. 233.

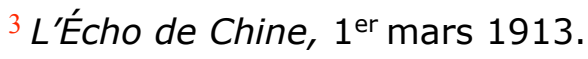




\section{Les Chinois}

Essai de Psychologie ethnographique.

campagne nationaliste contre le ministre des Communications, Cheng Kong-pao, à propos d'une manifestation qui avait eu lieu à Canton, le Mingliépao de Shanghaï écrivait :

« Tous les Cantonnais veulent manger la chair de ce traître.

Le Senpao, également de Shanghaï, racontait de son côté :

« Alors tout le monde s'est mis à manger du gâteau et beaucoup de Cantonnais sont mêmes allés jusqu'à dire qu'en le mangeant, ils ne faisaient que manger la chair de Cheng Kong-pao.

Tous ces indices, auxquels on pourrait encore en ajouter d'autres, auraient suffi pour me convaincre de la nervosité anormale des Chinois, mais j'ai voulu avoir en outre l'opinion des médecins et j'ai interrogé à ce sujet ceux que j'ai eu la bonne fortune de rencontrer là-bas au cours de mes voyages. A ma question sur l'axiome du Chinois sans nerfs, le docteur F..., de Shanghaï, m’a répondu :

- Le Chinois sans nerfs ! mais c'est un névropathe, un hystérique et un neurasthénique. De plus, c'est un mauvais malade qui se plaint beaucoup et qui est difficile à soigner parce qu'il se frappe.

Son confrère, le docteur P..., qui exerçait dans la même ville, m'a fait une réponse analogue.

Le docteur M..., de Hankéou, me dit, au moment même où les alternatives de la lutte dans cette région faisaient passer successivement entre ses mains des blessés de l'armée impériale 


\section{Les Chinois}

Essai de Psychologie ethnographique.

et de l'armée révolutionnaire, que les soldats du Nord supportaient bien la souffrance, mais que ceux du Sud étaient si douillets qu'ils rendaient toute intervention chirurgicale presque impossible. Ceci est d'autant plus caractéristique que les soldats sont, en Chine, du plus bas peuple.

Le docteur C..., de Canton, voulut bien rédiger par écrit, à mon intention, la consultation suivante :

« C'est une opinion communément acceptée par les Européens que les Chinois présentent à la douleur physique une résistance plus grande que d'autres peuples et notamment les peuples de race blanche, Les Chinois, a-t-on coutume de dire familièrement, n'ont pas de «nerfs » et par là on sous-entend que I'invraisemblable calme extérieur, qui est une des caractéristiques de leur personne morale, se retrouve, dans le domaine physique, sous forme d'une indifférence plus grande à la douleur.

«Quatre années de pratique médicale à Canton nous ont convaincu qu'une telle opinion est complètement erronée. Il nous paraît que non seulement les Chinois redoutent la douleur à l'égal des autres races, mais encore qu'ils font preuve à cet égard d'une pusillanimité particulière. Nous avons pu constater combien peu, devant la souffrance physique, les Célestes savent commander à leurs nerfs. Il n'est opération de petite chirurgie, si insignifiante soit-elle, pour laquelle ils ne réclament à cor et à cri l'anesthésie générale, se 


\section{Les Chinois}

Essai de Psychologie ethnographique.

soustrayant à nos soins si elle leur est refusée ${ }^{1}$. L'avulsion d'une dent cariée, même déchaussée et branlante, est reculée indéfiniment sur leur demande, uniquement par crainte du davier. Toute exploration plus ou moins douloureuse entraîne de leur part des grimaces, des cris et des mouvements de recul hors de proportion avec la souffrance provoquée, plus marqués certainement que les manifestations du même ordre chez les malades européens.

« Il faut cependant distinguer. Ce qui précède s'applique surtout au Cantonnais, affiné et plutôt débile, mais serait moins vrai des montagnards du Kouang-si ou du Hounan. Ceux-ci, nous semble-t-il, opposent à la douleur des réactions un peu moins vives que les Européens d'une classe sociale équivalente.

« Un autre fait prouve que les Chinois ont des « nerfs », des nerfs très excitables ou très dépressibles, c'est le grand nombre de névrosés qu'on trouve parmi eux.

Un médecin américain, spécialisé en neurologie, le docteur Woods, nous disait que I'hystérie convulsive est plus fréquente à Canton que dans les villes des EtatsUnis qui sont pourtant la terre d'élection des névroses.

Pour notre part, nous en avons observé, même chez les hommes, de nombreux cas. Plus fréquente encore est la neurasthénie, surtout parmi les jeunes lettrés des

${ }^{1}$ On a vu plus haut, page 99, que John Barrow signale, au XVIII ${ }^{\mathrm{e}}$ siècle, cette nervosité spéciale des Célestes, qui rend presque impossible, avec eux, toute chirurgie. 


\section{Les Chinois}

Essai de Psychologie ethnographique.

écoles chinoises, soumis à un travail cérébral épuisant dans des conditions d'hygiène défectueuses. Nous ajouterons que ces malades, dont le traitement est en tous pays fort délicat, sont particulièrement difficiles à soigner. Le fossé profond qui sépare notre âme de la leur voue à un échec certain toute tentative de suggestion et, d'autre part, l'esprit d'observation si aiguisé des Chinois, se tournant vers l'examen de leurs symptômes, en fait des analystes aussi minutieux et prolixes qu'impitoyables pour la patience du médecin.

Ces divers diagnostics, émanant de praticiens résidant dans des régions très différentes de la Chine, joints à celui du docteur Matignon, qui fit ses observations à Pékin, à l'époque, particulièrement fertile en manifestations nerveuses, du soulèvement boxer, corroborent pleinement les réactions de cet ordre qui m'ont frappé chez le Chinois.

Celui-ci, en dépit de I'opinion vulgaire, a incontestablement des nerfs et des nerfs singulièrement à vif.

On doit d'autant plus tenir compte de ces « nerfs » qu'à mon humble avis ils expliquent une bonne part de ce qui est soidisant inexplicable, aussi bien dans sa vie mentale que dans son existence quotidienne.

Il serait donc très utile de l'étudier méthodiquement à ce point de vue. C'est pourquoi il faudrait charger de missions en Chine, plutôt que des hommes politiques figés dans des formules, des neurologues et des psycho-physiologues comme il 


\section{Les Chinois}

Essai de Psychologie ethnographique.

y en a maintenant quelques-uns dans notre jeune école de philosophie expérimentale.

(a) 


\section{Les Chinois}

Essai de Psychologie ethnographique.

\section{Le stoïcisme et l'insouciance. La pusillanimité. Les armes du faible. Le « squeeze». La « face ». L'instinct anarchique.}

Ce névrosé fait, dans la vie courante, un être assez singulier, complexe et déconcertant. Continuons de rechercher, sous les apparences, ses vraies caractéristiques. Et d'abord, d'une manière bien inattendue et tout à fait contraire aux conséquences qu'entraîne d'ordinaire une pareille constitution physique, il a une exceptionnelle force de résistance au mal. Il la doit sans doute à sa longue expérience des catastrophes de toutes sortes, qu'elles viennent de la malignité des hommes : abus mandarinaux, révolutions, pillages et massacres, ou de la nature : disettes, inondations, épidémies, si nombreuses et virulentes en Chine. Il fuit, s'il le peut, dans tous les cas, il « rapetisse son cœur » et subit patiemment l'épreuve. Après la tourmente, souvent sa maison est détruite, sa boutique pillée, son champ dévasté, sa femme et ses enfants disparus. Il reconstruit, il reprend la charrue ou son commerce de gagnepetit, il reconstitue un autre foyer et fait de nouveaux rejetons. Je lui ai vu cette résignation et cette endurance en Mandchourie, pendant la guerre et, pendant la révolution dernière, dans divers 


\section{Les Chinois}

Essai de Psychologie ethnographique.

coins de la Chine. Et j'ai assisté ainsi en quelque sorte à sa résurrection. A Canton, au lendemain des plus dures secousses, j'ai vu l'énorme ville et la rivière, un moment terrorisées et désertes, reprendre leur vie allègre et intense, comme si rien ne s'était passé. Sur le Yangtsé, le formidable centre de Hankéou, incendié et anéanti, au milieu des ruines duquel je m'étais promené un an auparavant, je le retrouvais en pleine renaissance, la populace grouillant de nouveau, dans des rues éblouissantes de lumière électrique. J'ai dit alors l'admiration que m'inspirait cette vitalité merveilleuse, ce perpétuel miracle de la Chine triomphant ainsi de toutes les puissances de destruction et de mort.

Cet amoureux du plaisir, ce voluptueux, est d'ailleurs tout le contraire d'un sybarite. Il n'est pas d'homme au monde, d'une civilisation égale à la sienne, qui se satisfasse d'aussi peu et qui ait son insouciance du confort. Sauf ceux, très rares, qui, dans les grands ports, imitent notre manière de vivre, les Célestes, même très aisés, ont en effet les intérieurs les plus simples, les plus sommaires, mangent, tous groupés, patrons et employés, maîtres et domestiques, autour de la même table, la même cuisine traditionnelle à base de riz, et couchent sans se déshabiller, sur de très minces matelas, voire des nattes, avec, pour supporter la tête, de minuscules oreillers fort durs, parfois même de bois ou de porcelaine.

Ce dédain du confortable va du reste beaucoup trop loin, jusqu'à la malpropreté. Chez des personnages même de haut rang, j'ai constaté, dans tout ce qui sert aux repas et dont nous 


\section{Les Chinois}

Essai de Psychologie ethnographique.

avons, nous, tant de soin : assiettes, verres, etc., une saleté surprenante. Un secrétaire d'ambassade, rentrant d'Europe, que j'avais invité au grand hôtel du quartier des Légations, à Pékin, et qui y avait fait, avec exagération même, la « fine bouche », difficile et accoutumée à notre luxe de table, me rendit la politesse dans un restaurant chinois de Shienmen, parfaitement répugnant, où il goinfra, tandis que je ne pouvais vraiment toucher à rien. Au surplus, ils mangent gloutonnement, sans délicatesse ni retenue. Il m'est arrivé d'avoir, à ma table, à I'hôtel, des mandarins d'une certaine importance ; ils bâfraient si voracement que les boys eux-mêmes, bien que Chinois, mais ayant l'habitude de la mesure européenne, les considéraient avec le plus évident mépris.

Ces Célestes de qualité - sauf quelques-uns qui, ayant vécu parmi nous, savent maintenant que ces choses-là ne se font pas entre gens civilisés, - ont la détestable habitude de tirer de leurs narines, à grand renfort de reniflements, d'énormes crachats dont ils étoilent le parquet. Invité, à mon premier voyage, quelques années avant la révolution, chez un maréchal tartare, j'eus la désagréable surprise de voir les convives se livrer à cet exercice pendant le repas. C'est une musique que I'on entend d'ailleurs de tous côtés dans les rues chinoises, où le sol est gras de ces déjections.

Cette absence radicale de propreté se rencontre dans les endroits les plus inattendus. Lors d'une de mes entrevues avec le président Yuan Chi-kaï, aux palais impériaux, à la fin de l'audience, après avoir suivi les plus délicates galeries de bois 


\section{Les Chinois}

Essai de Psychologie ethnographique.

laqué, sous des plafonds de chinoiseries aux couleurs vives, mon guide, modifiant l'itinéraire habituel, où tout était irréprochable, me fit traverser des salles où je vis, dans les coins, des tas de détritus et des ruisselets d'urine. Nous allions faire une visite au fils aîné du Président. Nous le trouvâmes vêtu d'une robe de soie blanche fortement teintée autour du cou et il était assis sur un fauteuil dont la housse avait, derrière la tête et à l'endroit où se posaient les mains, de larges taches graisseuses. L'état maladif de ce jeune homme, à la suite d'un accident de cheval, ne suffisait tout de même pas à justifier un pareil laisser-aller.

Dans le peuple : petits marchands et agriculteurs, mariniers, colporteurs et coolies, cette indifférence du bien-être est poussée à un degré invraisemblable. Ceux-là ont des besoins tout à fait rudimentaires et tout leur est bon pour les contenter. Ils ne méprisent du reste rien et ramassent, pour s'en servir, tout ce que les autres mettent au rebut. Mais c'est en fait de vêtements peut-être qu'ils sont le moins difficiles. Il y a des habits, luisants d'antique crasse, qui ont déjà été portés par plusieurs générations et dont l'ouate hivernale s'échappe par de multiples déchirures ; vendus au fripier, ils trouvent encore des amateurs. A Hei-Loun-cheng, pendant la guerre de Mandchourie, après une exécution où dix têtes étaient tombées sous le sabre du bourreau, j'ai vu la foule chinoise se précipiter sur les cadavres, les mettre à nu et se disputer leurs effets sanglants.

Les plus étonnants sont à coup sûr les coolies qui, dans une existence très pénible et à peu près complètement dénuée, en dehors de la pitance quotidienne, conservent une insouciance 


\section{Les Chinois}

Essai de Psychologie ethnographique.

sereine et la plus inaltérable gaieté. Je les ai toujours observés avec intérêt sur le quai des ports, deux à deux, pliés sous le bambou où se balançaient les lourdes balles de marchandises, allant et venant des cargos aux docks, dans un mouvement continu, plein d'allégresse, et une rumeur de cris admirablement rythmés. Mais c'est peut-être au large, dans la baie de Takou, en face de la cote du Petchili, que je les ai vus mener la vie la plus dure. Le manque de fond fait que les bateaux ne peuvent passer la barre du Peï-ho avec le plein de leurs cales ; ils jettent donc l'ancre à une distance telle qu'on ne voit pas le rivage. De gros chalands viennent se coller à leurs flancs et on passe là des heures à contempler le travail de chargement ou de déchargement. Le spectacle que m'ont donné les coolies en action m'a, chaque fois, préservé de l'ennui d'un aussi long arrêt en pleine mer. Ils grouillent, sur ces pontons de fer, vêtus de loques sordides, la tête et la tresse enserrées par un chiffon de toile terreuse. Leurs misérables hardes sont pliées et roulées dans une affreuse natte qui leur sert de literie, car ils couchent là pendant des semaines et parfois par très mauvais temps. Quand il n'y a plus rien à faire sur le chaland, ils passent sur un autre avec leur petit baluchon.

Au moment de l'amarrage, ils se démènent comme des diables. Pour une planche à poser, un table à tirer, tous crient leur avis à pleine gorge. Quand la besogne est en train, ils n'arrêtent pas de rire, de plaisanter ou de chanter comme des perdus. Si l'un d'eux se trouve fatigué ou a envie de faire un petit somme, il s'écarte sans que personne lui dise rien et il s'en va dormir, étalé au soleil. Étant payés selon le nombre de 


\section{Les Chinois}

Essai de Psychologie ethnographique.

fardeaux qu'ils ont portés, ils n'abusent pas de cette licence. Quoi qu'il en soit, ils sont bien loin de donner l'impression d'être malheureux.

D'autres joyeux drilles, ce sont encore les tireurs de poussepousse et les porteurs de chaise. On ne voit guère d'hommes âgés parmi eux, car le métier les use très vite ; les plus robustes ne peuvent y résister bien longtemps, ils disparaissent, un jour, soit qu'ils aient abandonné pour faire autre chose ou qu'ils soient morts. Il n'y a donc guère, aux stations où ils attendent les clients, que des jeunes qui n'arrêtent pas de jacasser et de lancer des lazzis le plus souvent obscènes, en grignotant des graines de pastèques. Ces êtres, qui mènent une existence si épuisante et si précaire, paraissent ignorer complètement la mélancolie.

Tous ceux qui ont écrit sur les Chinois ont parlé de leur manque de caractère, de leur pusillanimité. C'est une observation que confirme ce que j'ai appris d'eux et ce que j'ai eu I'occasion d'en vérifier moi-même. J'ai notamment pu constater combien était juste ce que I'Américain Arthur $\mathrm{H}$. Smith dit de leur « flexible inflexibility », dans ses Chinese Characteristics. Toutes les fois qu'injurié - comme il arrive de temps à autre, aux étrangers, dans les rues de Chine - je regardais fixement mon insulteur, je le voyais se troubler, rougir, perdre contenance et s'éloigner dans la plus grande confusion.

Une attitude ferme peut même en imposer à toute une foule déchaînée. Un diplomate français m'a raconté qu'ayant dû aller régler un incident à Itchang, il avait traversé ce grand centre, 


\section{Les Chinois}

Essai de Psychologie ethnographique.

pour se rendre à la préfecture, en uniforme et en chaise, entre une double haie de Chinois hurlant à la mort et tendant les poings. Alors que la moindre apparence de crainte l'eût infailliblement perdu, son visage résolu suffit à les clouer sur place. Une semblable impassibilité, doublée d'énergie, a sauvé bien des missionnaires.

Plus encore que le peuple, les grands chinois sont susceptibles de cette couardise. Que de fois n'a-t-on pas vu, à Pékin, accourir à la moindre alerte, affolés, pour se mettre à l'abri dans le quartier des Légations, les plus hauts personnages ! Aussi facilement, d'ailleurs, qu'ils se sont effondrés, le risque passé, ils se redressent et retrouvent leur superbe. On cite volontiers le cas du ministre des Communications, Cheng Kong-pao, qui, disgracié, au début de la révolution, se réfugia, piteux et larmoyant, auprès des ministres européens, en implorant leur secours. Parti en chemin de fer, pour Tientsin, sous la protection de soldats étrangers, à peine fut-il installé, à l'abri, sur un bateau en partance, qu'il se transforma comme par enchantement, et manifesta une hauteur et des exigences intolérables.

Ce qui montre bien qu'il y a là une caractéristique profonde des Chinois, c'est que leur morale, basée sur les maximes anciennes, y pousse en quelque sorte. Elle ne cesse, en effet, de louer, d'exalter la prudence, la circonspection, qui dégénèrent si facilement en hésitation et en lâcheté, et de condamner la hardiesse, parente du courage, en dénonçant même la témérité comme le plus coupable de tous les vices. Il y a bien peu de 


\section{Les Chinois}

Essai de Psychologie ethnographique.

délations, de rapports d'accusation, de blâmes officiels qui ne contiennent ce reproche de «témérité ».

Cela contribue à faire, au Céleste, une âme de faible qui l'éloigne plus que toute autre chose de nous. N'étant pas organisé pour la lutte ouverte, il est en effet porté à se servir des moyens qui nous sont le plus antipathiques. C'est ainsi que le mensonge, si réprouvé des Occidentaux, sinon des Grecs du temps d'Ulysse, est considéré, en Chine, comme une arme légitime. Le premier secrétaire d'une légation anglo-saxonne me dit, un jour, que, dans les relations officielles avec les Chinois, il fallait l'admettre.

« Les plus grands personnages, m'expliqua-t-il, mentent couramment. Par la suite, lorsque le mensonge se découvre, cela ne les confond pas, ni ne les disqualifie. Ils estiment que vous êtes malin, que vous ne vous êtes pas laissé tromper, et, ce qui est essentiel pour eux, leur face n'en est pas atteinte.

Un médecin européen de Canton me rapporta que, complimentant une Chinoise sur la bonne apparence de son fils, un tout jeune enfant, la mère lui répondit avec un naïf orgueil :

- Oh ! il commence à savoir très bien mentir.

On comprendra tout ce qui nous sépare d'une pareille mentalité, en se rappelant ce passage d'une lettre écrite par le général de Maud'huy, après la mort d'un de ses fils tué au feu, et que les journaux reproduisirent : 


\section{Les Chinois}

Essai de Psychologie ethnographique.

« Je puis vous dire, écrivait le général, que mon fils est mort sans avoir jamais menti une fois dans sa vie, c'est de cela que je suis le plus fier ».

Tromper est, du reste, une chose méritoire pour tous les Asiatiques. Le comte de Gobineau a donné, de cette action qui fait partie, en Perse, d'une doctrine appelée : le Ketmân, une analyse pénétrante qui s'applique aussi bien à la Chine.

« Un Européen, écrit-il, serait porté à voir dans ce système, qui ne rend pas seulement la réticence indispensable, mais qui détermine l'emploi du mensonge sur la plus vaste échelle, il y verrait, dis-je, une situation humiliante.

« L'Asiatique, au rebours, la trouve glorieuse. Le Ketmân enorgueillit celui qui le met en pratique. Un croyant se hausse, par ce fait, en état permanent de supériorité sur celui qu'il trompe, et fût, ce dernier, un ministre ou un roi puissant, n'importe ; pour l'homme qui emploie le Ketmân à son égard, il est, avant tout, un misérable aveugle auquel on ferme la droite voie, qui ne la soupçonne pas ; tandis que vous, déguenillé et mourant de faim, tremblant extérieurement aux pieds de la force abusée, vos yeux sont pleins de lumière ; vous marchez dans la clarté devant vos ennemis. C'est un être intelligent que vous bafouez ; c'est une bête 


\section{Les Chinois}

Essai de Psychologie ethnographique.

dangereuse que vous désarmez. Que de jouissances à la fois ${ }^{1}$ !

Avec une pareille disposition d'esprit, la fausseté, la dissimulation, la déloyauté sont, ainsi que le mensonge et pour les mêmes raisons, d'usage courant. La diplomatie francobritannique en fit l'amère expérience durant les négociations que les deux pays eurent à mener avec la Cour de Pékin, au cours des conflits de la première moitié du XIXe siècle. C'est avec la même insincérité que, beaucoup plus tard, nous avons vu l'Empire cédant à la pression des modernistes et des circonstances, rédiger son plan de réformes ${ }^{2}$, puis Yuan Chi-kaï donner son concours à la dynastie pour mieux l'abattre ${ }^{3}$ et prêter enfin serment à la République, dont il était le président, pour se faire ensuite proclamer empereur. En tout cela, il est vrai, on s'efforce d'observer les rites et de sauver les apparences. Yuan Chi-kaï, dès le début de sa présidence, fit, dans un accès de franchise, à un diplomate étranger, cette confidence qui valait un programme :

- On ne peut pas, dit-il, violer la Constitution au bout de quinze jours.

Il y mit en effet toutes les formes. Au cours de sa dictature, un général ayant tenté une rébellion au Houpé, il l'attira à Pékin par de fallacieuses promesses et, l'ayant fait massacrer à la fin

\footnotetext{
${ }^{1}$ Les Religions et les Philosophies dans I'Asie centrale, chap. I : Caractère moral et religieux des Asiatiques.

${ }^{2}$ Voir La Chine nouvelle et La Chine et le Mouvement constitutionnel.

${ }^{3}$ Voir La Fin des Mandchous.
} 


\section{Les Chinois}

Essai de Psychologie ethnographique.

d'un banquet offert par une de ses créatures, il lui décerna ensuite les honneurs posthumes dus aux militaires morts au champ d'honneur.

J'ai connu d'autres personnages du même genre et qui, pour n'être pas si importants, n'en étaient pas moins très représentatifs. A Canton, à la plus belle époque du réformisme, le leader, le tribun de la Société du « Self Government», un académicien fort connu, qui avait mené la campagne contre I'opium, était, lui-même, un grand fumeur. Étant aussi un joueur invétéré, cela ne l'avait pas empêché d'attaquer avec la plus extrême violence les maisons de jeu. Il passait pour avoir été, de tous temps, un intermédiaire fort habile dans les pots-de-vin mandarinaux. C'était le grand homme de la capitale du Sud, en 1910-1911. La population I'appelait : «Kong ha » (crevette de fleuve). Ce crustacé se nourrit d'ordures, mais le sobriquet, dans l'esprit du peuple, comportait plus d'estime que de mépris ; c'était comme si on eût dit : « Quel homme adroit, quel débrouillard! »

Sous la présidence de Yuan Chi-kaï, un jeune colonel que j'avais précédemment connu dans l'armée révolutionnaire du Yangtsé, mécontent de sa nouvelle situation à Pékin, écrivit, au ministre de la Guerre, une lettre de réclamation non signée et rédigée de telle sorte qu'on pouvait l'attribuer à un de ses camarades de même grade, également très répandu dans le monde des Légations, et auquel un pareil acte pouvait valoir, à cette époque-là, une condamnation à mort. L'auteur de la lettre 


\section{Les Chinois}

Essai de Psychologie ethnographique.

s'était d'ailleurs empressé de partir de la capitale, pour se mettre à l'abri, en cas d'accident.

« L'Oriental, dit Arminius Vambéry, le fameux faux derviche, naît et meurt avec un masque ; la loyauté lui demeurera toujours inconnue ${ }^{1}$.

Cette appréciation peu favorable visant les Persans, les Turcomans et les Afghans, on se rend compte, par tout ce qui précède, qu'elle est également méritée par les Chinois. Tous ces Asiatiques ont beau jeu avec les Européens occidentaux, si portés à généraliser et à croire que tout le monde leur ressemble. Ceux de I'Asie antérieure, - comme j'ai pu m'en convaincre, dans les séjours que j'y ai faits, -aussi bien que ceux de I'Asie la plus extrême, les prennent, à cet égard, dans une méprisante pitié ; ils se moquent, entre eux, de ces Francs stupides qui croient tout ce qu'on leur dit et qui disent tout ce qu'ils pensent.

A Pékin, la grande habileté des hommes d'État chinois était de faire croire à chaque ministre étranger qu'ils s'adressaient à lui seul et qu'ils comptaient sur son appui pour les aider. Cela flatte toujours la vanité du diplomate et lui donne des illusions sur un succès possible pour lui et son pays ; alors il marche et fait tout ce qu'il peut pour satisfaire le rusé Céleste. Yuan Chi-kaï s'est abondamment servi de ce truc et il n'est pas de représentant d'Europe ou d'Amérique qui ne puisse raconter quelque entrevue émouvante qu'il a eue avec lui.

${ }^{1}$ Voyages d'un faux derviche, traduction E. D. Forgues, chap. XV. 


\section{Les Chinois}

Essai de Psychologie ethnographique.

Il ne faut pas s'étonner qu'avec une telle nature, le Céleste soit avant tout un utilitaire et que sa conduite ne s'inspire guère d'autre mobile que celui de l'intérêt personnel. Le souci dominant du bien public, le sentiment du devoir, la probité, dans le sens élevé et total que nous attachons à ce mot, lui sont, en dépit de la réputation d'honnêteté commerciale qu'on lui a faite, tout à fait inconnus. Chacun, du haut en bas de l'échelle, ne se préoccupe que de tirer le maximum de la situation et des circonstances dans lesquelles il se trouve. Chez les fonctionnaires, c'est traditionnel. Leur charge, qui leur a coûté cher en cadeaux, sinon en achat direct, doit leur rapporter en conséquence. Les appointements étant fort modestes, il s'agit donc, pour eux, d'extorquer le plus adroitement possible de l'argent à leurs administrés, dans toutes les matières qui leur sont soumises. Cela est tellement admis et d'une réussite si certaine que les banques indigènes consentent des avances à gros intérêts sur ce genre d'opérations. Avant la révolution, on disait couramment qu'un vice-roi, en trois ans, mettait assez d'argent de côté pour rembourser son prêteur et enrichir sa famille durant plusieurs générations. La plupart réalisaient des fortunes scandaleuses; le célèbre Li Hung-chang en est resté le prototype.

L'établissement, à la fin de l'Empire, du régime constitutionnel, avec création d'organismes tels que le Parlement, les conseils provinciaux, les municipalités autonomes, bien loin d'améliorer, à cet égard, la moralité publique, l'aggrava encore, en donnant le jour à d'autres rongeurs, plus avides encore que les anciens. Après la révolution, ce fut pis, car les 


\section{Les Chinois}

Essai de Psychologie ethnographique.

nouveaux venus, ignorant les limites traditionnelles qui présidaient à ce péculat séculaire et profitant du grand désordre qui supprimait tout contrôle, n'eurent plus aucun frein. A I'heure actuelle, la situation est plus mauvaise que jamais. Dans l'effondrement de plus en plus accusé du gouvernement central et I'anarchie générale, des chefs de bande, mués en généraux, rançonnent et pillent les provinces jusqu'au sang. L'irrespect des deniers publics est d'ailleurs si invétéré chez les uns et les autres que, lorsqu'ils doivent céder la place et filer, ils ne manquent pas d'emporter la caisse. C'est ce que fit, lors de la révolution, à Canton, le vice roi Tcheng Ming-ki ; son remplaçant, président de la République Cantonnaise, Tcheng Kiong-ming, fit de même, quand, en 1913, I'approche de Long Si-kouang le poussa à s'enfuir. Et tout récemment, lorsque les chefs du gouvernement cantonnais se séparèrent, l'un d'eux, cependant très modernisé, très américanisé, le vieil Ou Ting-fang, aurait emporté les fonds officiels avec lui jusqu'à Shanghaï. Tous les journaux de cette dernière ville ont relaté I'incident. Le président du premier conseil des ministres qui ait existé dans la jeune république, Tong Chao-yi, n'a-t-il pas été accusé, lui aussi, d'avoir détourné, en quittant subrepticement Pékin pour se réfugier à Tientsin, les fonds d'un emprunt étranger?

On a donné, à tous ces profits illicites, pour lesquels le Céleste a un goût si prononcé, le nom de : squeeze. Les cadeaux, par lesquels la complaisance du mandarin s'acquiert, y tiennent une large place, mais encore faut-il savoir les faire, car la susceptibilité, la pudeur du Chinois, sont très ombrageuses. 


\section{Les Chinois}

Essai de Psychologie ethnographique.

Un homme qui veut mener de grandes affaires en Chine doit savoir en jouer et beaucoup échouèrent pour ne l'avoir pas su.

- Le Chinois, me dit un consul, est très habile à prendre un grand air d'incorruptibilité. Pour lui offrir un cadeau, il faut prendre les moyens les plus détournés, qu'il suggère d'ailleurs lui-même la plupart du temps. Un Français, grand entrepreneur de travaux du Yunnan, se vit, un jour, à sa grande stupéfaction, refuser de magnifiques bijoux. Son ingénieur ayant besoin de coolies, on lui opposa à ce sujet toutes sortes de difficultés. Finalement, on lui en donna, à la condition qu'il aurait des chefs de dizaines, de centaines et un cuisinier par cinq hommes. L'ingénieur refusa parce qu'il craignait que tous ces hommes n'existassent que sur le papier, et il eut tort parce que c'était, en effet, le moyen que le subtil fonctionnaire, réfractaire aux cadeaux, avait choisi pour « squeezer ».

Les Allemands, qui sont fort cyniques et se servent sans scrupules de tous ces moyens qui nous répugnent, réussissaient à merveille en Chine. L'un d'eux plaça pour deux cent mille taëls de fusils Mauser de la manière suivante : Il avait affaire à un officier du ministère de la Guerre qui passait pour être inaccessible. Il allait le voir, dans une très jolie voiture fort bien attelée. Le Chinois I'avant, un jour, admirée, l'Allemand répondit qu'elle était médiocre, mais que, puisqu'elle lui plaisait, il se ferait un plaisir de la lui prêter. Et le lendemain, il l'envoyait à ses ordres. L'affaire des fusils, qui avait traîné jusque-là, se fit de 


\section{Les Chinois}

Essai de Psychologie ethnographique.

suite, et, bien entendu, l'adroit fournisseur oublia complètement de réclamer sa voiture.

Il faut le répéter, les Allemands ont l'art de manier ces hommes d'Orient et d'Extrême-Orient. Avant la dernière guerre, ils avaient, à Pékin, la même situation qu'à Constantinople, et de même que, dans cette dernière capitale, ils avaient eu le ministre de la Guerre, Mahmoud Chefket pacha, comme agent de la maison Krüpp, ils eurent le ministre de la Guerre chinois, Ying Tchang, dans les mêmes fonctions. Ces deux généraux avaient du reste été, l'un et l'autre, attachés militaires à Berlin.

Il y a, dans le squeeze, des profits moins exceptionnels, en quelque sorte réguliers, mécaniques, et qui consistent à toucher une commission sur toutes les dépenses dépendant de la place qu'on occupe, comme sur tous les services qu'on est appelé à rendre. En vertu de cet usage, les mandarins touchent pour les travaux publics aussi bien que pour la justice. La construction des écoles, des casernes, des nouvelles prisons etc., furent, dans ces conditions, une excellente aubaine, et on s'explique l'ardeur progressiste dont la plupart firent preuve. Ils touchent encore pour les adjudications des fermages d'impôts, pour fermer les yeux sur la piraterie, les maisons de jeu, la culture du pavot, contrebande de l'opium ou du sel, le commerce d'enfants, etc. Quand, à la fin de 1910, je remontai le Sikiang, surpris qu'on ne s'arrêtât pas à une ville assez importante, située au bord de ce fleuve, j'en demandai la raison au capitaine du bateau. Celui-ci me répondit qu'il brûlait cette station parce que le sous-préfet de l'endroit passait pour être de connivence avec une bande de 


\section{Les Chinois}

Essai de Psychologie ethnographique.

pirates de la région, et qu'il eût été trop imprudent d'y prendre des passagers.

Naturellement, pour pouvoir exercer cette fructueuse industrie, il faut obtenir que les supérieurs consentent à fermer les yeux. On y parvient de la manière que I'on devine. On est exposé à toutes sortes de chantages et de dénonciations de gens sans place, en expectative d'emploi, comme il y en a tant dans les capitales provinciales de ce pays d'aspirants au fonctionnariat. On les calme de la même manière. A l'époque où il était vice-roi du Petchili, Yuan Chi-kaï ne manquait pas, quand il recevait une accusation, de charger de l'enquête un des nombreux bacheliers ou licenciés en expectative à Tientsin. L'enquêteur, après s'être abouché avec le dénoncé, rédigeait un rapport qui le rendait blanc comme neige. Yuan savait à quoi s'en tenir, mais il usait sans scrupule de ce moyen pour maintenir dans la tranquillité cette gent particulièrement turbulente. Tout le monde y trouvait son compte, même le peuple qui, de toutes façons, ne pouvait éviter d'être tondu et avait plutôt intérêt à s'accommoder d'un fonctionnaire dont il avait I'habitude.

Cette façon de monnayer sa place n'est pas seulement le fait des mandarins, mais de tous, du plus grand au plus petit, c'est véritablement dans les mœurs. Nul n'est plus expert en cela que le domestique, le « boy ». Il touche sur tous ses achats. Si vous avez fait une emplette vous-même, il se rend dans le magasin d'où vous sortez, vous en demande au besoin l'adresse, et va toucher sa commission. Si vous êtes dans un hôtel, les 


\section{Les Chinois}

Essai de Psychologie ethnographique.

marchands à qui vous avez fait des commandes et qui viennent vous les remettre doivent aussi verser une rétribution au portier. Si vous avez une situation officielle, soyez certain que, pour arriver jusqu'à vous, le commun des Chinois devra « graisser la patte » à votre entourage indigène. Bien heureux êtes-vous si, à votre insu, votre serviteur ne réclame rien en votre nom. C'est ainsi que le mafou (cocher) d'un consul, dans une ville importante, s'était, à ce qu'on me raconta, fait remettre, par des femmes, deux et trois cents taëls pour une affaire qui devait venir devant le tribunal mixte. Le tribunal s'étant déclaré incompétent, les femmes, qui croyaient avoir acheté un jugement favorable, vinrent se plaindre. Le mafou, peu au fait de notre jurisprudence, n'avait évidemment pas prévu cela ; il s'en tira en niant comme un beau diable.

Ce qu'il faut retenir, pour donner à cette pratique sa vraie valeur, c'est qu'il ne s'agit pas d'escroqueries comme on en commet partout, mais d'un usage généralisé et courant. Il est tellement coutumier que, dans les relations mondaines même, où on se pique habituellement de délicatesse, les Chinois ne se font pas faute de I'appliquer. Si quelqu'un, parmi vos relations, se charge d'organiser une partie quelconque, soyez sûr qu'il y aura son bénéfice. Le secrétaire d'ambassade, dont j'ai parlé plus haut, me montra qu'à ce point de vue la Chine la plus récente ressemblait à la plus vieille. Au cours du déjeuner que je lui avais offert et de celui, particulièrement répugnant, qu'il m'offrit à son tour, il m'avait parlé avec beaucoup d'insistance d'un très beau magasin de porcelaines qu'il désirait me faire visiter. Je croyais qu'il s'agissait de porcelaines artistiques et 


\section{Les Chinois}

Essai de Psychologie ethnographique.

anciennes ; je l'y accompagnai donc bien volontiers, en sortant du restaurant. Quelle ne fut pas ma stupéfaction, en rentrant dans la boutique, où visiblement nous étions attendus, de constater qu'elle ne contenait que de la marchandise la plus moderne, la plus usuelle et la plus banale. Je ne voulus pas en voir davantage et repris aussitôt la porte, devant le personnel déconfit et mon singulier amphytrion, plus déconfit encore. Je voulais acheter des disques de gramophone donnant des airs chinois ; mon compagnon me conduisit dans un magasin où j'en achetai quelques-uns. Quelques jours après, étant revenu, seul, dans cette même maison, pour faire l'acquisition d'autres chants, je payai ces nouveaux disques moins cher que les premiers. C'est qu'ils n'étaient, cette fois, grevés d'aucune commission. C'est d'autant plus curieux et significatif qu'il ne pouvait s'agir que d'un profit minime.

Ce penchant à vouloir tirer, d'une situation donnée, le maximum, est si incoercible qu'il efface toute autre considération et peut même faire aller à l'encontre du véritable intérêt. Un ingénieur de l'arsenal de Hanyang me raconta que lorsque Cheng Kong-pao avait pris en main ces usines, il avait créé une école pour former des techniciens chinois. On avait, à cet effet, recruté, à Hongkong et à Shanghaï, tout ce que I'on pouvait avoir de mieux comme professeurs. On avait également choisi très soigneusement les élèves. Ceux-ci, au nombre d'une trentaine, étaient très bien logés, fort bien nourris et touchaient en outre, pour leur argent de poche, quinze dollars par mois. Au bout de quatre mois, on dût fermer l'école ; les élèves étaient partis. Ne se rendant pas compte qu'ils étaient là pour 


\section{Les Chinois}

Essai de Psychologie ethnographique.

s'instruire, qu'ils ne rendaient aucun service et que leur situation était de la sorte très avantageuse, ils avaient demandé à toucher plus que les quinze dollars mensuels. Pensant qu'on avait besoin d'eux puisqu'on les avait ainsi comblés, ils voulaient en profiter davantage.

La probité stricte, telle que nous la concevons, n'a rien à voir avec une pareille mentalité. L'honneur commercial des Chinois dont on a parlé, le respect de la signature et de la parole, semblent relever beaucoup plus d'une question d'amour-propre et de face que de cette probité-là. Un directeur de grande banque me disait que même cette honnêteté de parade tendait à disparaître, comme en ont fait foi les nombreuses faillites, plus ou moins frauduleuses de ces dernières années, de même que les histoires de compradors autrefois inconnues.

Le vol, du reste, le vol tout cru, du moins en certaines circonstances : incendie, troubles politiques, etc., est pratiqué couramment par les Chinois de toutes classes. Dès qu'un feu éclate quelque part, la foule accourt ; c'est une véritable ruée, non pour porter secours, mais pour profiter de l'aubaine. C'est pourquoi, à Canton, les coolies chargés du transport des meubles d'une maison en flammes sont armés d'un coutelas, pour écarter les amateurs. Il y a quelques années encore, il y avait, dans cette dernière capitale du Sud, une foire des voleurs, qui était autorisée et qui se tenait de une heure à quatre heures du matin. On n'y vendait que des objets volés. Il y a toujours, au centre de la ville, un grand magasin de brocante où je suis allé souvent et où on vend à meilleur marché que toute autre part, 


\section{Les Chinois}

Essai de Psychologie ethnographique.

parce que les objets mis en vente proviennent de larcins et de pillages. Le patron de cette boutique est connu de tous sous le nom de « roi des voleurs » et nul ne songe à le gêner dans son commerce.

Dans ces conditions, on s'explique que les grandes entreprises d'ordre public, dès qu'elles tombent entre les mains chinoises, périclitent infailliblement. C'est, par exemple, le cas des chemins de fer. La seule administration qui marche correctement est celle des douanes, dont font également partie les Postes, parce que, par suite des traités, elle est dirigée par des Européens.

Cette baisse des affaires passées aux mains des Célestes n'est pas due seulement aux malversations, mais aussi à la négligence et à la paresse. J'en ai eu la preuve sous les yeux. J'étais, à chacun de mes voyages, le client d'un bateau qui faisait le service de Hongkong à Canton. Je le prenais de préférence parce qu'il appartenait à une compagnie française ; il était du reste admirablement tenu. Il fut, à un moment donné, vendu à des Chinois ; je continuai à le prendre parce qu'il avait conservé son capitaine français ; mais, malgré les efforts de celui-ci, qui en était absolument navré, - ce n'était plus le même bateau. On ne changeait plus les draps dans les cabines, le chargement se faisait au petit bonheur, on ne partait plus à I'heure, etc., c'était la pétaudière. C'était en petit l'image de ce qui se passait, sur une beaucoup plus vaste échelle, dans les affaires plus importantes. 


\section{Les Chinois}

Essai de Psychologie ethnographique.

La grande réputation d'habileté, d'activité et de célérité que I'on a faite aux Chinois est surfaite. Un directeur de grande banque, à Pékin, m’a dit que c'était une erreur de croire à la supériorité du Céleste en matière de banque et de commerce ; c'est, au contraire, un médiocre banquier et un médiocre commerçant. Joueur effréné, il spécule ou plutôt il joue au hasard et il a un estomac énorme. Il y a ainsi des situations d'apparence qui se maintiennent pendant quelques années, sans aucune base. Et puis, un jour, tout craque. C'est ce qui explique les nombreuses déconfitures de banques dans ce pays.

Pour la compétence et le sérieux des employés, me disait encore ce directeur, un fait est très édifiant : il faut avoir tout le temps l'œil sur les « schroffs » (caissiers) qui, par exemple, additionneront, sans s'apercevoir qu'ils se trompent, des taëls avec des dollars. A l'actif de ces banquiers chinois, on peut dire qu'ils ont un assez grand esprit de solidarité, une certaine probité et qu'ils se contentent de maigres bénéfices.

Pour les travailleurs de l'industrie, il faut également en rabattre. Le directeur de la ligne de chemin de fer du Chansi, le directeur de l'arsenal de Hanyang, à Hankéou, et un de ses ingénieurs me dirent, tous les trois, la même chose, à savoir qu'il fallait trois ouvriers chinois pour donner le rendement d'un ouvrier européen. L'enquête faite par I'Humanité, au commencement de 1914, sur le travail de quarante ouvriers chinois, dans une usine des environs de Dieppe, aboutit exactement à la même constatation. 


\section{Les Chinois}

Essai de Psychologie ethnographique.

L'ingénieur de Hanyang m'expliqua en outre qu'on peut faire, du Chinois, un assez bon ouvrier d'usine, un ajusteur suffisant, mais qu'il ne soignera qu'une pièce, sans jamais considérer I'ensemble dont cette pièce fait partie. Il n'a aucune initiative, il n'est adroit et soigneux que dans sa spécialité la plus étroite. Il ne travaille d'ailleurs pas pour le bon travail lui-même, mais uniquement pour le gain. S'il s'élève tant soit peu, il se prend pour un personnage et croirait perdre la face s'il mettait encore la main à la pâte.

En dernière analyse, pour la plupart des actes ou attitudes du Chinois, on arrive presque toujours à la face, c'est-à-dire à une susceptibilité invraisemblable, un amour-propre maladif, à base de vanité, d'une vanité d'autant plus excessive qu'elle est secrète et habituellement cachée sous une modestie de commande. Cela existe certes partout, c'est humain, mais n'atteint nulle part à un pareil degré d'exaltation de la personne et d'inquiétude ombrageuse.

Les relations avec les Célestes en sont singulièrement compliquées, parce qu'on ne sait jamais à quel point leur face est intéressée dans ce qu'on leur dit ou ce que l'on débat avec eux. Le chef d'une grande entreprise étrangère me disait quel ennui et quelle gène il en éprouvait parfois.

- Quand on est occupé, expliquait-il, à préparer une affaire avec un Chinois, il y a des choses, qu'il aurait à dire et qu'il ne dit pas, qu'il faut deviner. Il ne les dit pas, bien qu'il pourrait parfaitement les dire, parce qu'à 


\section{Les Chinois}

Essai de Psychologie ethnographique.

un degré même infime cela atteint sa face. C'est une des causes qui les rendent presque incapables de prendre une décision et c'est pourquoi il est presque impossible de conclure avec eux. Quand on croit tout fini, on s'aperçoit qu'il n'y a rien de fait.

Un ingénieur de l'arsenal de Fou-tchéou m'a raconté qu'ayant eu, une fois, un bon ouvrier, absolument innocent, condamné par le mandarin, il était intervenu, pour lui, auprès de ce fonctionnaire. Il vit donc celui-ci, mais il se garda bien de parler de l'innocence de l'homme, auquel le mandarin aurait infligé une peine double - question de face - ; il lui demanda son « pardon » et il l'obtint.

Un jeune médecin chinois, de l'École de Tientsin, dont les professeurs sont Français, ayant été nommé dans un régiment à Canton, les médecins de I'hôpital français de cette ville l'engagèrent à venir les voir et ils mirent à sa disposition leur bibliothèque et toutes les ressources de l'établissement. Comme on ne le voyait jamais, l'un d'eux lui ayant demandé, un jour, les motifs de son abstention, il lui répondit qu'il craignait qu'on le prît pour un élève. De même, dans les écoles d'enseignement secondaire, tous les élèves, quelle que soit leur instruction, veulent faire partie des cours supérieurs.

Cette sensibilité particulière, si aiguë, a besoin, pour être mise en mouvement, d'un tiers. Le Chinois n'aura honte de rien vis-à-vis de soi seul.

- Il peut même, déclarait un ministre étranger, faire beaucoup de choses humiliantes, à la condition de ne 


\section{Les Chinois}

Essai de Psychologie ethnographique.

jamais le reconnaître en paroles. Et c'est pourquoi, le mauvais moment passé, il se doit à lui-même d'oublier les services qu'on a pu lui rendre.

Si son propre jugement n'est en aucune façon susceptible d'inquiéter sa face, par contre celle-ci est mise désormais en éveil, d'une manière permanente, par les témoins étrangers. C'est dû sans doute au désarroi dans lequel l'a plongé l'incertitude toute nouvelle, provoquée par le mouvement moderniste et aussi par les événements, sur la supériorité de sa civilisation nationale. Après avoir systématiquement tourné en dérision tout ce qui provenait du dehors, il a honte maintenant, à tort et à travers, de toutes les coutumes, bonnes ou mauvaises, de son pays. Le commerce, par exemple, des rats tapés, des quartiers de chien, des tranches de serpent, pour l'alimentation se cache. Les Chinois savent que les Européens s'en moquent et cela suffit ; si un indiscret cherche à se renseigner là-dessus, celui à qui il s'adresse, en rougissant très fort, affirme que cela n'a jamais existé. Du reste, toutes les fois qu'on pose une question, on voit le visage de celui à qui on s'adresse se rembrunir, son angoisse est visible : que faut-il répondre pour garder la face ? Et il arrive qu'il nie des choses qu'on n'a jamais eu l'idée de critiquer.

Ainsi pour I'habitude de porter, le soir, son oiseau favori au bord de la rivière ou sur une colline, afin de l'entendre chanter de plaisir. Un jour, à Fou-tchéou, je demandai à. un jeune Chinois, pourtant intelligent, si cela se pratiquait dans la région ; il parut très décontenancé et, après une seconde d'hésitation, il 


\section{Les Chinois}

Essai de Psychologie ethnographique.

me répondit tout net que cela ne s'était jamais fait. Je lui déclarai que c'était regrettable, car, l'ayant vu partout ailleurs, je l'avais trouvé charmant. Je compris bien qu'il ne croyait pas à la sincérité de mes paroles.

Cette méfiance et cette crainte perpétuelle d'être en infériorité sont bien désagréables pour les interlocuteurs du Céleste. Mais combien plus agaçant est-ce encore quand ce dernier, pour faire figure d'homme complètement européanisé, dénigre lui-même systématiquement les choses de son pays. Ce type commence à paraître parmi les jeunes Chinois qui ont vécu à l'étranger. C'était le cas du secrétaire d'ambassade, plusieurs fois mentionné déjà, et à qui je dois décidément de la reconnaissance pour toutes les indications qu'il m'a involontairement données. Il était uniquement préoccupé de paraître à mes yeux affranchi de tout ce qui est chinois. Dès que j'ouvrais la bouche, il arborait déjà, sans savoir ce que j'allais lui demander, le sourire du reniement, du reniement de tous les siens. Comme dans la belle voie, qui va de la porte Shienmen au temple du Ciel, j'admirais I'ordonnance des boutiques, avec le décor de leurs tablettes et de leurs hautes hampes, en lui disant combien j'étais frappé par l'allure originale et grandiose de Pékin, il souriait encore incrédule. Il finit par concéder :

- Oui, oui, c'est intéressant pour les étrangers!

Il ne parlait certainement pas de la sorte pour obéir à la vieille politesse chinoise qui force à se rabaisser quand on reçoit des éloges ; il ne songeait, au contraire, qu'à prendre une posture d'homme tout à fait supérieur. 


\section{Les Chinois}

Essai de Psychologie ethnographique.

Se grandir la face, ou se faire une face intéressante, impressionnante, voilà la chose principale. Cela se voit surtout dès qu'un événement quelconque crée une occasion de se mettre en évidence. La presse ayant attaché le grelot, les « héros » se produisent aussitôt de toutes parts. On assiste alors à des engouements et à des surenchères extraordinaires, auxquels du reste la névrose, dont il a été parlé, a aussi sa part. A la suite d'incidents avec les Anglais à la frontière birmane et avec les Russes en Mongolie, en 1910, on parlait de tous côtés de former des troupes populaires, de partir en guerre contre I'Europe, tous voulaient mourir. C'était un assaut de rodomontades.

Dans la même année, au Yunnan, à l'occasion d'un mouvement contre une concession de mines accordée à une société étrangère, un journal, le Yunnanjépao, publiait une lettre écrite par un élève de l'école militaire, dans laquelle on lisait ceci :

« On ne croyait pas que je pourrais me sacrifier moimême, et j'ai coupé ma chair pour répandre mon sang sur le papier, dans le but de faire un serment. Si, dans la suite, il y a des malheurs grands ou petits, j'ai la ferme idée de marcher en avant et, si je tombe, j'espère que vous me suivrez. Mon humble corps ne mesure que sept pieds chinois entre le ciel et la terre. On peut le scier, on peut le couper, on peut le cuire, on peut le décapiter, mais on ne peut pas le faire rougir de honte, etc. 


\section{Les Chinois}

Essai de Psychologie ethnographique.

Plus tard, il s'agit de réunir des fonds pour rembourser en bloc le reliquat de l'indemnité des Boxers aux étrangers. On forme la société de la «Honte nationale » et, cette fois, c'est un débordement d'héroïsme financier ; on promet par écrit de magnifiques sommes dont le versement ne s'effectuera jamais.

A la même époque, à Canton, un mouvement de ce genre s'étant produit pour la fermeture des maisons de jeu, une liste de souscriptions avait été ouverte pour remplacer les fonds que la suppression du jeu devait faire perdre au budget de la ville. Comme toujours, les signatures affluèrent ; un chef de pirates, entre autres, s'inscrivit pour dix mille dollars, avec cette mention que le jeu était une mauvaise chose et qu'il lui devait le recrutement de la plupart de ses brigands. Quand il s'agit de réaliser toutes ces promesses de concours, cela se réduisit à si peu de chose, qu'il fallut, pour combler le vide, élever les taxes sur la vente du riz, ce qui provoqua une inquiétante grève des marchands de ce produit de première nécessité. Pour la campagne anti-opium, qui se faisait à la même époque, dans cette capitale provinciale, les plus grands fumeurs paradaient à ces réunions, comme en fait foi une photographie prise à la suite d'un de ces meetings et qui constitue le plus beau groupe d'opiomanes qui se puisse voir.

En 1918, lors d'une famine, une demoiselle de Shanghaï, fille d'un ancien sous-préfet, fit publier, par la presse chinoise, qu'elle ouvrait une loterie de trente mille billets de un dollar en faveur 


\section{Les Chinois}

Essai de Psychologie ethnographique.

des faméliques et qu'elle se donnerait en mariage au gagnant du gros lot.

On pourrait allonger considérablement la liste ; au moment de la révolution surtout, les faits de ce genre furent innombrables, mais ils sont tous « ejusdem farinae » et ont pour but : la face. Il s'agit uniquement de parader et de devenir un objet d'admiration. On s'arrange pour que ça ne coûte pas trop cher et au besoin rien du tout, s'il est question d'argent, et pour se faire le moins de mal possible, si on s'est livré sur soi-même à quelque violence. Les précautions dont s'entourent le plus souvent ces mutilés volontaires sont à cet égard des plus typiques. Ils se font une très légère incision et ils proclament qu'ils se sont coupé le bras. Un élève de l'école de médecine de Moukden s'étant tailladé de cette manière, pour écrire une lettre au sang, répondit à son professeur, médecin américain missionnaire, qui exprimait la crainte qu'il se fût empoisonné le sang :

- Oh ! soyez sans inquiétude, monsieur, j'avais passé le couteau à la flamme ».

L'amour-propre national des Chinois, même chez ceux qui, par snobisme d'européanisation, affectent de dédaigner les traditions de leur pays, est extrême, parce qu'ils sentent leur face personnelle engagée dans tout ce qui le touche. Aussi ne faut-il pas compter sur eux pour être véridiquement renseigné sur les choses de la Chine. Que I'on interroge un professeur sur le régime des écoles, un officier sur celui de l'armée, etc., il 


\section{Les Chinois}

Essai de Psychologie ethnographique.

répondra toujours par la lettre même du règlement, alors que, le plus souvent, dans ce pays, et surtout depuis la modernisation apparente, il n'y a à peu près rien de commun entre la théorie et la pratique. Leur vanité est d'ailleurs telle qu'ils se croient naïvement supérieurs à toutes les nations. Quand on parle d'une grande invention faite ailleurs, il y a toujours un journal pour déclarer qu'on avait trouvé ça en Chine, bien avant. Cela s'est produit pour la navigation aérienne, et peut-être autrefois pour la poudre. Étant donnée leur incapacité de comprendre ce qui sépare le fait scientifique de l'imagination poétique, la réalité, de I'intention, une légende quelconque d'Icare Céleste peut être, à leurs yeux, le début de l'aviation.

Cette mégalomanie aveugle complètement les Chinois sur la situation réelle de leur pays. Au moment du conflit avec les Russes, au sujet de l'affaire des consulats en Mongolie, le ministre de la guerre Yung-tchang opinait pour la guerre. Il fallut que le ministre d'Allemagne à Pékin, inquiet de la tournure que tout cela pouvait prendre, lui ouvrît les yeux sur sa faiblesse. La menace de rupture inquiétait si peu les banques indigènes qu'elles jouaient à la hausse de l'argent. Les Chinois d'une certaine classe croyaient qu'ils pouvaient, comme les Japonais, mener une guerre victorieuse contre une grande puissance européenne. Un jeune officier envoyait une pétition au ministère de la guerre dans laquelle il disait, d'après le Tchongvaijépao, de Shanghaï : 


\section{Les Chinois \\ Essai de Psychologie ethnographique.}

«A mon humble avis, si la Chine veut se conserver, elle doit commencer par vaincre une ou deux puissances étrangères au moyen de sa force militaire.

Le Jentchéoujépao, également de Shanghaï, écrivait :

«Si la Chine veut connaître la valeur de ses soldats, elle doit déclarer la guerre à ses voisines qui la convoitent.

Un Chinois ayant résidé quinze ans en Europe disait à un ministre étranger, à Pékin :

« Quand on voit deux peuples comme la France et I'Allemagne ne pas oser se battre, comment une nation quelconque pourrait-elle déclarer la guerre à la Chine ?

Tout récemment, une jeune Chinoise ne proclamait-elle pas, dans un discours prononcé au cours d'une solennité de la Sorbonne, que la tâche de la Chine était de rendre la liberté à tout I'univers ? Cela partait certainement d'un excellent cœur, mais révélait une ignorance bien curieuse de l'état de son pays. Jusqu'à I'actuel président de la République, Siu Che-cheung qui, au moment où la Chine traverse une effroyable crise de violence, provoquée par une soldatesque pillarde et barbare, et où luimême est sous le joug des grands condottières du Nord, dessine de son élégant pinceau ces belles phrases reproduites, avec admiration par notre presse :

« Les historiens d'Occident, écrit le grand lettré, membre de I'Académie des Han-lin, magnifient la gloire des combats et des généraux ennemis de la paix, tandis 


\section{Les Chinois}

Essai de Psychologie ethnographique.

qu'ils ne donnent que peu de place aux vrais bienfaiteurs de I'humanité. Si tous les hochets de la gloire sont accordés au guerrier, faut-il s'étonner que l'enfant croisse dans la folle idée que la grandeur d'une nation est déterminée par la somme de ruses et de brutalités qui lui ont assuré du profit ? L'Occident, qui a sans doute beaucoup à nous apprendre, pourrait apprendre à son tour de l'âme orientale le mépris de l'égoïsme sans borne qui recherche la puissance et la fortune en versant le sang des hommes.

Cette tirade, écrite à l'instant où Siu Che-cheung lui-même et son gouvernement subissent la loi qu'est venu leur dicter à Pékin le dictateur de Mandchourie, I'ancien chef de bande Tchang Tsoling, est un remarquable spécimen de la composition académique en usage en Chine, sans relation aucune avec la réalité.

Une dernière caractéristique très importante à signaler dans la conduite habituelle du Chinois, c'est son esprit d'indiscipline. Cela peut surprendre, car on a fait, aux Célestes, une solide réputation de soumission passive et aussi parce que l'instinct d'association qu'on leur connaît ne s'accorde pas à première vue avec la tendance anarchique. Or, le curieux précisément c'est qu'ici ces deux contraires, comme beaucoup d'autres déjà indiqués, s'accouplent fort bien. Le fait que, depuis des siècles, ils sont durement asservis par le despotisme mandarinal, le plus abusif et le plus malhonnête qu'on ait vu, explique que les 


\section{Les Chinois}

Essai de Psychologie ethnographique.

Chinois ont de tous temps éprouvé le besoin de s'unir pour se défendre. Ils s'associent toujours contre l'autorité à laquelle ils se trouvent soumis. Chez nous, cela ne se produit que dans le monde des travailleurs qui se syndiquent contre le capital ; en Chine, c'est le cas des élèves à l'école, des soldats au régiment, des domestiques dans la maison. Et cela a dégénéré en insubordination systématique, car il ne s'agit plus de défendre ses justes droits, d'améliorer sa situation matérielle, mais d'imposer sa manière de voir, sa volonté, à ceux-là même qui ont pourtant mission de diriger.

Dans l'armée, les mutineries de soldats massacrant leurs officiers et pillant leurs villes de garnison ne se comptent plus. Si I'on feuillette la collection des derniers mois de n'importe quel journal européen de Chine, il n'y aura certainement pas de semaine où des incidents de ce genre ne soient signalés. J'ai indiqué, dans un autre livre, comment les domestiques ont littéralement établi leur domination sur leurs maîtres, du moins chez les étrangers ${ }^{1}$. Il est à croire que les mêmes choses se passent dans les maisons chinoises. Mais ce qui est encore plus symptomatique, c'est la conduite des élèves dans les écoles. On peut dire que la rébellion y est à l'état permanent. La presse donne encore à ce sujet d'abondantes informations ; j'en ai relevé une, particulièrement significative, à propos de I'opinion si favorable de Reclus sur la docilité des écoliers célestes ${ }^{2}$. J'ai du

\footnotetext{
${ }^{1}$ Voir la Chine nouvelle, p. 313.

2 Voir page 140.
} 


\section{Les Chinois}

Essai de Psychologie ethnographique.

reste recueilli, de la bouche même de professeurs qui ont eu à en souffrir, des renseignements très édifiants à cet égard.

A l'Université de Pékin, chaque section a un président et une délégation permanente, par laquelle elle fait connaître, à la direction et aux professeurs, ses désirs et ses décisions. Un professeur de droit me racontait qu'il avait ainsi reçu à diverses reprises les directives de ses élèves. Ils vinrent, un jour, lui dire qu'ils rayaient, de leurs études, les rudiments de latin inscrits au programme, parce qu'ils les jugeaient inutiles. Une autre fois, avant un examen périodique, ils vinrent lui demander de leur faire connaître à l'avance les questions qu'il comptait leur poser. Une autre fois encore, ils vinrent lui dire sans ambages de leur donner la note maxima, parce que leurs camarades des autres sections l'obtenant souvent, cela leur faisait, à eux, perdre la face. Ce professeur, qui avait, de la justice et de sa dignité, une plus haute conception que certains de ses collègues, résista, mais il eut toutes sortes d'ennuis et dut finalement quitter la place.

Au collège des Jésuites de Ziccavey, près de Shanghaï, les élèves, des enfants de 14 à 15 ans, avaient, en 1910, demandé que les séances réglementaires d'exercices militaires fussent doublées, parce qu'ils voulaient, eux aussi, s'engager dans les « troupes populaires » et partir en guerre contre I'Europe. La direction ayant refusé, ces gamins se mirent en grève et désertèrent l'école. Depuis plusieurs années, les étudiants et simples collégiens ont pris l'habitude d'envoyer des pétitions au gouvernement, en donnant des conseils, sinon des ordres, en 


\section{Les Chinois}

Essai de Psychologie ethnographique.

matière de politique intérieure et extérieure. Si la direction ou les autorités provinciales refusent de transmettre, ils quittent I'Université ou l'école et souvent même se livrent à des manifestations violentes. Cela aussi, c'est devenu, en Chine, presque du pain quotidien.

En présence de ce relâchement de l'autorité, naguère si implacable et si dure, cet esprit de rébellion prend des proportions inconnues dans les pays de vieille liberté. Un consul de Canton me raconta qu'un Chinois lui avait dit que son fils, un tout jeune garçon, avait déclaré que désormais il déciderait luimême de ce qu'il devait faire et qu'il ne lui obéirait plus. Le père avait giflé le gamin et l'avait retiré de l'école, car, selon lui, c'était là qu'on inculquait de pareilles idées aux élèves. Les professeurs disent qu'il faut les écouter, eux, et non les parents. Au même moment, des jeunes filles de cette ville formaient une association dite de $I^{\prime} \gg$ Union libre ». Elles proclamaient leur volonté de se marier avec des hommes de leur choix et de changer de maris dès que ceux-ci auraient cessé de leur plaire. Elles firent des promenades de manifestation dans les rues.

Certes, l'état lamentable de la femme, dans la société chinoise, justifie toutes les révoltes chez celles qu'un commencement $d$ 'instruction libère, mais ces revendications excessives ont quelque chose d'étrange, dans un pays où I'esclavage existe encore pratiquement ${ }^{1}$. Elles sont une nouvelle preuve de l'instinct d'insubordination de la race et qu'il n'y a pas de milieu, pour le Chinois, entre la contrainte la plus étroite et

${ }^{1}$ Voir Le Céleste Empire avant la Révolution, p. 79 et suiv. 


\section{Les Chinois}

Essai de Psychologie ethnographique.

l'anarchisme effréné. Il n'est pas d'être moins susceptible que lui d'atteindre l'idéal que nous poursuivons d'une morale sans obligation ni sanction, basée sur la simple conscience du devoir. Affranchi des règles traditionnelles et des pénalités terribles qu'elles comportaient, il devient l'homme le plus difficile à gouverner qu'il y ait au monde.

(a) 


\section{Les Chinois}

Essai de Psychologie ethnographique.

\section{III}

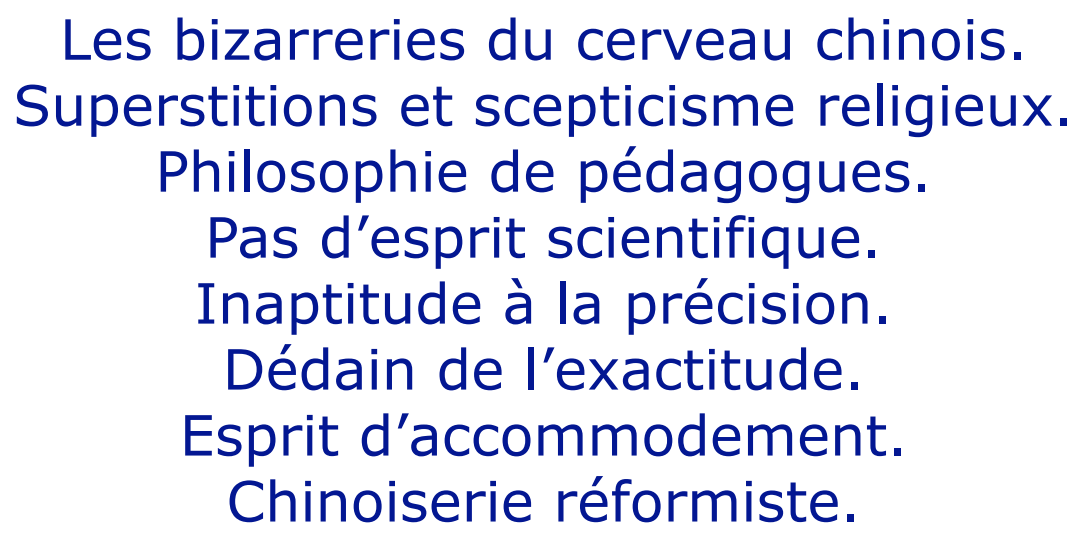

@

Dès le début de mes voyages en Chine, j'avais eu l'impression que rien ne nous séparait plus profondément du Céleste que les bizarreries de son cerveau. J'en avais relevé un certain nombre dont je me servis pour l'esquisse psychologique que je donnai dans mon premier ouvrage sur ce pays ${ }^{1}$. Ce que j'y écrivais est aussi exact aujourd'hui qu'alors. Je ne puis mieux faire que d'en reprendre les traits essentiels, en y ajoutant quelques notes nouvelles.

Ce qui domine toute la mentalité du Chinois, disais-je, c'est un extraordinaire mélange de puérilité et de malice aiguë, de matérialisme étroit et de crédulité, qui fait de lui une sorte de vieillard enfant. Le nom de « Laotzeu », qui signifie « vieil enfant » et qui fut donné au fameux philosophe de l'ancienne Chine, parce qu'une légende voulait qu'il ait longtemps séjourné dans le ventre de sa mère et qu'il soit venu au monde les

\footnotetext{
${ }^{1}$ La Chine nouvelle. « Le Chinois ».
} 


\section{Les Chinois}

Essai de Psychologie ethnographique.

cheveux blancs, conviendrait à merveille à l'ensemble des sujets de la Chine. Il semble, en effet, que le Céleste, si expert et rusé pour tout ce qui concerne ses intérêts immédiats, n'ait pu, en des matières plus élevées, atteindre à la plénitude de la raison virile.

Cette inaptitude à la haute intellectualité, associée à cet enfantillage et à une ignorance à peu près complète des lois de la nature, aboutit, dans le domaine religieux, par exemple, à de bien curieux résultats. En le maintenant dans une atmosphère de merveilleux, elle limite le Chinois aux croyances du paganisme le plus ancien et le soumet au monde redoutable et charmant d'une théogonie primitive qui a son recrutement dans la déification des forces naturelles et des grands hommes.

Avec une conception aussi naïve des effets et des causes, le moindre phénomène reste chargé de signification mystérieuse et la science des présages a une importance au moins égale à celle qu'elle pouvait avoir dans l'antique Rome. Les divers aspects du ciel, surtout, et les faits astronomiques suscitent toutes sortes d'horoscopes et provoquent d'ordinaire les craintes les plus vives. A Shanghaï, centre pourtant européanisé, lors d'une éclipse de soleil, en 1904, le taotaï fit venir des bonzes et des musiciens, pour prier dans son yamen. Puis, il fit tirer deux coups de canon, pour protéger l'astre. Pour une éclipse de lune, en 1906, les Chinois, dans la même ville, firent partir de nombreux pétards et tirèrent des coups de fusil, « pour empêcher le mauvais génie de dévorer la lune ». On sait par ailleurs quelle importance a le dragon de la pluie et avec quelle 


\section{Les Chinois}

Essai de Psychologie ethnographique.

ardeur on l'invoque aux époques de sécheresse, pendant lesquelles on tient soigneusement fermée, dans les villes, la porte du Sud, qui est celle du feu.

Les grands incendies qui éclatèrent à Pékin, en avril 1908, furent attribués par les astronomes au dieu du feu descendu du ciel pour une promenade d'une centaine de jours. « Lorsque cette divinité malfaisante aura réintégré sa résidence habituelle, dirent-ils, il n'y aura plus d'incendies! »

Alors que, chez les autres peuples, l'instinct religieux a pour base la préoccupation de l'inconnaissable, le désir élevé de trouver une solution à l'angoissant problème des origines et de la destinée, il est fait, chez le Céleste, d'une terreur enfantine des esprits qui a donné de la force au seul culte vraiment pratiqué en Chine, le culte des ancêtres. Les esprits des défunts, auxquels on attribue les besoins et les passions des vivants, font peser, sur ceux-ci, grâce aux plus invraisemblables superstitions, une effroyable tyrannie de tous les instants. Il s'agit donc, par toutes sortes de moyens, soit de se les rendre favorables, soit de leur inspirer une crainte salutaire ${ }^{1}$.

Des usages insensés en sont la conséquence. Pour peu que I'on séjourne dans le pays, il n'est pas rare d'en être le témoin. Durant l'été de 1907, alors que le choléra faisait de grands ravages, j'ai vu des rues entières, dans les quartiers chinois de la concession internationale de Shanghaï, tendues de cordes auxquelles étaient suspendus, à l'adresse des esprits, des

${ }^{1}$ Voir à ce sujet les textes traduits par le père Wieger et publiés sous les titres de : Morale et Usages et Folk-lore chinois moderne. 


\section{Les Chinois}

Essai de Psychologie ethnographique.

simulacres de monnaies et de beaux costumes en papier peint. Sur la rivière, le soir, des sampans et des jonques partaient d'innombrables pétards destinés à jeter dans l'effroi les esprits particulièrement nocifs des noyés. Le même vacarme sévissait à Ningpo, où venait d'avoir lieu, un peu avant mon arrivée, l'amusante cérémonie de la procession de la septième lune, par laquelle on conjure d'ordinaire la peste, le choléra et les autres fléaux de la saison. A l'aide d'un bruit infernal de gongs, de cymbales et de mousqueterie, aux quatre coins de la ville, on avait rassemblé la foule errante des petits esprits, c'est-à-dire ceux qui ont animé des corps misérables et auxquels, après la mort, aucun culte n'a été rendu, ce qui les a naturellement irrités. Ensuite, pour calmer leur colère, on les avait conduits en un endroit où des tables étaient, à leur intention, chargées des mets les plus variés, et, finalement, on les avait régalés d'une représentation théâtrale.

Ces superstitions, qui nous stupéfient par leur insondable puérilité, peuvent avoir des inconvénients plus graves que ce tintamarre auquel on s'habitue. Lors de cette même épidémie de 1907, la presse chinoise faisait savoir que les habitants de Kaïping, dans le Liaotoung, se refusaient à massacrer les rats parce qu'ils les considéraient comme des esprits. Le rat était, sans doute, à la façon de la vieille Égypte, leur totem. Aussi ne pouvait-on enrayer la peste et le choléra qui faisaient beaucoup de victimes dans la région. En août 1908, dans un village voisin de la préfecture de Yeng-chon-fou, une jeune femme, morte récemment, était accusée d'être la cause de la sécheresse. Son corps fut déterré et découpé en morceaux qui furent brûlés en 


\section{Les Chinois}

Essai de Psychologie ethnographique.

différents endroits. Tout cela, pour mettre l'esprit de la défunte à la raison. La grande peste pulmonaire de 1910-1911 donna lieu, en Mandchourie et dans la Chine du Nord, à toutes sortes de pratiques abracadabrantes dont ont parlé les journaux européens de Shanghaï. Dans cette dernière ville, qui passe cependant pour être modernisée, les précautions prises pour prévenir le fléau, dans la concession internationale, provoquèrent une véritable émeute, contre laquelle il fallut faire appel aux compagnies de volontaires étrangers.

Diverses coutumes, qui m'ont été indiquées par un vieux missionnaire, le père M..., à Kouang-tchengtze, en Mandchourie, sont également très significatives. On jette, par exemple, aux champs, en les abandonnant aux bêtes, les enfants au-dessous de cinq ans, quand ils sont très malades et sur le point de mourir. On ne les enterre pas parce qu'on croit que leur esprit, trop faible, écrasé par la terre et ne pouvant s'en aller librement, appellerait à lui un membre de la famille. Pour la même raison, au Yunnan, on suspend les jeunes enfants morts, roulés dans des nattes, à des branches d'arbres. Quand je suis allé à Yunnan-fou, on voyait, un peu avant cette ville, près de la voie ferrée, un arbre chargé de ces grappes macabres. En Mandchourie encore, selon le père $M \ldots$, quand une grande personne est très malade, on la retire du lit commun en brique recouvert de nattes et on la dépose sur le sol, de manière à ce que son esprit n'entraîne personne en s'en allant. Pour une raison identique et pour détruire complètement leur esprit essentiellement malfaisant, on brûle, sur un bûcher, les jeunes filles poitrinaires avant qu'elles ne meurent. 


\section{Les Chinois}

Essai de Psychologie ethnographique.

Toujours du père M... cette anecdote typique. Au cours d'une de ses promenades, il vit, un jour, plusieurs hommes qui pesaient de toutes leurs forces sur un autre homme étendu à terre et recouvert de briques. Ce malheureux avait eu une attaque de choléra et, à la suite d'une syncope, on l'avait cru mort. Quand il était revenu à lui, les Chinois avaient pensé qu'un mauvais génie s'était emparé de son corps et l'avait animé. Les pesées qu'ils exerçaient étaient destinées à provoquer la fuite de I'hôte malencontreux. Le Père leur adressa de vifs reproches et parvint à leur faire porter le malade chez lui. Il le soigna et fut assez heureux pour le guérir. Il dut, d'ailleurs, à cette cure, une solide réputation de sorcier. Le fait suivant, rapporté par le même missionnaire, n'a heureusement pas cette horreur, mais est un exemple du funambulesque mélange de ruse et de naïveté qui est le fond même de la mentalité chinoise. Quand, dans une ramille, on a perdu consécutivement plusieurs garçons, s'il en naît un nouveau, on l'appelle « fille », afin de tromper l'esprit mauvais et d'éviter ainsi qu'il l'enlève.

En somme, ce n'est pas I'infini qui tourmente le Chinois, et son inquiétude de l'au-delà se borne à éviter les maléfices des défunts et à s'assurer, par une descendance mâle, qu'il ne manquera pas de soins après sa mort. En dehors de ce culte tout matériel, il est, en matière de religion, d'un éclectisme qui révèle une indifférence et un scepticisme profonds. Quand il y est poussé par l'intérêt, soit qu'il désire obtenir une faveur ou qu'il ait un malheur à conjurer, il va faire des offrandes à la pagode la plus proche, qu'elle soit taoïste ou boudhiste. Il irait pareillement à l'église chrétienne, à la synagogue et à la mosquée, là où il 


\section{Les Chinois}

Essai de Psychologie ethnographique.

s'en trouve, s'il en connaissait les rites. Ces diverses religions sont évidemment, à ses yeux, autant de sorcelleries qui ont, chacune, à leur disposition, des trucs efficaces.

Cette facilité à recourir indistinctement et avec une confiance plutôt médiocre, sans doute, à toutes les puissances surnaturelles, d'une part, et, de l'autre, ce scepticisme, aboutissent parfois à un irrespect bien amusant dans ses manifestations. Il n'est pas rare, par exemple, ainsi que le rapporte Smith, dans ses Chinese Characteristics, que le Boudha, prié en vain par un village, soit finalement jeté à la rivière. Il s'est passé, à Canton, en 1903, une chose plus singulière encore. La sécheresse ravageait le pays. Le Boudha d'une pagode auquel on s'adressait d'ordinaire pour avoir la pluie, tardant à obtempérer aux prières qu'on lui adressait, le vice-roi prit un arrêté ordonnant de découvrir la toiture juste audessus du dieu, de manière à ce qu'ayant trop chaud sous le soleil implacable, il se hâtât d'envoyer une ondée salutaire. La pluie se fit encore attendre et, quand elle tomba enfin, pour punir le Boudha d'avoir tant tardé, on le laissa se mouiller, en ne recouvrant pas la toiture. Le vice-roi, trouvant même la punition insuffisante, fit désaffecter la pagode et mettre en vente tout ce qui la garnissait. Un de mes amis y acheta de fort jolis chandeliers de bronze, terminés en feuilles de lotus.

En 1910, à Fou-tcheou, la mort d'un officier supérieur fut attribuée aux idoles d'un temple qui avaient précisément pour spécialité de satisfaire la vengeance de ceux qui venaient les en 


\section{Les Chinois}

Essai de Psychologie ethnographique.

prier. La foule avant accusé ces dieux, le gouverneur donna l'ordre d'arrêter et de punir les coupables.

Les représentants de l'autorité se présentèrent donc au temple et mirent en état d'arrestation les quinze idoles - tout en bois et d'une hauteur de cinq pieds chacune.

Mais, avant de les traduire devant un tribunal, on creva leurs yeux de verre afin, disait-on, qu'elles ne pussent voir leurs juges et, par vengeance, provoquer chez eux quelque catastrophe.

Le résultat de l'enquête ayant été alors soumis au gouverneur, celui-ci ordonna de décapiter les idoles, de les jeter dans un étang, et, finalement, de raser le temple où elles avaient été abritées, « afin que d'autres idoles du même genre ne puissent venir troubler la tranquillité de Fou-tcheou.

Dans la même année, à la date du 7 octobre, un correspondant écrivait au grand journal anglais de Shanghaï, le North China Daily News, la savoureuse histoire suivante :

La fille d'une riche famille de la préfecture de Song-kiang, province du Kiang-sou, non loin de Shanghaï par conséquent, étant tombée malade, on vint raconter, à la mère de la jeune fille, qu'un dieu, dont la pagode était dans la ville voisine de Chinzah, souhaitait la mort de son enfant, pour en faire, dans l'éternité, sa concubine. La mère, bouleversée de douleur, pria son mari de se rendre en toute hâte à Chinzah, pour faire des offrandes à ce dieu. Mais le mari suivit une tout autre ligne de conduite ; il se rendit chez le préfet de Songkiang et le pria de mettre fin à la carrière de ce dieu. Faisant droit à la demande du père de la jeune fille, le préfet de Songkiang et le magistrat de 


\section{Les Chinois}

Essai de Psychologie ethnographique.

Tsinpao partirent pour Chinzah, sur deux jonques de guerre en bois, remorquées par deux chaloupes.

Arrivés devant le temple, il donnèrent l'ordre d'en enlever le dieu et la déesse ; mais les sbires du yamen, qui avaient été achetés par les prêtres, dirent que les deux divinités étaient trop lourdes et qu'on ne pouvait pas les bouger de place. Rendu furieux par cette réponse, le magistrat pénétra immédiatement dans le temple, et précipita lui-même de ses propres mains les deux divinités en bas de leurs trônes.

Le dieu fut exécuté avec « six sabres »: deux servirent à lui trancher la tête, et les quatre autres servirent à le découper en quatre morceaux.

Le déesse fut brûlée, et ses cendres, ainsi que les morceaux du dieu, furent jetés ensemble dans un lac se trouvant à proximité. Les portes du temple sont maintenant scellées, et une compagnie d'infanterie a été installée devant ses portes pour en interdire l'entrée aux adorateurs de ces deux divinités, mais on dit que ceux-ci brûlent de l'encens sur les bords du lac, et continuent à faire leurs dévotions à ces dieux infortunés.

De tels actes, dans nos pays, seraient le fait d'une impiété catégorique et la marque d'une forte certitude négative. Il n'en saurait être ainsi pour les Chinois, si superstitieux, si incertains et si crédules. Et c'est précisément parce qu'ils réunissent en eux de tels contraires que nous avons tant de peine à les comprendre. 


\section{Les Chinois}

Essai de Psychologie ethnographique.

La philosophie chinoise se ressent de cette espèce de débilité mentale qui empêche le Céleste de dépasser un certain niveau, de s'élever au-dessus du plus étroit réalisme et qui est symbolisée par cette phrase de Confucius : «Comment pourraisje m'occuper du ciel, quand il est si difficile de connaître la terre ? 》 Les hautes spéculations métaphysiques, les grands systèmes par lesquels les philosophes anciens et modernes de I'Occident se sont efforcés d'expliquer le monde, d'approfondir le mystère des origines et de la foi, sont inconnus en Chine. Laotzeu, il est vrai, a émis des idées intéressantes sur l'être primordial, le principe (táo), qu'il rapportait sans doute du séjour qu'il fit dans I'Inde, à peu près vers l'époque où on croit que Pythagore voyageait dans ce pays, ce qui expliquerait l'étrange parenté de leurs doctrines. Mais il n'a aucun écho dans la suite de la pensée chinoise. Les maîtres, indubitablement, sont Confucius, le grand moraliste et, beaucoup plus tard, son commentateur matérialiste, Tchou-hi, véritable initiateur de la doctrine des Lettrés.

Certes, Confucius professe la soumission et le respect voulus pour la métaphysique officielle du Ciel, sublime souverain de toutes choses ${ }^{1}$. C'est la vieille tradition de la divinité une, dont Renan croit avoir trouvé la trace dans les vestiges du plus ancien temple de l'Égypte, proche du Sphinx des grandes pyramides ${ }^{2}$. La Chine la tient peut-être, elle aussi - comme I'hypothèse en a été faite à I'Introduction de ce livre - du peuple éducateur des

1 Voir, pour tous ces philosophes chinois, les textes traduits par le père Wieger, dans le volume: Textes philosophiques.

${ }^{2}$ Mélanges d'histoire et de voyages : «L'Ancienne Égypte ». 


\section{Les Chinois}

Essai de Psychologie ethnographique.

premiers âges. Elle l'a conservée, en lui superposant toute la théogonie enfantine du dragon et des génies. Cette révérence de commande faite à la religion d'État, Confucius ne s'occupe plus que de donner des règles de conduite, basées sur la morale la plus pratique. Il recommande instamment le « juste milieu », et c'est bien le conseil qui pouvait convenir le mieux à la nature excessive de ses compatriotes. A quelqu'un qui lui demande s'il faut rendre le bien pour le mal, il dit :

- Alors que rendrez-vous pour le bien?

Il dit encore :

- L'opportunisme est la marque du sage. Il faut méditer dans le cadre de son temps.

Et ceci, en quoi s'exprime à merveille le peu de goût du Chinois pour le changement :

- Celui qui, trois ans après la mort de son père, n'aura encore fait aucune innovation dans sa maison, mérite d'être appelé fils pieux.

Cette pédagogie, toute de bon sens terre à terre, de prudence et de conservatisme, a eu une part considérable dans la formation de I'âme chinoise ; et, dans le mélange des éléments contradictoires qui la composent, c'est probablement le meilleur.

Onze siècles plus tard, sous la dynastie des Song, âge d'or de la littérature chinoise, Tchou-hi, tout en prétendant commenter Confucius - le maître désormais sacré - s'efforce de donner une explication scientifique de la vie, et cette explication est 


\section{Les Chinois}

Essai de Psychologie ethnographique.

strictement matérialiste ${ }^{1}$. D'après lui, l'univers et tous les êtres qu'il contient sont composés de deux principes coéternels, infinis, distincts, mais inséparables : la norme (li) et la matière (ki). La norme ne tombe pas sous les sens, la matière tombe sous les sens. La norme est illimitée. La matière est aussi illimitée quant à soi, mais, dans les individus, elle est limitée et limite, pour un temps, une portion de norme, laquelle retourne au grand tout, quand le composé se dissout. La norme et la matière coexistèrent de tous temps. Il n'y a pas, dans l'azur, de souverain du ciel qui gouverne, quoi qu'en disent les anciens livres 2 , etc.

Par la suite, de nombreux philosophes ont compliqué cette doctrine - qui avait le grand mérite d'être simple - par d'extravagantes conceptions physiologiques:

L'être commence par le concours du yinn (sperme) et du yâng (souffle), qui forment son p'ái et son hoûnn. L'être finit par le départ du hoûnn et la décomposition du p'ái. Le p'ái est d'origine spermatique ; les quintessences puisées par les yeux et les oreilles le nourrissent. Le hoûnn est d'origine respiratoire ; le souffle puisé par la bouche et le nez le nourrit. La réunion du p'ái et du hoûnn forme un être. Lors de leur séparation, le hoûnn et le p'ái rentrent dans le yâng et le yinn, etc... Nous sommes en pleine chinoiserie.

\footnotetext{
1 Il ne peut être question, ici, que d'indiquer très sommairement les caractères les plus généraux d'une philosophie qui a puissamment contribué à former la mentalité chinoise.

2 Pour Tchou-hi, voir : La Philosophie de Tchou-hi, par le père Le Gall, et Les Textes philosophiques du père Wieger.
} 


\section{Les Chinois}

Essai de Psychologie ethnographique.

Des conceptions aussi enfantines se retrouveraient dans les philosophies anciennes par suite du même défaut de base scientifique. Telle celle de Pythagore qui, selon Macrobe,

« pense que c'est de la voie lactée que part la descente vers I'empire de Pluton, parce que les âmes, en tombant de là, paraissent déjà déchues d'une partie de leurs célestes attributs. Le lait, dit-il, est le premier aliment des nouveau-nés, parce que c'est de la zone de lait que les âmes reçoivent la première impulsion qui les pousse vers les corps terrestres ${ }^{1}$.

Cicéron reprend plus tard cela, dans le Songe de Scipion, et il y a des inventions de ce genre dans le Phédon de Platon.

De même pour la superstition du nombre qui existe chez les uns et chez les autres.

Au temps de Confucius, pour les Chinois, le chiffre neuf était le plus sacré de tous. Les vers dorés, attribués à Pythagore, parlent du sacré quaternaire, source de la nature éternelle ${ }^{2}$. Apulée dit que, selon le même Pythagore, le nombre sept est le plus convenable en matière de cérémonies religieuses ${ }^{3}$. Chez les Hébreux, le sept joue aussi un très grand rôle : les sept jours de la création, les sept jours de la traversée du désert, les sept péchés capitaux, etc. Cette mystique du nombre tient une place considérable dans I'œuvre de Platon. Son disciple, Théon de Smyrne, a écrit tout un ouvrage pour l'expliquer. De même chez

\footnotetext{
${ }^{1}$ Macrobe, Commentaire du Songe de Scipion, liv. I.

2 Vers XXIV.

${ }^{3}$ Métamorphoses, liv. XI.
} 


\section{Les Chinois}

Essai de Psychologie ethnographique.

Aristote. Pour les Babys, dit le comte de Gobineau, dans son livre sur Les religions et les philosophies de l'Asie centrale, le chiffre sept est l'expression des sept énergies de la parole divine, d'où émane le monde. Le nombre dix-neuf équivaut à la vie. En Chine, le système quinaire a pris une place prépondérante : les cinq relations, les cinq éléments, les cinq bonheurs, les cinq vertus, etc. Cette place est aussi importante, aujourd'hui, qu'elle le fut jamais.

Le rappel de ces analogies est utile uniquement pour connaître le degré de maturité de la pensée chinoise. Elle a exactement l'âge des époques antérieures à l'avènement de la science. Rien ne peut en donner une idée plus exacte que le fait que le vénérable système des Mutations, qui remonte à la dynastie des Tchéou, est toujours tenu dans la même estime. Ce système est composé de huit trigrammes - les trigrammes de Fou-hi - dont la combinaison par deux forme 64 hexagrammes, à l'aide desquels on répond à toutes les questions, à la façon des tarots de diseuses de bonne aventure ${ }^{1}$. Il faut aussi se souvenir que le rôle des astrologues et des géomanciens est toujours très important et que, en raison de la superstition du fong choui, on continue de s'adresser à eux pour déterminer l'emplacement favorable d'une maison, d'un tombeau, etc.

Cette sorte de rachitisme, qui gêne la croissance intellectuelle normale, doit être due en grande partie à ce que les Chinois

\footnotetext{
${ }^{1}$ Les sept carrés de Paracelse, dont Eliphas Levi expose le mécanisme dans Dogme et rituel de haute magie, sont quelque chose dans le même genre.
} 


\section{Les Chinois}

Essai de Psychologie ethnographique.

n'ont pas la curiosité scientifique. Il leur a suffi jusqu'à présent de connaître des recettes pour se servir de nos inventions : télégraphe, téléphone, traction mécanique, etc.

L'explication scientifique leur est indifférente. Ils croient connaître toute notre science quand ils sont initiés à quelquesunes de ses applications, sans qu'ils puissent avoir la moindre idée du long effort, de l'enchaînement de travaux et de conquêtes que celles-ci représentent. Un Chinois de Shanghaï, de bonne situation, à qui on demandait, un jour, s'il n'était pas surpris de voir voler un aéroplane, répondit : «Mais non, c'est bien naturel, puisque cette machine a été faite pour cela ».

Ils n'ont aucune idée de la progression méthodique des études scientifiques. Un ingénieur, qui avait suivi quelque temps les cours d'une école de chimie récemment créée, me racontait qu'au bout de quelques jours, les élèves, alors qu'ils n'avaient vu que la première partie du traité, demandèrent à leur professeur de passer à la fin. Toutes ces matières éveillent si peu leur intelligence qu'ils croient pouvoir s'en remettre, pour les acquérir, à leur seule mémoire qui est, à dire vrai, exceptionnelle. Le grand lettré Tchang Tche-tong, I'initiateur du nouveau savoir en Chine, soupesant un ouvrage de trigonométrie et en compulsant les feuillets, disait :

- Pour nos élèves, c'est l'affaire d'un mois.

Dès qu'ils possèdent, d'ailleurs - dans la nouvelle génération surtout, - quelques rudiments de nos sciences, ils croient tout savoir et sont d'une suffisance insupportable. Le médecin en chef de I'hôpital français de Canton en eut, un jour, cet exemple : 


\section{Les Chinois}

Essai de Psychologie ethnographique.

Comme il examinait un malade en vue de déterminer s'il y avait lieu à opération et qu'il hésitait, voulant étudier le cas plus à fond, il eut la stupéfaction d'entendre tout près de lui un de ses plus jeunes élèves dire d'un ton doctoral :

- Moi, je n'interviendrais pas.

Une autre caractéristique, qui contribue à éloigner le Céleste de la vraie science, c'est son inaptitude à la précision, son goût de l'imprécision, devrait-on même dire. Plus un texte est obscur, plus il prête à de nombreuses interprétations, plus il est admiré. Le père Le Gall fait cette observation dans son étude sur Tchouhi ${ }^{1}$. Cette indication m'a été aussi donnée par plusieurs missionnaires, bons sinologues. Le Chinois aime de rêver devant une phrase, comme il rêve devant les veinules capricieuses d'un morceau de marbre. C'est un artiste et un poète, rien ne le prédispose à devenir un savant.

L'écriture idéographique est du reste bien le symbole de ce génie de l'imprécision. Cette écriture, qui représente les idées et les objets par autant de petits dessins immuables et qui ne peut par conséquent épouser, comme la nôtre, tous les contours de la pensée, a contribué à la fixation d'une langue sans souplesse ni clarté. Aussi une conversation de Célestes est-elle faite de répétitions, de ressassements, de pléonasmes, parce que, pour arriver à se faire comprendre, celui qui parle est contraint de faire appel à tous les synonymes connus. La chose est surtout sensible quand on use d'un interprète. Une phrase française

${ }^{1}$ Le Philosophe Tchou-hi, sa doctrine, son influence, p. 4. 


\section{Les Chinois}

Essai de Psychologie ethnographique.

nécessite toujours, pour être traduite, cinq ou six phrases chinoises.

C'est ce qui explique la multiplicité de commentaires qu'ont suscités les classiques et les querelles de nos sinologues sur le moindre texte.

Le Chinois n'a pas davantage l'esprit d'exactitude. Outre que la question de face le pousse à arranger les faits - comme le remarque le père Wieger dans ses Textes historiques ${ }^{1}$, - il n'a à aucun degré notre amour du vrai. On connaît du reste son habitude du mensonge signalée plus haut. Sa profonde nature subjective lui rend sans doute impossible le désintéressement objectif indispensable à la recherche de la vérité. C'est ce qui fait que le président Siu Che-cheung exalte sans sourciller le pacifisme chinois, au moment où la Chine est déchirée par les guerres intestines que se font, aux quatre coins du pays, les grands chefs de bande, convertis en «tochuns ». Pareillement le ministre de Chine à Londres, Alfred Sze, n'hésite pas à faire, dans un récent article de revue, une déclaration du même ordre, aussi contraire à la réalité des faits ${ }^{2}$. Cette tendance à « arranger » les choses de la manière qui convient le mieux à l'auteur, sans aucun souci de la vérité, est également bien remarquable dans un recueil de souvenirs révolutionnaires publié, l'année dernière, par une Chinoise diplômée de nos écoles.

1 T. I, p. 26.

${ }^{2}$ Asiatic Review, janvier 1921. 


\section{Les Chinois}

Essai de Psychologie ethnographique.

Le dédain de la vérité pure est, du reste, le cas de tous les Orientaux.

«Une longue pratique, dit le comte de Gobineau, m'a rendu absolument indifférent à toute allégation numérique émanée d'un Persan, d'un Arabe, d'un Turc ou d'un Hellène. Je crois souvent à leur bonne foi, jamais à leur exactitude, la nature leur ayant refusé tout instinct du vrai en ce genre ${ }^{1}$.

Notre ordre, notre régularité sont également désagréables aux Célestes qui en sont gênés et leur préfèrent leurs vieilles habitudes, leurs accommodements empiriques. En matière de finances, par exemple, des petits prêts, avec lesquels on bouche les trous au jour le jour leur conviennent infiniment mieux que les grands emprunts garantis et contrôlés selon des règles strictes. Des villes et des régions entières s'arrangent très bien de payer un tribut à une bande de brigands qui, en revanche, leur assure la sécurité de leurs biens et de leurs personnes et constitue ainsi une sorte de maréchaussée. A Hankéou, m’a-t-on dit, il y a une association de voleurs à laquelle même les étrangers propriétaires d'entrepôts de commerce ont intérêt à payer une espèce d'assurance. On me raconta qu'une maison française, ayant été victime d'un vol de soie assez important, s'adressa au chef de cette association qui retrouva le voleur et fit rendre la marchandise. C'était, disait-on, une excellente police parce que, ayant intérêt à ce que d'autres brigands ne lui fissent pas concurrence, elle les pourchassait sans pitié, par des moyens

\footnotetext{
${ }^{1}$ Histoire des Perses, chap. VI.
} 


\section{Les Chinois}

Essai de Psychologie ethnographique.

efficaces dont n'usent pas les polices officielles. Il n'y a jamais eu de police plus sévère que celle qui fut formée avec les bandes de pirates, à Canton, pendant la révolution.

On imagine facilement quelle peut être, dans ces conditions, la fameuse modernisation de la Chine. Je me suis efforcé d'en donner une analyse dans une série d'ouvrages précédents ${ }^{1}$. Elle consiste surtout, pour le gouvernement, à prendre certaines apparences, à rédiger de beaux rapports académiques, à promulguer des lois qui ne sont pas, qui ne peuvent pas être appliquées. De même pour l'individu : il se coupe la tresse, revêt notre costume, sous lequel il arrive parfois qu'on aperçoive son vêtement national ; il a ainsi à bon compte l'apparence d'être européanisé, de posséder le nouveau savoir. La transformation ne va, le plus souvent, pas plus loin.

C'est là, du reste, une très mince façade, derrière laquelle l'énorme Chine poursuit son existence traditionnelle.

Des auteurs superficiels voient la modernisation chinoise dans le fait qu'on a construit des chemins de fer, qu'on constate un commencement d'exploitation industrielle scientifique et que tous les instruments pratiques de notre civilisation sont en usage. Outre que c'est uniquement I'œuvre des Européens et que ces choses-là ne marchent que grâce à leur présence, on ne pourra pas parler de modernisation réelle tant que se maintiendra une mentalité aussi archaïque. Les journaux de Shanghaï mentionnaient récemment que le grand «tochun » de

${ }^{1}$ Dix ans de politique chinoise. 


\section{Les Chinois}

Essai de Psychologie ethnographique.

Mandchourie, I'homme le plus puissant et le plus écouté ${ }^{1}$, à I'heure actuelle, par le gouvernement de Pékin, bien qu'il ait commencé sa carrière comme chef de brigands, Tchang Tso-ling, venait d'acheter une magnifique auto blindée de trente-cinq mille dollars. Voilà le vrai symbole de la modernisation de la Chine.

(a)

1 Battu depuis lors par son rival, Ou Pei-fou, son influence sur le Gouvernement de Pékin a, pour l'instant, disparu. 


\section{Les Chinois}

Essai de Psychologie ethnographique.

\section{CONCLUSION@}

L'enseignement qu'il convient de retirer de ces observations, c'est que le Chinois apparaît comme un être d'une vitalité intense, d'une nervosité extrême, absolument subjectif et inapte aux spéculations désintéressées. Ainsi constitué, il est livré à I'instinct : c'est l'enfant de la nature. Je crois que cela l'explique tout entier.

La nature, en effet, si on ne lui oppose pas les aspirations d'un idéal supérieur, ce que Stendhal appelait : « l'espagnolisme », pousse à réussir, à se tirer d'affaire par tous les moyens ; à préserver également sa vie avant tout autre chose ; sous cet angle, l'abnégation et le courage ne peuvent apparaître que comme une duperie ; on n'y songe d'ailleurs même pas. Il n'est pas de goût plus naturel que celui du plaisir ; l'argent étant un instrument indispensable pour le satisfaire, il s'agit de l'acquérir de n'importe quelle façon. L'instinct est impatient de toute discipline, mais tend aussi à durer et à se reproduire envers et contre tout. Le mélange irraisonné de cruauté et de douceur a toujours été le fait des enfants, et la vie, dominée par l'instinct, n'est qu'une enfance prolongée. Enfance aussi, et enfance nerveuse, que la crainte maladive des esprits, la croyance puérile à toutes sortes du loups-garous et la facilité de panique. Enfin, la sensibilité exagérée de la « face » et le besoin immodérés de la grandir sont au premier chef une manifestation de névrose.

Cette nature instinctive tend invinciblement au désordre ; elle a été contenue pendant des siècles par une pénalité terrible et 


\section{Les Chinois}

Essai de Psychologie ethnographique.

une éducation étroite et méticuleuse, qui - on le voit bien, maintenant que tout cela s'effrite - étaient nécessaires. Casanova, ce Chinois d'Occident, dit quelque part, dans ses Mémoires, que le préjugé est en nous ce qui lutte contre nousmême. Lutter contre soi-même, voilà la chose dont le Céleste tel qu'il se révèle de plus en plus, privé de son masque rituel est certainement le plus incapable. 